\title{
Low Molecular Weight Fluorescent Probes (LMFPs) to Detect the Group 12 Metal Triad
}

\author{
Ashley D. Johnson, Rose M. Curtis and Karl J. Wallace * \\ The Department of Chemistry and Biochemistry, The University of Southern Mississippi, Hattiesburg, MS 39406, \\ USA; Ashleydjohnson@usm.edu (A.D.J.); Rose.curtis@usm.edu (R.M.C.) \\ * Correspondence: karl.wallace@usm.edu; Tel.: +1-601-266-4715
}

Received: 2 March 2019; Accepted: 19 April 2019; Published: 28 April 2019

\begin{abstract}
Fluorescence sensing, of d-block elements such as $\mathrm{Cu}^{2+}, \mathrm{Fe}^{3+}, \mathrm{Fe}^{2+}, \mathrm{Cd}^{2+}, \mathrm{Hg}^{2+}$, and $\mathrm{Zn}^{2+}$ has significantly increased since the beginning of the 21st century. These particular metal ions play essential roles in biological, industrial, and environmental applications, therefore, there has been a drive to measure, detect, and remediate these metal ions. We have chosen to highlight the low molecular weight fluorescent probes (LMFPs) that undergo an optical response upon coordination with the group 12 triad $\left(\mathrm{Zn}^{2+}, \mathrm{Cd}^{2+}\right.$, and $\left.\mathrm{Hg}^{2+}\right)$, as these metals have similar chemical characteristics but behave differently in the environment.
\end{abstract}

Keywords: chemosensors; fluorescence; recognition; sensing; group 12 metals (zinc; cadmium; and mercury)

\section{Introduction}

Sensors are used in every aspect of modern life; for example, many modern households have a carbon monoxide sensor or a smoke detector installed. In industry, fiber-optic sensors are used for monitoring process variables, such as temperature, pressure flow, and the level of a liquid. The environment requires sensors to monitor toxic gases and air pollution, and in clinical applications for the detection of medical conditions, i.e., Type 1 diabetes.

The field of sensor technology has rapidly been expanding over the last several decades, and the field can be categorized into two broad areas (1) chemical sensors and (2) biosensors. Chemical sensors measure, monitor, and identify chemical compounds, whereas biosensors combine a biological component, for example, microorganisms, tissue, cells, organelles, nucleic acids, enzymes, or antibodies [1]. Both types of sensors have the same purpose; to measure an analyte, either qualitatively or quantitatively. Some excellent reviews have covered recent advances in biosensors, and these have been omitted in this article [2-14].

The word sensor has become more ambiguous over time, and there is no universal definition of the term chemical sensor; the term is highly debated in the scientific community. Therefore, there has been much confusion over the two broad definitions of "chemical sensors" and "biosensor." One definition states that "chemical sensors are miniaturized devices which can deliver real-time and online information in the presence of a specific compound or ions in complex samples" [15]. This definition itself is not concise, as the term device is also unclear. Interestingly, the International Union of Pure and Applied Chemistry (IUPAC) does not have a specific definition of "chemical sensor" defined in the Compendium of Chemical Terminology: "Gold Book" [16]. The term "biosensor" is also broad, but the IUPAC does define a biosensor "as a device that uses specific biochemical reactions mediated by isolated enzymes, immune systems, tissues, organelles or whole cells to detect chemical compounds usually by electrical, thermal or optical signals" [16]. 
The focus of this review is to highlight how Low Molecular Weight Fluorescent Probes (LMFP), act as chemical sensors. These molecules are defined as a small organic or inorganic molecule that has a molecular weight that is no more than a 1,000 Daltons [17]. The molecules are used to monitor metal ions (chemical analytes). Sensors that contain any biological component as defined by IUPAC or containing proteins and amino acids as part of the receptor (the device) unit are not considered, as the authors argue that a molecular receptor containing a "biological" component should be considered to be a biosensor.

Based on our interpretation of a chemical sensor described above, chemical sensors can be described as devices that convert the response into a measurable signal, which can either be related to the concentration of the analyte [18] or provide a binary "on" or "off" signal [15]. The signal can be a change in magnetic or electrical fields [19], resistance [20], capacitance [21], inductance [22], frequency [23] or optical response [24]. Monitoring and measuring metal ions can be carried out using analytical techniques, including atomic absorption spectroscopy (AAS) [25], atomic emission spectroscopy (AES) [26], inductively coupled plasma mass spectrometry (ICP-MS) [27], electrochemical techniques [28], surface plasmon resonance [29], and X-ray spectroscopic methods (e.g., X-ray fluorescence (XRF), X-ray photoelectron spectroscopy (XPS), and X-ray absorption spectroscopy (XAS)) [30]. Each technique has its specific advantages and disadvantages, but all suffer from similar problems, including signal-to-noise ratio, drift, sensitivity, selectivity, specificity, stability, reusability, cost of the specialized technique, the preparation of the samples, and fouling/clogging of instruments. Measuring analytes at low concentrations offers additional challenges too. For example, high sensitivity detection, and false positives can arise. As a consequence, a professionally trained technician is needed to prepare samples, operate (and maintain) instrumentation, and interpret the results. The techniques also need to be tailored to different settings (for different metal ions), and some of these techniques cannot monitor every metal ion, due to interferences. Many of the instruments required are big and bulky, and samples have to be sent back to the lab for analysis, therefore, conducting onsite analysis can be problematic. Nevertheless, these techniques have their uses and will continue to play important roles in the analysis of metal ions.

There has been a push to develop analytical methods that are simple, fast, and reliable to detect metal ions in the field. Optical spectroscopy is of particular interest as it provides the basis for sensitive and inexpensive methods of detection. Optical spectroscopy comprises a group of spectroscopic analytical techniques that measure the intensity and wavelength of radiation absorbed and emitted by the sample. Luminescence is a spontaneous emission of radiation from an electronically or vibrationally excited species, not in thermal equilibrium with its environment, the resulting emission is either in the form of fluorescence or phosphorescence. Luminescence covers several techniques that involve the emission of radiation (emissive or non-emissive) by either atoms or molecules, but varies in the manner in which the emission is induced. Optical spectroscopy, for example, UV-Vis and fluorescence, are of particular interest to the sensor community. Fluorescence spectroscopy is particularly attractive, as the scientist can take advantage of manipulating different fluorescent mechanisms. The theoretical aspects of optical spectroscopy and the mechanisms that initiate a recognition event have been covered in reviews, including those by de Silva [31] and Wang [32], which are of particular relevance. The mechanisms involved include - photoinduced electron transfer (PET) [33], intramolecular charge transfer (ICT) [34], the heavy atom (metal) effect [35], the destabilization of nonemissive n- $\sigma^{*}$ excited states, metal-to-ligand charge transfer (MLCT) [36], Dexter (exchange mechanism), and Förster (coulombic) resonance energy transfer (FRET) [37], excimer/exciplex formation [38], twisted intramolecular charge transfer (TICT), electronic energy transfer (EET), aggregation-induced emission (AIE) [39], excited-state intramolecular proton transfer (ESIPT) [40], and chelation enhancement fluorescence (CHEF) [41].

These mechanisms can be tuned to prepare the fluorescent supramolecular probes for metal ion detection, monitoring, and remediation. In addition to these mechanisms, the underlying principles of molecular recognition and disclosure of analytes have also been extensively reviewed [42-52]. The review articles can be broad, covering a range of metals or probes, or could be very specific, 
highlighting the work on one particular cation, such as $\mathrm{Fe}^{3+}$ [53], a specific fluorescent mechanism, such as excimer formation [54], or a specific type of chromophore, for example, squaraine dyes [55]. Alternatively, reviews might highlight the different probes within a given period [56]. In this review, we have highlighted some of the most recent work on the development of low molecular weight fluorescent probes for the group 12 metal ions $\left(\mathrm{Zn}^{2+}, \mathrm{Cd}^{2+}\right.$, and $\left.\mathrm{Hg}^{2+}\right)$. We have chosen to focus on these specific metal ions because they play significant roles in biology and the environment, for better or worse [57-66]; these analytes are optically silent, whereby an outside source is required for monitoring; to the best our knowledge this is the first time a review focuses on this specific triad. Most reviews focus on either the biologically important metal ions $\left(\mathrm{Zn}^{2+}, \mathrm{Cu}^{2+}, \mathrm{Fe}^{2+}\right.$, and $\left.\mathrm{Fe}^{3+}\right)$ or environmentally important ions $\left(\mathrm{Hg}^{2+}, \mathrm{Pb}^{2+}\right.$, and $\left.\mathrm{Cd}^{2+}\right)$, that have very little, if any, biological roles. There are a handful of reviews that cover the optical response of a number of different metal ions, but they seem to lack focus. Moreover, the year 2019 is the 150th year since Dimitri Mendeleev has been credited for the development of the periodic law, thus, focusing on a specific group is a modest way to honor the achievement by Mendeleev.

The goal of this review is to highlight some of the more recent developments of low molecular weight fluorescent probes that quench the initial fluorescence signal, but the fluorescence signal is switched on upon the addition of metal ions (CHEF) for $\mathrm{Zn}^{2+}$ and $\mathrm{Cd}^{2+}$ ions, or the metal aids in a chemical reaction that produces a new compound that is fluorescent, commonly reported for $\mathrm{Hg}^{2+}$ ion molecular probes. Traditionally, the molecular sensor design has been carried out using two different approaches. The most common method is the intuition method of rational design, from years of experience being in the desired field, using a pen and paper (or chemical drawing software), followed by synthesis, and experimentation. The studies are then usually confirmed (or not) by computational methods, for example density functional theory (DFT) calculations, either to support the fluorescence mechanisms (which cannot be achieved easily by the traditional way) or to propose a binding mode between the analyte and the molecular probe, if a crystal structure cannot be obtained. As computer power is increasing and software is becoming more sophisticated the time required to run a calculation has been reduced. A new strategy in molecular probe design is to initially utilize a computational approach. The advantage of this approach is to investigate the fluorescence mechanisms first, to prepare a more efficient LMFP to improve the limit of detection for the desired analyte. This method has been used successfully for zinc sensors [67-70].

\section{Chemosensors for the Group 12 Triad (Zinc, Cadmium, and Mercury)}

The group 12 elements, zinc, cadmium, and mercury have a valence shell configuration of $[\mathrm{Ar}] 3 d^{10} 4 s^{2},[\mathrm{Kr}] 4 d^{10} 5 s^{2}$, and $[\mathrm{Xe}] 4 f^{14} 5 d^{10} 6 s^{2}$, respectively. They are known as the "silent ions" as they lack any intrinsic spectroscopic or magnetic properties and, as a consequence, cannot be monitored directly. The chemistries of zinc and cadmium are similar; however, that of mercury is vastly different. All three elements are found in the +2 oxidation state, they all adopt a range of coordination numbers $(2,4$, and 6 being the most common) and form tetrahedral and octahedral complexes [71]. Mercury is found predominantly in a linear (coordination 2) or tetrahedral (coordination 4) geometry [72,73]. The $3 \mathrm{~d}$ sub-shell for zinc is somewhat polarizable, despite its high charge-to-volume ratio [74]. It is well-known that $\mathrm{Zn}^{2+}$ plays pivotal roles in biochemical processes. Over 300 zinc enzymes carry out specific functions and zinc also plays a structural role, helping to stabilize protein binding domains, for example in zinc fingers [75]. Cadmium and mercury have no known biological functions, although there have been reports that cadmium has a limited biological function in marine diatoms [76]. Lane et al. reported that the growth of the diatom Thalassiosira Weissflogii is enhanced when there is a limited supply of zinc, suggesting that under extreme conditions, the presence of cadmium can be biologically beneficial $[77,78]$.

All three group 12 elements form alloys with the other d-block elements [79]. For example, brass is a well-known alloy of copper in which the weight ratio between the metal alloys (and $\mathrm{Sn}$ and $\mathrm{Pb}$ ) gives rise to a specific type of brass [80]. Common brass, used to make the Lincoln cent, is made up of $63 \%$ 
copper and 37\% zinc. Since 1982, a copper-coated zinc alloy has been used instead due to increases in the copper price. Amalgams, such as mercury-containing alloys, are often associated with the teeth and the dentistry fields [81]. Tooth fillings consist of mercury, silver, copper, and tin, as the predominant contributors to amalgam. Cadmium alloys are known, but many have had their alloying element replaced with other metals, due to the fear of leeching into the environment, where it is readily absorbed through the roots and shoots of crops [82]. This impedes the uptake of nutrients required by the plant, disrupting photosynthesis, stunting growth, and resulting in diminished crop yield. Moreover, the bioaccumulation of cadmium in plants, increases the risk of cadmium entering the food chain. This is particularly concerning where extensive agricultural procedures occur, for example, in China [83].

It is often assumed that mercury is "bad", due to misleading public information. Mercury is found in three broad forms, metallic mercury, inorganic mercury salts, and organic mercury and its form dictates its toxicity [84]. For example, inhaled mercury vapor will accumulate in the body mainly in the central nervous system (CNS) [85]. Ingesting metallic mercury under standard conditions poses a negligible risk of severe toxicity. The toxicity of inorganic mercury salts is dependent on their $K_{\mathrm{sp}}$ value. For example, the $K_{\mathrm{sp}}$ for $\mathrm{Hg}_{2} \mathrm{I}_{2}$ is $5.2 \times 10^{-29} \mathrm{M}^{-1}$ (+1-oxidation state) and for $\mathrm{HgS}$ (+2-oxidation state) is $2 \times 10^{-53} \mathrm{M}^{-1}$. As salts are non-volatile, inorganic mercury salt poisoning is at a greater risk by oral digestion than inhalation. Additionally, inorganic mercury salts have very low solubility in lipids, so their abilities to cross the blood-brain barrier are significantly reduced [86]. Any ingestion of an inorganic mercury salt that accumulates in the liver, is processed by bile and the kidneys, and then excreted out via urine. Mercury found in its organic form (for example methyl mercury), is the species that the general public refers to as "mercury poising" and is highly toxic [87]. Organic mercurials are formed from elemental mercury through micro-organisms and make their way up the food chain, because methyl mercury is very soluble in lipids and bioaccumulates readily [88]. As mercury is one of the oldest known elements it has extensively been studied and the toxicity of its three forms is well understood. Even though mercury can enter the environment readily, gone are the days of being "mad as a hatter"-mercury poising is rare in the developed world.

As there are various ways in which the group 12 triad of metals can enter a biological or environmental surroundings, all three metal ions are toxic above specific concentrations. For example, the World Health Organization (WHO) and the Environmental Protection Agency (EPA) limit for these metal ions in water should not exceed $0.005,0.001$ and $5.0 \mathrm{mg} \cdot \mathrm{L}^{-1}$ for $\mathrm{Cd}^{2+}, \mathrm{Hg}^{2+}$, and $\mathrm{Zn}^{2+}$ ions, respectively $[89,90]$.

\subsection{Zinc Probes}

Zinc is arguably the most frequently studied d-block metal, due to its biological importance [91]. The $\mathrm{Zn}^{2+}$ ions are predominantly located within the confines of proteins and enzymes where they are essential to many biological functions [92]. The human body contains approximately $2-3 \mathrm{~g}$ of zinc; the amount found in the blood is kept constant $(12-16 \mu \mathrm{M})$, however, higher concentrations $(\mathrm{mM})$ are localized in many parts of the body, for example in the breast [93], prostate [94], brain [95], and pancreas [96]. The association constants range from tightly bound $(\log K>11)$ and moderately bound ( $\log K=7-9$ ) to loosely bound ( $\log K<7$ ), and affect the bioavailability of $\mathrm{Zn}^{2+}$ ions. Loosely bound zinc is responsible for the dark side of $\mathrm{Zn}^{2+}$ ions. For example, free zinc has an active role in neuronal injury [93], and there have since been numerous reports on the acute toxicity of free zinc and its link to neurodegenerative effects in Alzheimer's disease [97] and amyotrophic lateral sclerosis (Lou Gehrig's disease) [98]. Low molecular weight probes that can chelate and monitor $\mathrm{Zn}^{2+}$ ions by an optical response are abound [99-108]. The subject matter appears in many authoritative reviews from investigators that have made seminal contributions in this field [109-123].

Whenever a molecular probe is being designed for a particular analyte, three crucial factors need to be considered; (1) high sensitivity (detection limit), (2) high specificity (distinguishing among metal ions), and (3) high selectivity (for the specific ion pool under investigation). Moreover, it might not be necessary to monitor metal ions at low concentrations, but rather over a dynamic range of 
concentrations $[124,125]$. For example, the concentration of intracellular "free" zinc can be as low as $1 \mathrm{nM}$, whereby, $\mathrm{Zn}^{2+}$ ions found in synaptic vesicles in the presynaptic bouton of a neuron can be as high as $300 \mathrm{mM}$ [126-128]. Therefore, developing molecular sensors that can work within this range is very challenging. An elegant example of a molecular receptor that can monitor $\mathrm{Zn}^{2+}$ ions over a wide concentration has been prepared by Zhu et al. [129].

The salicylaldehyde motif is a popular organic functional group, often incorporated into molecular probes [130], as it readily undergoes Schiff base reactions, and therefore, introduces the Lewis basic sites to bind metal ions in a stable chelating ring system. Compound 1, a bis(bidentate) iminophenol ligand was synthesized by Chakraborty et al. (Figure 1A) [131], through the condensation of salicaldehyde and 4-aminobenzylamine in ethanol. The X-ray crystal structure shows that two resonance-assisted hydrogen bonding (RAHB) interactions are present. Therefore, in order for compound $\mathbf{1}$ to act as a molecular probe, $\mathrm{Et}_{3} \mathrm{~N}$ was added to the DMF solution to disrupt the intramolecular hydrogen bonding interaction to produce the chelating motif. Upon the addition of $\mathrm{Zn}^{2+}$ ions the absorbance wavelength, initially seen at $321 \mathrm{~nm}$, bathochromically shifted to $406 \mathrm{~nm}$. Unfortunately, the X-ray structure of the zinc complex could not be solved as the crystals diffracted weakly, but the analogous $\mathrm{Co}^{2+}$ complex was solved, showing a 2:2 binding ratio in the solid state. Based on the $\mathrm{Co}^{2+}$ structure (a tetrahedral arrangement around the $\mathrm{Co}^{2+}$ ions) and the $\mathrm{Zn}^{2+}$ ions UV-Vis titration data, the authors speculated that a 1:1 binding stoichiometry occurs in the solution phase. Their UV-Vis does show a pseudo-isosbestic point at $365 \mathrm{~nm}$, but yet the binding isotherm saturates upon the addition of two equivalences of $\mathrm{Zn}^{2+}$ ions. Therefore, the author's interpretation of a 1:1 binding is misleading. No calculated binding constants were reported, presumably due to a number of different species existing in solution, rendering it difficult to calculate a precise binding constant, and their claim of 1:1 binding mode is questionable. The free ligands (1) are essentially non-fluorescent $(\phi=0.025 \mathrm{in} \mathrm{DMF})$ but on addition of $\mathrm{Zn}^{2+}$ ions, a new emission band is observed at $527 \mathrm{~nm}\left(\lambda_{\mathrm{ex}}=406 \mathrm{~nm}\right)$, Figure 1B,C. This increase did not occur in the presence of the other metals studied $\left(\mathrm{Fe}^{3+}, \mathrm{Co}^{2+}, \mathrm{Cu}^{2+}, \mathrm{Ni}^{2+}, \mathrm{Cr}^{2+} \mathrm{Mn}^{2+}, \mathrm{Cd}^{2+}, \mathrm{Hg}^{2+}\right.$, and $\left.\mathrm{Pb}^{2+}\right)$ and the authors attributed this to a CHEF fluorescence mechanism. Unfortunately, no fluorescence binding isotherms were reported and, upon closer inspection of their titration data, the fluorescence spectra seemed to increase continuously. This could be due to an aggregated fluorescence enhancement, as it is reasonable to assume that other polymeric species are present in solution, and not only in the discrete 2:2 model, which has been suggested from their solid-state studies. This might explain why the binding constants were not calculated, as they could not be easily modeled.

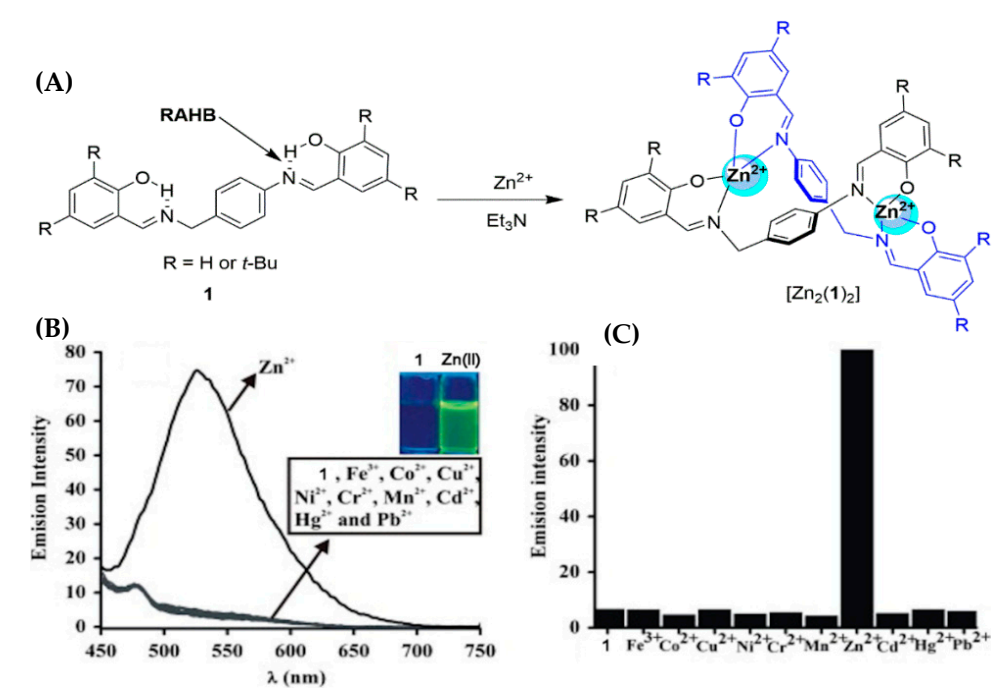

Figure 1. (A) The proposed coordination structure (based on the $\mathrm{Co}^{2+}$ crystal structure) and (B) the emission spectrum of compound 1 (DMF $10 \mu \mathrm{M}$ and two equivalents of $\mathrm{Et}_{3} \mathrm{~N}, \lambda_{\mathrm{ex}} 422 \mathrm{~nm}$ ) and (C) bar chart highlights the emission intensity at $527 \mathrm{~nm}$, upon the addition of metal salts (1.2 equivalents). Adapted from [131], with permission from Elsevier. 
Zhang, Zhao, and Zhou prepared chemosensor $\mathbf{2}$ (Scheme 1), by incorporating a binding motif to the dye [132]. The optical studies were carried out in a $\mathrm{CH}_{3} \mathrm{CN}-\mathrm{HEPES}$ buffer (6:4 v/v; pH 7.4). On adding the 20 equivalents of metal salts $\left(\mathrm{Na}^{+}, \mathrm{Co}^{2+}, \mathrm{Ni}^{2+}, \mathrm{Cu}^{2+}, \mathrm{Zn}^{2+}, \mathrm{Pb}^{2+}, \mathrm{Cd}^{2+}, \mathrm{Ag}^{+}, \mathrm{Hg}^{2+}, \mathrm{Fe}^{2+}\right.$, $\mathrm{Mg}^{2+}$, and $\left.\mathrm{Cr}^{3+}\right)$, negligible emission enhancement was seen, except for in $\mathrm{Zn}^{2+}$ ions. The emission spectra of LMFP 2 was very weak ( $\phi=0.06)$, and was attributed to the PET quenching by the lone pair of electrons residing on the nitrogen atom on the imine group. A 13-fold increase in the fluorescence intensity was seen at $556 \mathrm{~nm}\left(\lambda_{\mathrm{ex}}=397 \mathrm{~nm}\right)$ when 20 equivalents of $\mathrm{Zn}^{2+}$ ions were added. The binding constant $K_{\mathrm{a}}$ for a 1:1 binding model was calculated to be approximately $3 \times 10^{3} \mathrm{M}^{-1}$. The stoichiometry was supported by a Job's plot analysis. As $\mathrm{Zn}^{2+}$ was the only species that produced a fluorescent signature, the authors investigated the biological imaging of compoun 2, with an array of cell lines. These included adenocarcinomic human alveolar basal epithelial cells (A549), bronchial epithelial cell (BEAS-2B), Chinese hamster ovary (CHO), Hela, and human liver cancer cells (HEP G2). Compound 2 showed different fluorescence emission colors in the cell nucleus and in the cytoplasm.

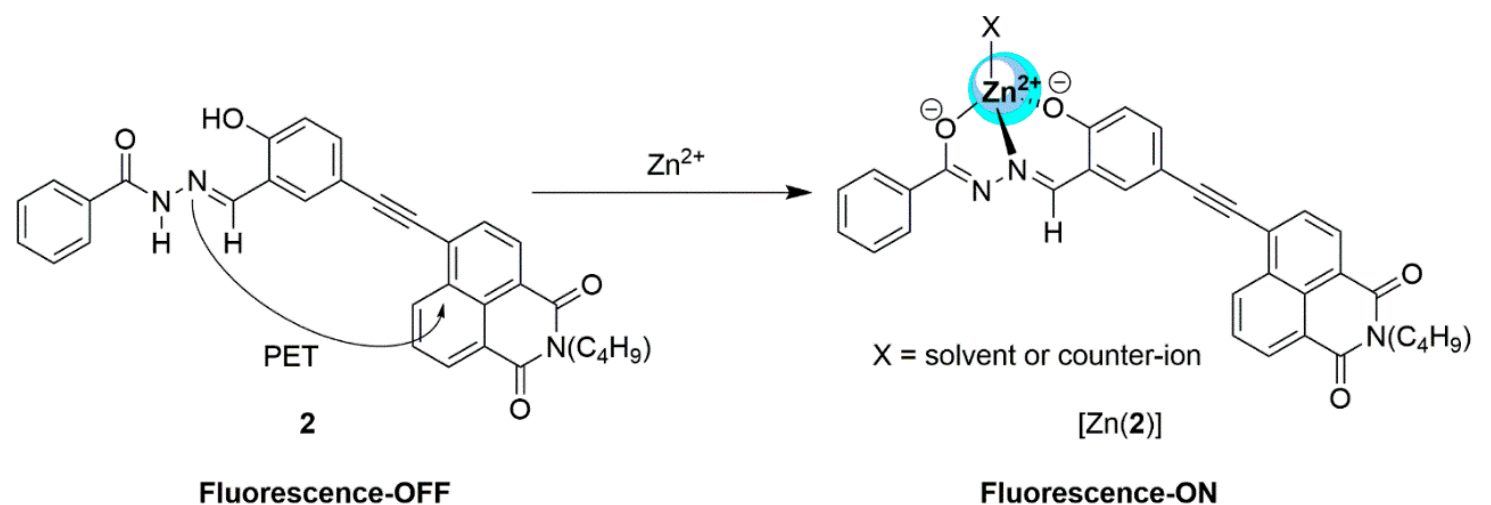

Scheme 1. The proposed binding motif between compound 2 and $\mathrm{Zn}^{2+}$ ions. The binding environment was also confirmed by ${ }^{1} \mathrm{H}$ NMR spectroscopy.

It is well-known that UV-visible irradiation can induce isomerization of organic and inorganic compounds $[108,133]$. This switching mechanism has been extensively used in molecular probe design [134]. The spyiropyran functional group is known to undergo a reversible heterolytic cleavage of the spiro C-O bond. A metastable merocyanine is then formed upon cis-trans isomerization. Giordani et al. synthesized a photochromic compound 3 containing a metal binding site, Figure 2A [135]. They utilized a methyl pyridinyl group, often used in zinc selective chromophores and incorporated the pyridinyl group onto the spirochromene indolic nitrogen atom. The stability of the open-closed form of the spiropyrene was affected by the electron withdrawing or electron donating groups attached to it, thus, influencing the feasibility of the open and closed form. Electron donating groups favor the closed system, whereas electron withdrawing groups favor the open form. Therefore, the Giordani team incorporated the electron withdrawing $\mathrm{NO}_{2}$ group into their molecular probe design, to favor the open form and, thus, making the Lewis basic sites available to coordinate to a metal center. Many metal perchlorate salts were added to a $1 \times 10^{-4} \mathrm{M} \mathrm{CH}_{3} \mathrm{CN}$ solution of probe 3 . The $\mathrm{Zn}\left(\mathrm{ClO}_{4}\right)_{2}$ salt produced a distinctive color at $504 \mathrm{~nm}$, from which the binding isotherm was obtained, Figure 2B, although these data points were not used to calculate the binding constant. A modified Benesi-Hilderbrand equation was used but the regression line showed curvature so the calculated binding constant $\left(K=1.6 \times 10^{4} \mathrm{M}^{-1}\right)$ should be viewed with a little skepticism. Upon the irradiation of the solution, the absorbance band disappeared. The switching was maintained over 100 second period. ${ }^{1} \mathrm{H}$ NMR studies showed that the trans configuration was sustained when the probe coordinated to the metal ion, confirmed by ${ }^{1} \mathrm{H}$ NMR, a large coupling constant was calculated $(J=16 \mathrm{~Hz})$. 
(A)<smiles>COc1cc([N+](=O)[O-])cc2c1O[C@@]1(C=C2)N(Cc2ccccn2)c2ccccc2C1(C)C</smiles>

3
(B)

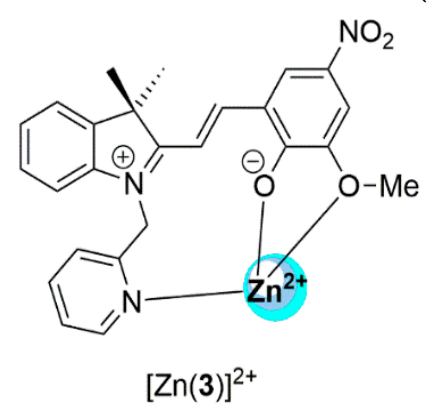

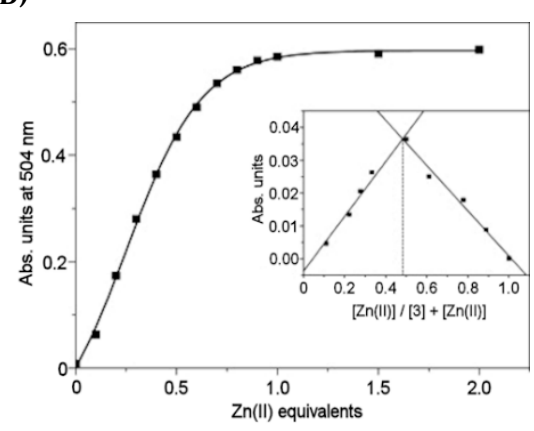

Figure 2. (A) The proposed binding of $\mathrm{Zn}^{2+}$ and molecular probe $3(\mathbf{B})$ The absorption binding isotherm obtained, upon the addition of $\mathrm{Zn}\left(\mathrm{ClO}_{4}\right)_{2}$ to a $1 \times 10^{-4} \mathrm{M}$ of 3 in $\mathrm{CH}_{3} \mathrm{CN}$ solution and Job's plot (insert). Unfortunately, the calculated binding constant was not calculated using the non-linear regression presented. Adapted from [135], with permission from Elsevier.

Another tridentate coordination moiety was incorporated onto a 1,8 naphthyridine scaffold where a protected L-proline was attached to position two on the naphthlyridine ring system, chemosensor 4 [136]. Upon the addition of various metal salts $\left(\mathrm{Li}^{+}, \mathrm{K}^{+} \mathrm{Cd}^{2+}, \mathrm{Mn}^{2+}, \mathrm{Fe}^{3+}, \mathrm{Cu}^{2+}, \mathrm{Mg}^{2+}, \mathrm{Fe}^{2+}, \mathrm{Ni}^{2+}, \mathrm{Co}^{2+}, \mathrm{Hg}^{2+}\right.$, $\mathrm{Pb}^{2+}, \mathrm{Ag}^{+}$, and $\left.\mathrm{Zn}^{2+}\right)$ in $\mathrm{MeOH}$, only the $\mathrm{Zn}^{2+}$ ions showed a significant fluorescence enhancement by a factor of 2.5, whereas all other metal ions quenched emission. The authors suggested that the CHEF mechanism was the reason for the fluorescence enhancement observed. The fluorescence signal was saturated after the addition of one equivalent of $\mathrm{Zn}^{2+}$ ions and the calculated $K_{\mathrm{a}}$ was approximately $6 \times 10^{4} \mathrm{M}^{-1}$. The coordination environment of compound 4 and the $\mathrm{Zn}^{2+}$ complex was investigated by IR spectroscopy and TD-DFT. The natural bond orbital (NBO) calculations suggested that the zinc metal ion preferred to coordinate with the two nitrogen atoms and the oxygen atom (the negative charge density on $\mathrm{N}(2), \mathrm{N}(3)$, and $\mathrm{O}(2)$, were calculated to be $-0.403,-0.63$, and -0.65 , respectively), the final coordination site was occupied by an $\mathrm{MeOH}$ molecule. Based on these theoretical calculations and, the IR study, they suggested that the $\mathrm{Zn}^{2+}$ ions had a tetrahedral geometry.

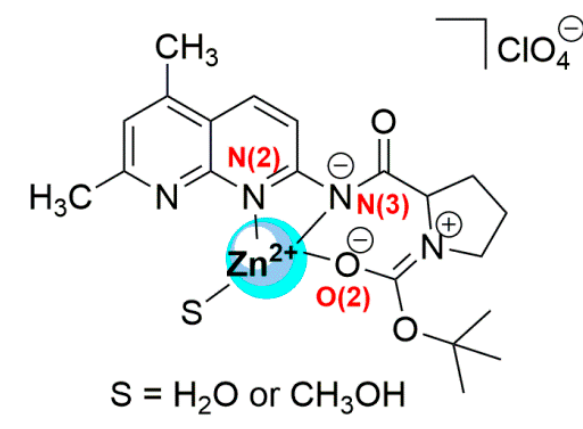

4

The naphthalene moiety has been used by Kim to prepare two very similar chemosensors, compounds $\mathbf{5}$ and $\mathbf{6}[137,138]$. The hydrazide functional group was utilized, as it readily undergoes a Schiff base condensation reaction, to prepare a tridentate binding site (shown in red). The binding group is shown to be ideal for $\mathrm{Zn}^{2+}$ ions and the compounds coordinated in a 2:1 fashion. In both examples, the fluorescent mechanism was due to inhibition of $\mathrm{C}=\mathrm{N}$ isomerization and ESIPT, upon the addition of $\mathrm{Zn}^{2+}$ ions, which drastically increased the emission intensity, via a CHEF mechanism. The calculated $\beta$ values were $1 \times 10^{9} \mathrm{M}^{-2}$ in a DMSO-buffer and DMF-buffer for compounds 5 and 6 , respectively. 


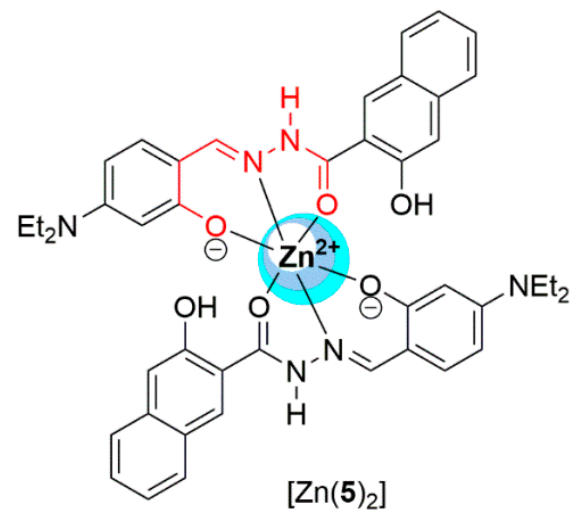

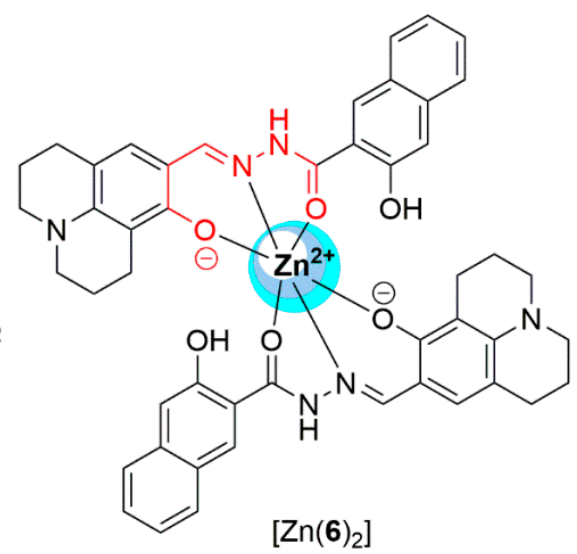

The chemosensor alone had hydrogen bonding donor and acceptor groups. Kim et al. also investigated the anion binding ability of compound 6 in DMF [138]. Upon the addition of $\mathrm{AcO}^{-}$and $\mathrm{F}^{-}$, to ligand 6, a $15 \mathrm{~nm}$ red shift was observed. The $\mathrm{AcO}^{-}$anion showed the greatest hyperchromic shift. This was attributed to a stable chelating binding mode between compound 6 and the $\mathrm{AcO}^{-}$ anion. The authors proposed a binding stoichiometry of 2:1, whereby, the $\mathrm{AcO}^{-}$molecules were bound on the same side of the ligand, although no evidence was provided to support their claim.

A similar binding motif was used as a tridentate binding environment by Erdemir et al. who prepared a triphenylamine derivative 7 [139]. The absorbance spectrum showed subtle wavelength changes which the authors claimed to represent a 1:1 binding stoichiometry with a binding constant of $6 \times 10^{6}$ in $\mathrm{CH}_{3} \mathrm{CN}$. It is reasonable to assume that a 1:1 complex would exist in solution. If this were true, the Benesi-Hildebrand plot would be a straight line, yet the data reported shows a curvature in the double reciprocal plot, indicative of stoichiometries other than a 1:1. The emission spectrum showed a distinctive enhancement upon the addition of $\mathrm{Cd}^{2+}$ and $\mathrm{Zn}^{2+}$, when a $1 \mu \mathrm{M} \mathrm{CH}{ }_{3} \mathrm{CN}$ solution was excited at $400 \mathrm{~nm}$.

Interestingly, the $\lambda_{\mathrm{em}}$ for $\mathrm{Cd}^{2+}$ and $\mathrm{Zn}^{2+}$ was seen at $595 \mathrm{~nm}$ and $620 \mathrm{~nm}$, respectively, a large enough difference to discriminate between these two metals. The optical responses between $\mathrm{Cd}^{2+}$ and $\mathrm{Zn}^{2+}$ ions are usually difficult to differentiate, due to the similarities of these ions. The authors argue that the difference in the metals radius (88 and $109 \mathrm{pm}$ for $\mathrm{Zn}^{2+}$ and $\mathrm{Cd}^{2+}$, respectively) was enough to influence the binding energy in the maximum wavelength seen. The fluorescence mechanism of compound 7 was due to the $\mathrm{C}=\mathrm{N}$ isomerization which was inhibited upon the coordination of metal ions, thus, the intensity enhancement was a consequence of CHEF. The fluorescence binding isotherms showed that the onset of curvature occurred at two equivalents of metal ion, suggesting that the binding constant was not 1:1.

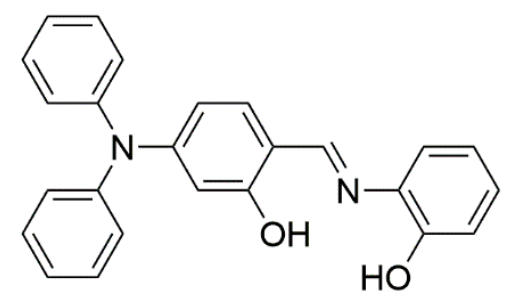

7

Lippard has made a career by designing and synthesizing molecules to bind $\mathrm{Zn}^{2+}$ ions selectively. Over the years, his group has incorporated the dipicoylamine functional group on to different organic scaffolds [140-144], including the rhodamine dyes 8a-c, Figure 3 [145]. The rhodamine dye itself has been used extensively as an off-on sensor to detect a number of metal ions [146]. These molecules are colorless in organic solvents (DMSO, acetone, $\mathrm{MeOH}$, and $\mathrm{CH}_{3} \mathrm{CN}$ ) but under simulated physiological conditions (50 mM PIPES, $100 \mathrm{mM} \mathrm{KCl} \mathrm{pH} \mathrm{7.0),} \mathrm{the} \mathrm{spirolactam} \mathrm{opens} \mathrm{upon} \mathrm{the} \mathrm{addition}$ 
of $\mathrm{ZnCl}_{2}$. The absorption band was observed at $569 \mathrm{~nm}$, and the emission wavelength was seen at $569 \mathrm{~nm}$. Once the concentration of $\mathrm{Zn}^{2+}$ ions was greater than $1 \mathrm{mM}$, no further optical response occurred. The $\phi$ yield was calculated to be 0.22 for the zinc complex, compared to 0.001 for the molecular probe 8a. The $\mathrm{Zn}^{2+}$ ions could be removed from the chelating motif by the addition of $N, N, N^{\prime}, N^{\prime}$-tetrakis(2-pyridinylmethyl)-1,2 ethanediamine (TPEN) or ethylenediaminetetra acetic acid (EDTA). Compounds $\mathbf{8 b}$ and $\mathbf{8 c}$ exhibited little zinc binding via the lactone ring. It was highly probable that $\mathrm{Zn}^{2+}$ ions did coordinate with the DPA group, but the $\mathrm{Zn}^{2+}$ ions were too far away to participate in the coordination of the Lewis basic sites, in the lactone ring. Therefore, no emission signal was observed. This suggested that the lactone group did partake in the binding of the $\mathrm{Zn}^{2+}$ ion with $\mathbf{8 a}$, but no evidence was offered to substantiate this. The other biological relevant ions $\left(\mathrm{Na}^{+}, \mathrm{K}^{+}, \mathrm{Ca}^{2+}\right.$, and $\mathrm{Mg}^{2+}$ ) did not generate the equivalent optical response. The authors calculated the $K_{\mathrm{t}}$ value to be $73 \mu \mathrm{M}$, which took into account the zinc dissociation constant and the lactam formation. Despite this calculated value being at the higher concentration range, in comparison to other dipicolylamine molecular probes, it was still in the biological sensing range for neurochemical applications [147]. The ability for probe 8a to track $\mathrm{Zn}^{2+}$ ions in Hela cells was also investigated and successfully showed cell permeability.
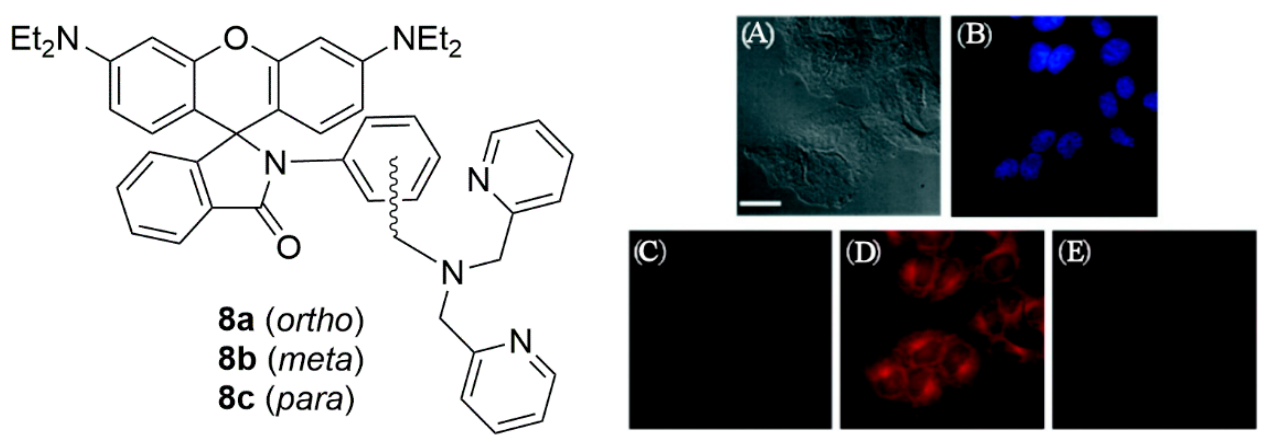

Figure 3. Live cell imaging of Hela cells after incubation with compound 8a (10 $\mu \mathrm{M})$ and Hoechst 33258 nuclear stain (blue): (A) Bright-field transmission image (B) Hoechst 33258 nuclear stain (C) fluorescence image without $\mathrm{Zn}^{2+}$ ions (D) Cells incubated with $8 \mathrm{a}$ for $15 \mathrm{~min}$, washed, and then

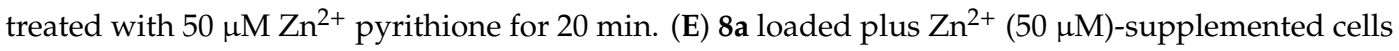
treated with $80 \mu \mathrm{M}$ TPEN after $10 \mathrm{~min}$. Scale bar $=25 \mu \mathrm{M}$. Adapted from [145], with permission from American Chemical Society.

Dipodal receptors have been used extensively in molecular recognition [148]. By incorporating pendent side arms with the appropriate functional groups to bind a guest species, the thermodynamic properties of the host-guest complex can be significantly enhanced, as it wraps itself around the guest. Kim et al. prepared dipodal chemosensor 9 from a piperazine group with two quinoline derivatives attached [149]. Many dipodal receptors are symmetrical but the group chose to synthesize an asymmetric system. On the addition of metal salts $\left(\mathrm{Na}^{+}, \mathrm{K}^{+}, \mathrm{Mg}^{2+}, \mathrm{Ca}^{2+}, \mathrm{Al}^{3+}, \mathrm{Ga}^{3+}, \mathrm{Cr}^{3+}, \mathrm{Mn}^{2+}\right.$, $\mathrm{Fe}^{2+}, \mathrm{Fe}^{3+}, \mathrm{Co}^{2+}, \mathrm{Ni}^{2+}, \mathrm{Cu}^{2+}, \mathrm{Zn}^{2+}$, and $\left.\mathrm{Pb}^{2+}\right)$, significant optical changes were seen. The $\mathrm{Zn}^{2+}$ ions produced a significant intense broad band centered around $500 \mathrm{~nm}$, Figure 4B. The authors claimed that the fluorescence signal was turned off, due to the PET quenching mechanism, which was subsequently inhibited by the coordination of the $\mathrm{Zn}^{2+}$ ions. 
(A)
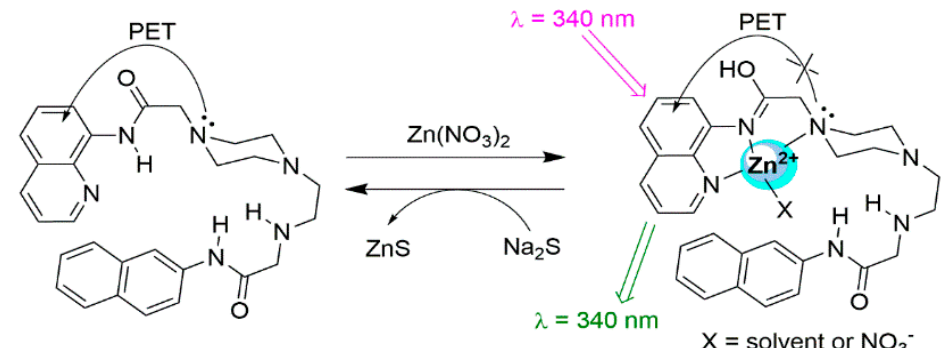

(B)

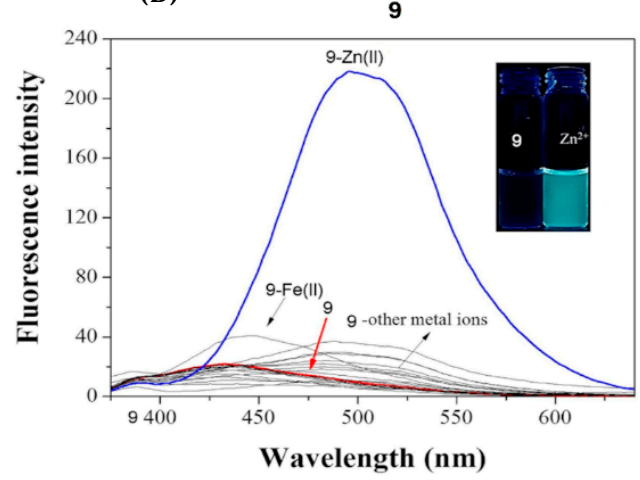

(C)

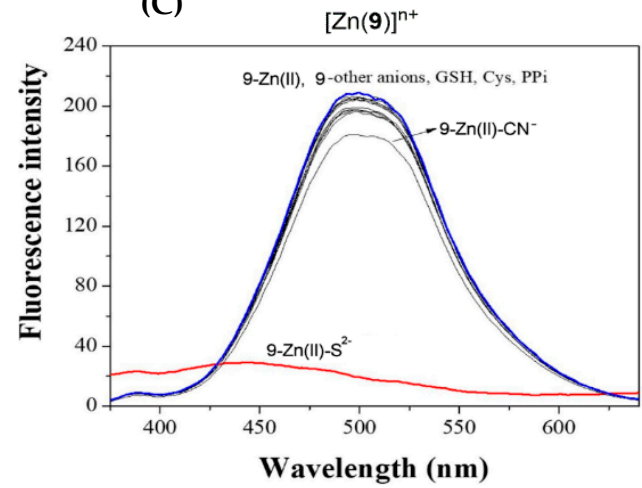

Figure 4. (A) Proposed binding mode of compound 9 and $\mathrm{Zn}^{2+}$ ions. (B) Fluorescence changes observed for compound $9(5 \mu \mathrm{M})$ upon the addition of different metal salts (3.0 equivalents) in bis-tris buffer $\left(10 \mathrm{mM}, \mathrm{pH} 7.0, \lambda_{\mathrm{ex}}=340 \mathrm{~nm}\right)$ and $(\mathrm{C})$ spectral changes of $\left[\mathrm{Zn}(9)\left(\mathrm{NO}_{3}\right)\right]^{+}$upon the addition of different anions added. $\mathrm{Br}^{-}, \mathrm{BzO}^{-}, \mathrm{Cl}^{-} \mathrm{ClO}^{-}, \mathrm{CN}^{-}, \mathrm{F}^{-}, \mathrm{H}_{2} \mathrm{PO}_{4}{ }^{-}, \mathrm{I}^{-}, \mathrm{N}_{3}{ }^{-}, \mathrm{NO}_{2}{ }^{-}, \mathrm{OAc}^{-}, \mathrm{SCN}^{-} \mathrm{SO}_{4}{ }^{2-}$, $\mathrm{HSO}_{4}{ }^{-}$, pyrophosphate (PPi), cysteine, and glutathione (thiol containing amino acids). Adapted and reprinted from [149], with permission from Elsevier.

On closer inspection, the broad band was more reminiscent of an excimer band (Figure 4B). It seemed that, in solution, the two naphthalene units in the dipodal system came closer together to produce this band. It just so happened that the $\mathrm{Zn}^{2+}$ ion was the correct size to bring the units together and maximize the excimer signal. Molecular modeling calculations, however, showed that the two fluorophores were significantly further apart, suggesting that this band was not an intramolecular excimer formation. An excimer band might be formed between molecules at concentrations greater than $1 \mu \mathrm{M}$ [38] and these studies were at $5 \mu \mathrm{M}$. Intermolecular excimer formation could have been ruled out by dilution experiments and intramolecular excimer formation could have been ruled out by a model compound with a single fluorophore. Other metals also showed broad bands but of significantly lower intensity. The emission bands were difficult to assess as the band for $\mathrm{Zn}^{2+}$ ions saturated the other metals' optical responses. Additionally, it was claimed that the $\mathrm{Zn}^{2+}$ molecular probe was reversible by adding $\mathrm{S}^{2-}$, yet the titration conditions did not seem to be conducive to sulfide chemistry. The studies were in $10 \mathrm{mM}$ bis-tris buffer at $\mathrm{pH}$ 7, but at this $\mathrm{pH}$ there was an equilibrium between $\mathrm{H}_{2} \mathrm{~S}$ and $\mathrm{HS}^{-}$, and it was not until the $\mathrm{pH}$ reached 13 that the sulfide could exist in solution. There is no doubt that the authors showed that upon the addition of $\mathrm{Na}_{2} \mathrm{~S}$ to their receptor, drastic spectral changes were observed (Figure 4C), but the $K_{\text {sp }}$ for $\mathrm{ZnS}$ was approximately $2 \times 10^{-25} \mathrm{M}^{-1}$ [150]. Thus, the onset of $\mathrm{ZnS}$ precipitation drove the equilibrium towards the formation of the salt under their conditions.

Photochromic sensors have been used in many applications. The development of ratiometric fluorescent sensors utilizing a UV-Vis switch to sense metal ions is a unique way to prepare logic gates, in which a unimolecular fluorescent probe was designed to bind a metal that could be removed by a competing ligand, such as EDTA. Photoisomerization by UV-Vis could act as an input and the fluorescence emission could act as the output. Pu et al. synthesized two similar molecular switches compounds $\mathbf{1 0}$ and 11, which were utilized as a logic circuit based on the truth table that could be constructed from four different inputs and one output (Table 1 and Figure 5) [151,152]. 
<smiles>Cc1noc(C)c1C1=C(c2cc(-c3ccc(O)c(/C=N/c4[nH]cnc4C(N)=O)c3)sc2C)C(F)(F)C(F)(F)C1(F)F</smiles>

10<smiles>Cc1noc(C)c1C1=C(c2cc(-c3ccc(CN(CC(=O)Nc4ccc5cccnc5c4)Cc4cccnc4)cc3)sc2C)C(F)(F)C(F)(F)C1(F)F</smiles>

11

The absorption band assigned to the open isomers is seen at $243 \mathrm{~nm}$ and a new band at $534 \mathrm{~nm}$ is seen upon irradiation in a $2.0 \times 10^{-5} \mathrm{M}$ solution of $\mathrm{CH}_{3} \mathrm{CN}$. The purple color is a consequence of the rigid conjugation of alternated double bonds, across the backbone of the organic molecule, when the molecule is in its closed state. This was shown to be reversible and was supported by the difference in quantum yields $(\phi)$ of 0.03 and 0.17 for the open and closed states, respectively. The spectroscopic signatures were different for the ring opening and closing, and upon interaction with $\mathrm{Zn}^{2+}$ by EDTA, dual-controlled-switching behavior of compound $\mathbf{1 0}$ and 11 was shown, Scheme 2.

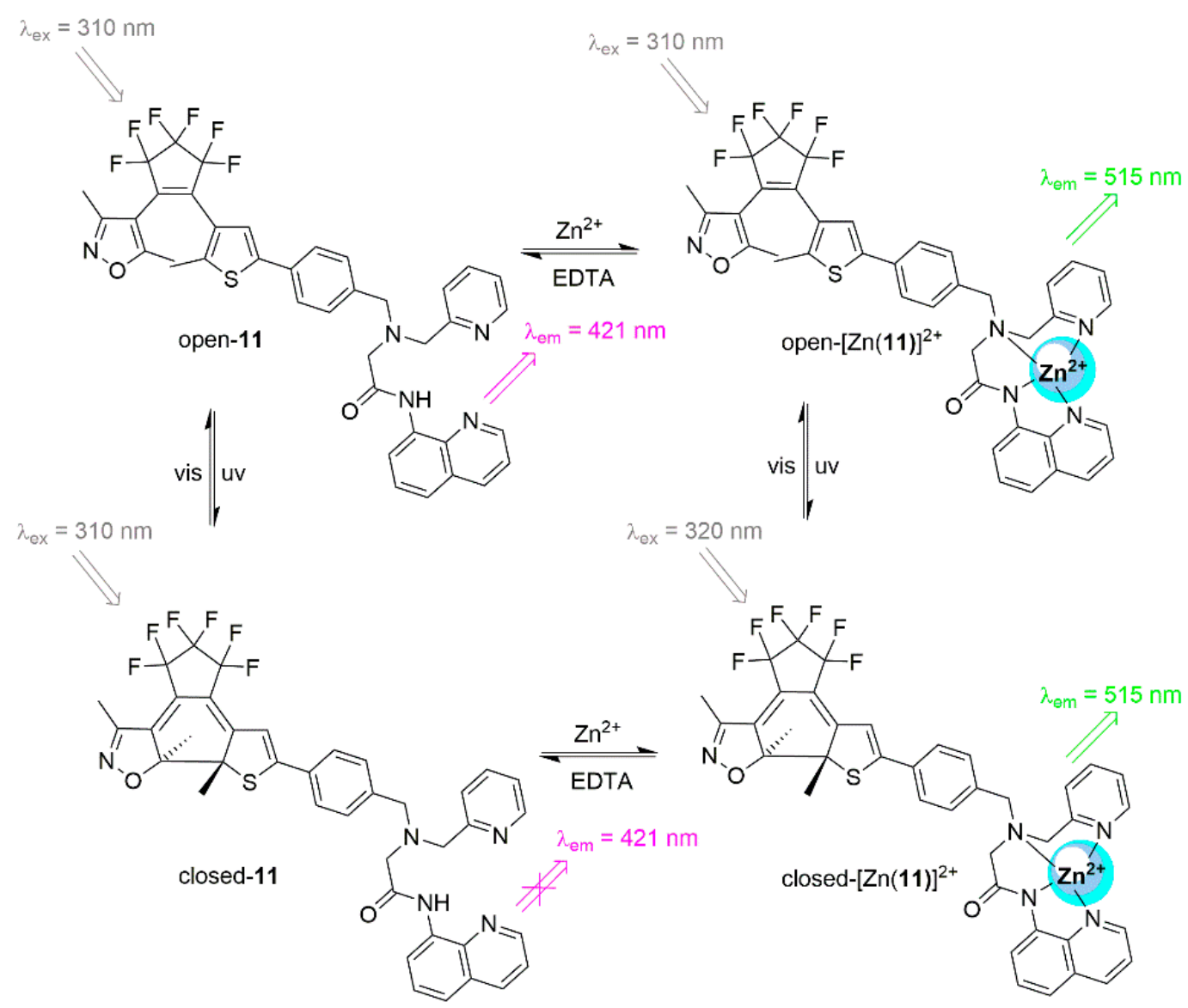

Scheme 2. The molecular switching behavior of molecular probe $\mathbf{1 1}$ with the interaction of $\mathrm{Zn}^{2+}$ ions/EDTA and UV-Vis stimuli. 
Table 1. Truth table highlighting the possible binary inputs and the corresponding digital output.

\begin{tabular}{ccccc}
\hline Input & & & & Output $^{*}$ \\
\hline In (1) & $\begin{array}{c}\text { In (2) } \\
\text { UV }\end{array}$ & $\begin{array}{c}\text { In (3) } \\
\mathrm{Zn}^{2+}\end{array}$ & $\begin{array}{c}\text { In }(4) \\
\text { EDTA }\end{array}$ & $\lambda_{\text {em }}=515 \mathrm{~nm}$ \\
\hline 0 & 0 & 0 & 0 & 0 \\
1 & 0 & 0 & 0 & 0 \\
0 & 1 & 0 & 0 & 0 \\
0 & 0 & 1 & 0 & 1 \\
0 & 0 & 0 & 1 & 0 \\
1 & 1 & 0 & 0 & 0 \\
1 & 0 & 1 & 0 & 0 \\
1 & 0 & 0 & 1 & 0 \\
0 & 1 & 1 & 0 & 1 \\
0 & 1 & 0 & 1 & 0 \\
0 & 0 & 1 & 1 & 0 \\
1 & 1 & 1 & 0 & 0 \\
1 & 1 & 0 & 1 & 0 \\
1 & 0 & 1 & 1 & 0 \\
0 & 1 & 1 & 1 & 0 \\
1 & 1 & 1 & 1 & 1 \\
\hline
\end{tabular}

* when the emission band at $515 \mathrm{~nm}$ is seven times larger than the initial band at $421 \mathrm{~nm}$, the output is "on", this is assigned a " 1 ". Otherwise a " 0 " is assigned, i.e., the "off" state.

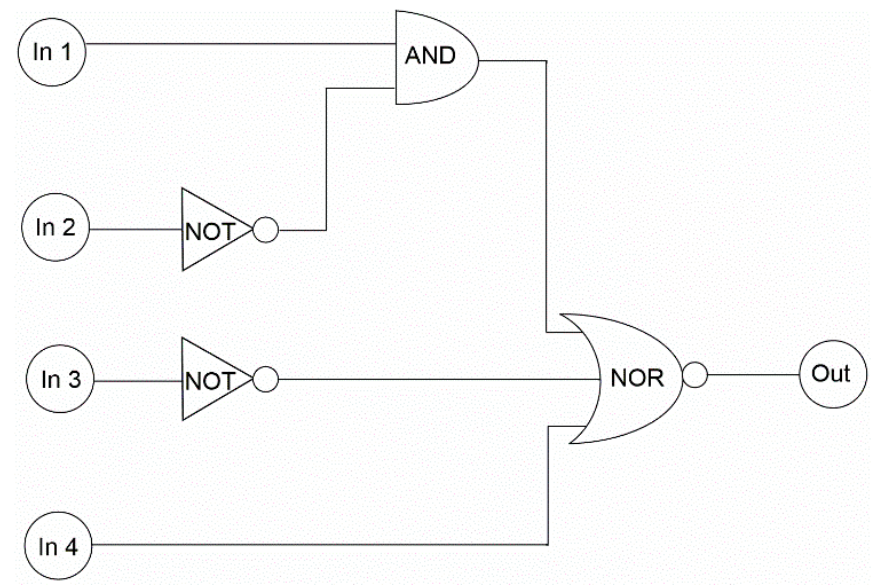

Figure 5. The logic circuit representing the Truth Table 1 (In 1 (UV), In 2 (Vis), In $3\left(\mathrm{Zn}^{2+}\right)$, In 4 (EDTA)).

Zhu et al. systematically changed the linker groups and fluorophores to improve the fluorescent output [153]. Zhu employed the PET switch mechanism to quench the fluorescence signal in a number of chemical fluorophores, which include the di(2-dicolyl) amino group (DPA) [154-156]. This functional group is known to bind $\mathrm{Zn}^{2+}$ ions and has been attached to anthracene [157], fluorescein [158], and rhodamine [159] groups, directly or via short linker groups, such as the methylene group. Zhu's team utilized the triazole functionality, to "click" the DPA binding site. Their early molecular probes relied on fluorophores that were excited around $400 \mathrm{~nm}$, but this visible wavelength region was not conducive if the fluorophore was to be used in fluorescence microscopy for cell imaging, whereby, fluorophores that emit in the near IR region were more desirable. Therefore, they prepared molecular probes 12 to $\mathbf{1 4}$ that used the visible region to excite the fluorophore. All of their compounds were evaluated as zinc sensors and studied for their cell imaging capabilities, and all but one was shown to report zinc ion concentration at $50 \mu \mathrm{M}$ in the Hela cells, by exciting the fluorophores at either 405 (compound 12 and compound 13) or $488 \mathrm{~nm}$ (compound 14). The anilino-DPA group was found to be the key to shift the excitation wavelength for the fluorophores and selectively coordinate the $\mathrm{Zn}^{2+}$ ions. 


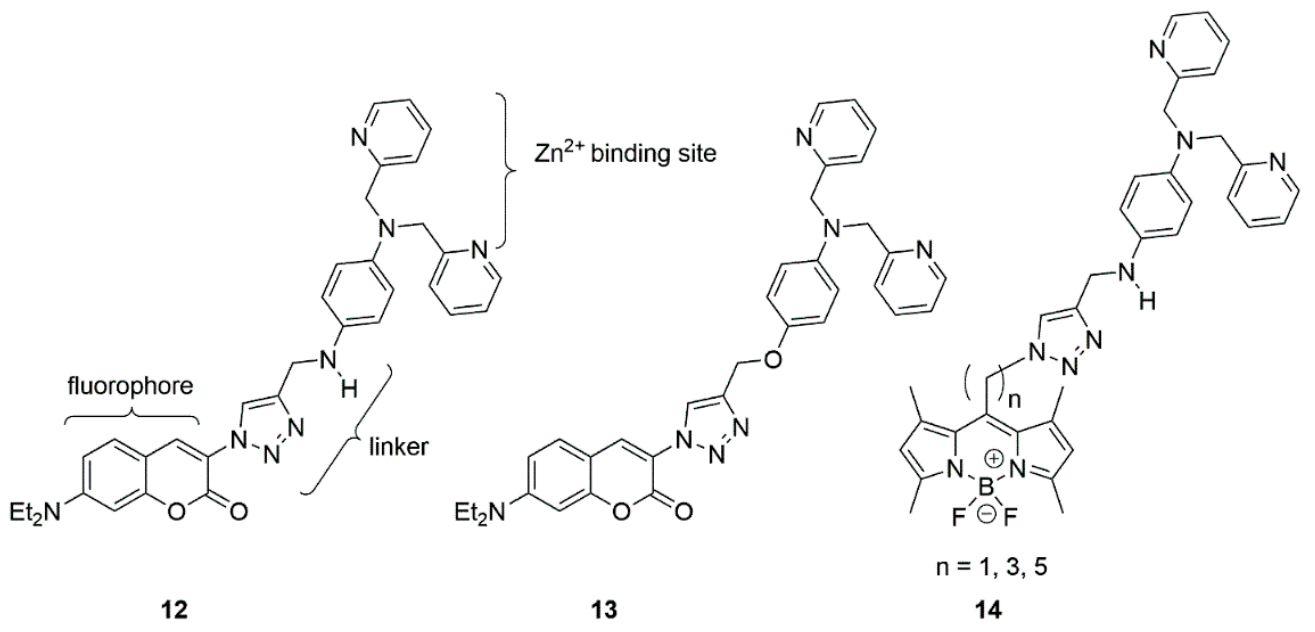

Another dipodal system was developed by Yang et al. who prepared a mixed fluorophore receptor (coumarin-naphthalene) which contained a very elaborate chelating motif, compound 15, Scheme 3 [160]. The absorbance spectra showed a hypochromic shift at $335 \mathrm{~nm}$ and a hyperchromic shift at $430 \mathrm{~nm}$, through a pseudo-isosbestic point at $307 \mathrm{~nm}$. The binding isotherm was sigmoidal, which is indicative of cooperative binding. The fluorescence spectrum in $\mathrm{EtOH}(50 \mu \mathrm{M})$ showed a very strong emission band at $498 \mathrm{~nm}\left(\lambda_{\mathrm{ex}}=430 \mathrm{~nm}\right)$. There was a preference to the $\mathrm{Zn}^{2+}$ ions, in comparison to the other metal ions studied $\left(\mathrm{Al}^{3+}, \mathrm{Ba}^{2+}, \mathrm{Ca}^{2+}, \mathrm{Cu}^{2+}, \mathrm{Hg}^{2+} \mathrm{Co}^{2+}, \mathrm{K}^{+}, \mathrm{Mg}^{2+}, \mathrm{Mn}^{2+}\right.$, $\mathrm{Na}^{+}, \mathrm{Cr}^{3+}, \mathrm{Li}^{+}, \mathrm{Pb}^{2+}, \mathrm{Cd}^{2+}, \mathrm{Ag}^{+}$and $\left.\mathrm{Fe}^{3+}\right)$, however, competition experiments showed that both $\mathrm{Cu}^{2+}$ and $\mathrm{Fe}^{3+}$ significantly quenched the fluorescence intensity, when added to a $[\mathrm{Zn}(\mathbf{1 5})]^{2+}$ solution. The binding constant was calculated to $K_{\mathrm{a}}=2.0 \times 10^{4} \mathrm{M}^{-1}$, using the Benesi-Hildebrand method and the stoichiometry was confirmed by a Job's plot. The fluorescence signal was off in the initial state, as a consequence of the $\mathrm{C}=\mathrm{N}$ isomerization and PET quenching. On addition of the $\mathrm{Zn}^{2+}$ ions, the fluorescence was turned on via the CHEF mechanism. The limit of detection (LoD) was calculated to be $10^{-7} \mathrm{M}$.

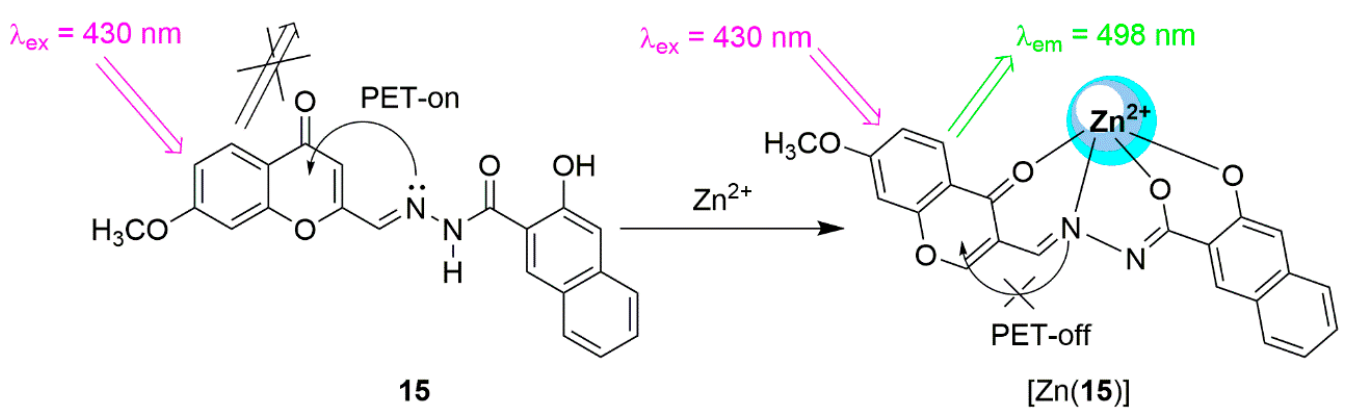

Scheme 3. Proposed binding motif between probe 15 and $\mathrm{Zn}^{2+}$ ions.

Another dual fluorescence mechanism used in sensor technology is the PET and ICT quenching approach, which is inhibited by the addition of $\mathrm{Zn}^{2+}$ ions. Molecular probe 16, Scheme 4, was synthesized by Wang et al. [161] based on a (1,4 diketo-3,6-diphenyl-pyrrolo[3,4-c]pyrrole derivative, which is known to be a brilliant red and strongly fluorescent dye. Additionally, this organic fluorophore is stable to heat with high photostability and shows a large Stokes shift, which makes it an excellent choice in sensor design. Compound 16 shows a weak emission band at $630 \mathrm{~nm}(\phi=0.07)$, in the absence of $\mathrm{Zn}^{2+}$ ions, but upon the addition of $\mathrm{Zn}^{2+}$ ions to compound 16, a blue shift to $560 \mathrm{~nm}(\phi=0.85)$ was observed; no other metal ion showed this enhancement. The optical studies (absorbance and fluorescence), and the NMR studies showed that no further optical or structural changes occurred after the addition of two equivalents of $\mathrm{Zn}^{2+}$ ions. A binding constant of $4.69 \times 10^{7} \mathrm{M}^{-2}$ was determined 
using the fluorescence data and the stoichiometry was confirmed as a 2:1 metal:probe complex formation, through MS studies.

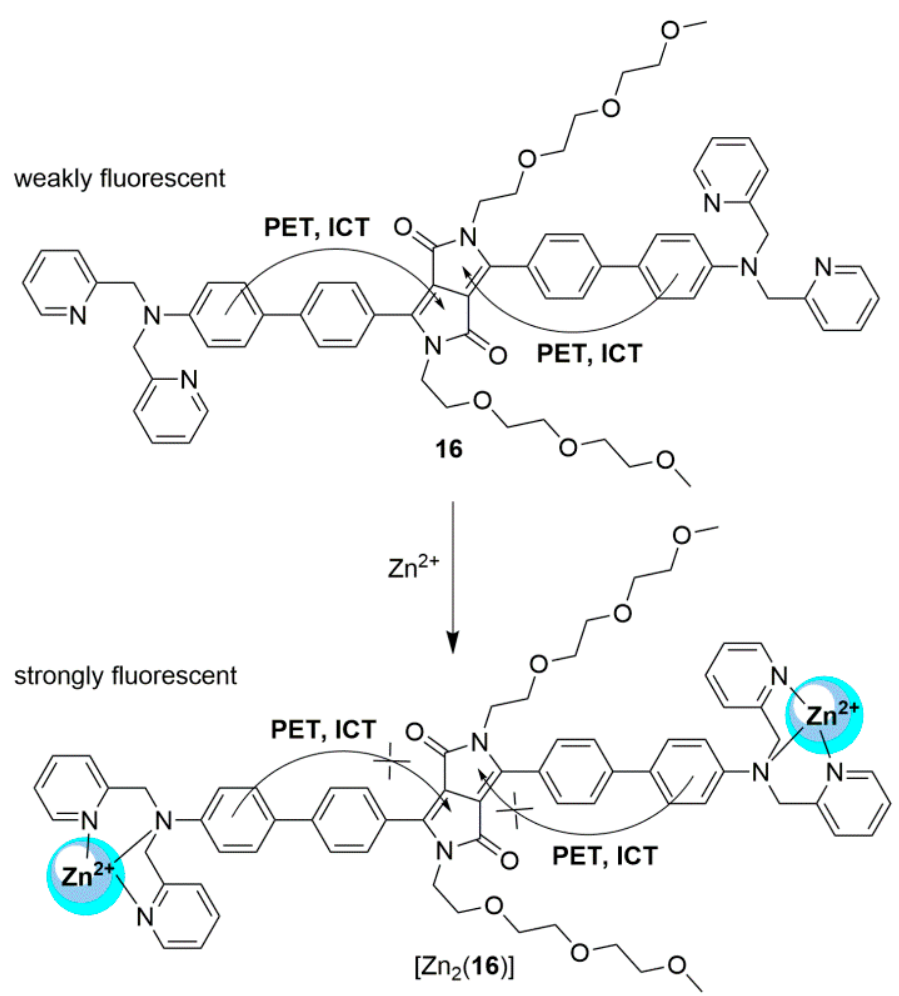

Scheme 4. Proposed binding motif between probe 16 and $\mathrm{Zn}^{2+}$ ions.

Throughout this section there have been examples of molecular probes for the detection of $\mathrm{Zn}^{2+}$ ions, but very few papers also discuss the counter-ion effect in their systems. Zinc complexes (in particular $\mathrm{ZnCl}_{2}$ ) also play an important role, as a moderate strength Lewis acid, in Friedel-Crafts acylations. Our own group has prepared pyrene-based molecular probes 17 and 18 [162]. Compound 17 was shown to simultaneously bind the cation and anion, in a self-assembled process. Self-assembly occurred in the presence of $\mathrm{ZnX}$ salts $\left(\mathrm{X}=\mathrm{F}^{-}, \mathrm{Cl}^{-}, \mathrm{Br}^{-}, \mathrm{I}^{-}, \mathrm{BF}_{4}^{-}, \mathrm{CH}_{3} \mathrm{CO}_{2}^{-}, \mathrm{H}_{2} \mathrm{PO}_{4}^{-}, \mathrm{ClO}_{4}^{-}, \mathrm{CN}^{-}\right.$, $\mathrm{NO}_{3}{ }^{-}$) and $\mathrm{ZnSO}_{4}$. The optical response was due to a strong excimer band observed at $410 \mathrm{~nm}$ in the presence of $\mathrm{ZnCl}_{2}$ in acetonitrile. DFT calculations supported the proposed structure (Scheme 5). The intensity of the excimer signal was dependent on the proximity of the two pyrene units. In absence of the $\mathrm{Zn}^{2+}$ ion, the excimer signal was not observed, as was confirmed by the analogous spectroscopic studies with tetrabutylammonium salts, i.e., the metal was required for the self-assembly process to occur. This suggests that the $\mathrm{Zn}^{2+}$ halide was templating the pyrene units. The geometry around the $\mathrm{Zn}^{2+}$ ion was tetrahedral and the pyrene moieties adopted a syn configuration. The fluorescence titrations were in good agreement with the NMR studies, which showed a 2:1 binding mode calculated by non-linear regression with a calculated binding constant $\left(K_{21}\right)$ of $1.8 \times 10^{6} \mathrm{M}^{-2}$ for $\mathrm{ZnCl}_{2}$. This example was a good example of size-selective self-assembled recognition and was carried out at a low concentration, to rule out intermolecular excimer formation. 


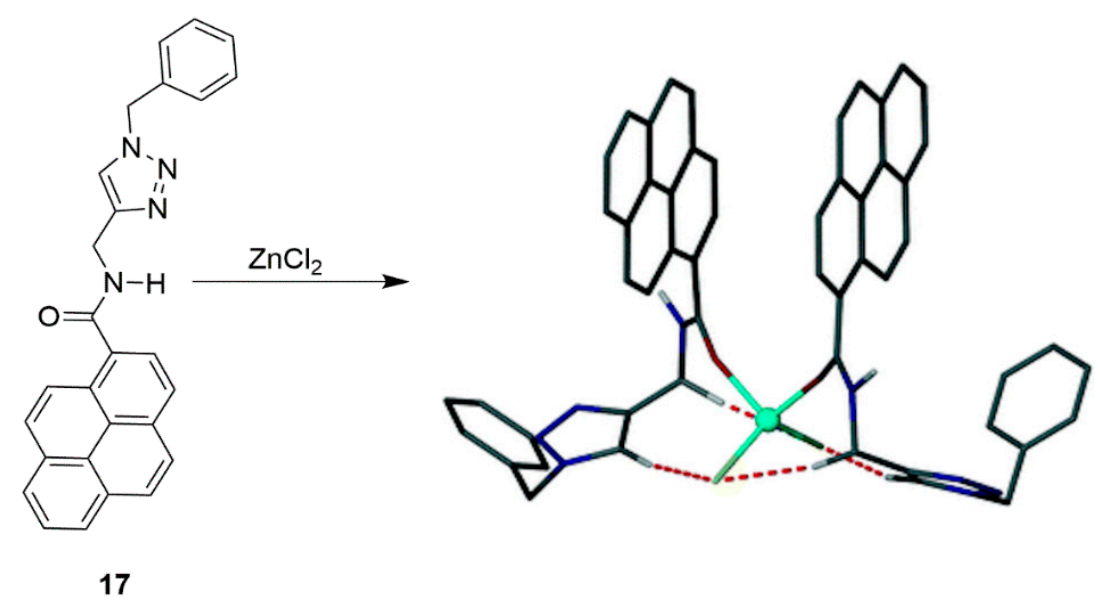

Scheme 5. A simultaneous ion pair recognition event. Adapted from [160] with permission from The Royal Society of Chemistry.

The next step our group took was to tether two of the pyrene units, shown in compound 17, onto an organic backbone, to prepare a dipodal receptor. Three molecular probes containing an amide functional group and a triazole moiety was attached to a benzene scaffold (18a-c ortho, meta and para respectively) [163].
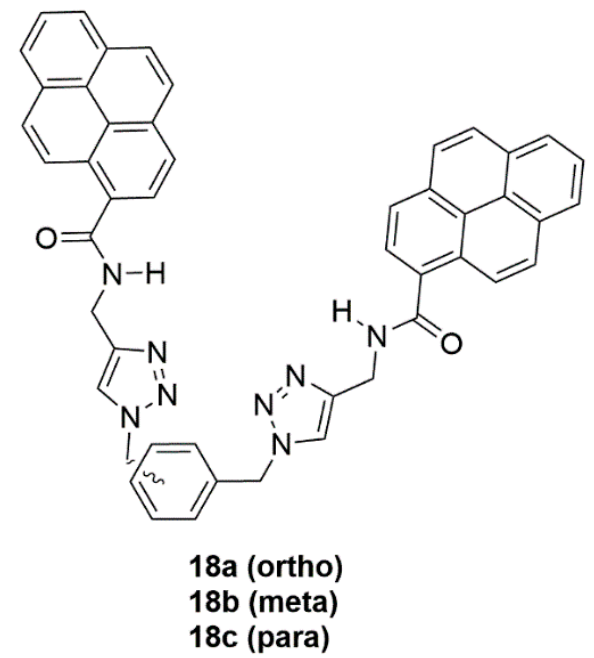

Fluorescence analysis of compounds $18 \mathrm{a}$ and $18 \mathrm{~b}$ with different metal ions $\left(\mathrm{Zn}^{2+}, \mathrm{Mg}^{2+}, \mathrm{Cd}^{2+}\right.$, $\mathrm{Al}^{3+}, \mathrm{Hg}^{2+}, \mathrm{Ni}^{2+}, \mathrm{Cu}^{2+}, \mathrm{Fe}^{2+}, \mathrm{Fe}^{3+}$ and $\mathrm{Na}^{+}$) as either their chloride or perchlorate salts were initially tested, with the addition of 10 equivalents of metal salts in $\mathrm{CH}_{3} \mathrm{CN}$ and excited at $325 \mathrm{~nm}$. The fluorescence signal of the free receptors showed the typical monomer bands at 380 and $400 \mathrm{~nm}$, characteristic of the unique electronic transitions in the pyrene-derived compounds, which were assigned to the $\pi-\pi^{*}$ electron transitions. A very broad band at $495 \mathrm{~nm}$ was also seen, which was assigned to the intramolecular excimer formation, upon excitation at $325 \mathrm{~nm}$. On inspection of the fluorescence spectrum, quenching was observed for all metals except $\mathrm{Zn}^{2+}$ (and to a lesser degree $\mathrm{Cd}^{2+}$ and $\mathrm{Mg}^{2+}$ ), and a new band was seen to increase at $400 \mathrm{~nm}$. It was evident that the $\mathrm{Zn}^{2+}$ salts showed significantly greater fluorescence at $400 \mathrm{~nm}$ for $\mathbf{1 8 b}$ than for 18a, for which a small increase in intensity was observed at $400 \mathrm{~nm}$. The fluorescence intensity at $400 \mathrm{~nm}$ for 18a was a consequence of the two pyrene units in 18a adopting an anti-orientation, which gave a greater pyrene-pyrene separation than was available to $\mathbf{1 8 b}$. It was shown that the binding affinity for $\mathrm{Zn}\left(\mathrm{ClO}_{4}\right)_{2}$ was a magnitude greater for 18a than for 18b, even though the fluorescence change at $400 \mathrm{~nm}$ was not observed to be as dramatic. In fact this trend was seen for all the other analytes studied, we argued that the more favorable chelating 
motif was the reason for the observed calculated binding constant. To understand the binding mode, extensive IR and molecular modeling studies were carried out. It is known that significant infrared spectral changes occur when perchlorate coordinates with a metal ion through different modes [164]. Determination of the changing symmetry of the $\mathrm{ClO}_{4}{ }^{-}$ion, upon binding, from $\mathrm{T}_{\mathrm{d}}$ (ionic) to $\mathrm{C}_{3 \mathrm{v}}$ (unidentate) and $\mathrm{C}_{2 \mathrm{v}}$ (bidentate or bridging), could help identify if the binding mode proposed model was consistent with IR data reported. Molecular mechanics calculations for 18a and $\mathbf{1 8 b}$ and their corresponding $\mathrm{Zn}\left(\mathrm{ClO}_{4}\right)_{2}$ complexes were carried out (Figure 6). Both of the free receptors showed very different $\pi$ stacking interactions. The ortho-isomer, 18a, showed that the aromatic scaffold of the molecular probes participates in $\pi$-stacking and one of the pyrene arms seemed to intercalate and form an intramolecular sandwich interaction Figure 6A. This intercalation was not observed in the meta-isomer, $\mathbf{1 8 b}$, which showed the $\pi-\pi$ distance between the two pyrene units to be $4.77 \AA$. The distance was measured between the pyrene centroids (Figure 6C) and the $\mathrm{CH}$ hydrogens on the triazole rings orientated towards the center of the molecular probes. This is in excellent agreement with the interactions expected to generate the excimer band seen in the fluorescence spectrum. Both of the $\mathrm{Zn}^{2+}$ complexes showed drastically different optimized geometries. The $\mathrm{Zn}^{2+}$ ion was bound in a tetrahedral arrangement, coordinated to the oxygen atom of the carbonyl functional group, and a nitrogen atom in the triazole ring, forming a seven-membered chelating ring. The distance between the two pyrene units in $[\mathrm{Zn}(\mathbf{1 8 a})]^{2+}$ was $10.8 \AA$, whereas the distance between the two pyrene units in $[\mathrm{Zn}(\mathbf{1 8 a})]^{2+}$ was $5.5 \AA$. This was in excellent agreement with the fluorescence data in which a broad excimer band was seen at $400 \mathrm{~nm}$ for the $\mathbf{1 8 b}$ complex; the same band was significantly less intense for the $\mathbf{1 6 a}$ complex.

A

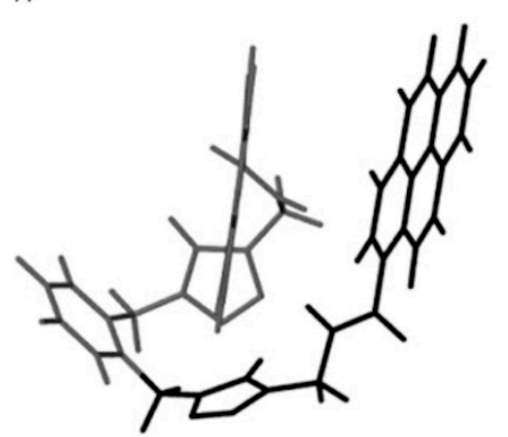

C

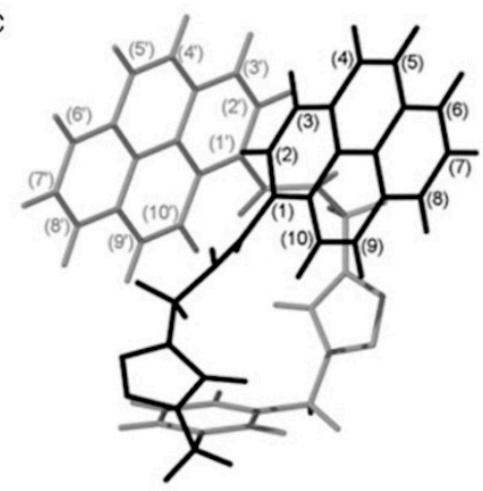

B
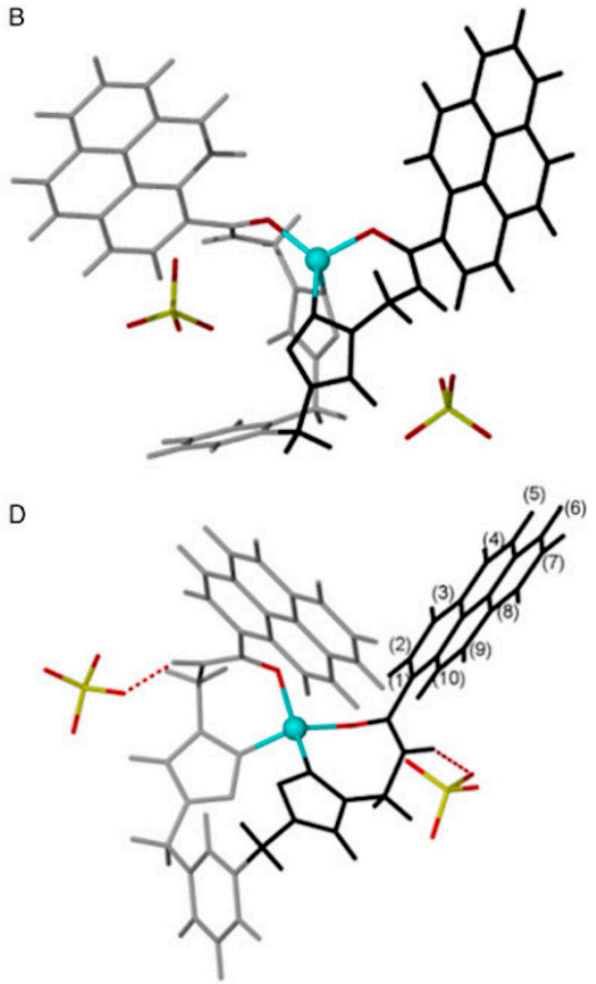

Figure 6. Fully optimized structures (DFT) in the gas phase of (A) compound 18a, (B) $[\mathrm{Zn} \cdot 18 \mathrm{a}]\left(\mathrm{ClO}_{4}\right)_{2}$, (C) compound 18b, and (D) [Zn·18b]($\left(\mathrm{ClO}_{4}\right)_{2}$. Adapted From [163], with permissiom from Taylor \& Francis Ltd.

\subsection{Cadmium Probes}

As cadmium has essentially no biological use and the bioaccumulation of $\mathrm{Cd}^{2+}$ ions in the environment is a real threat, there is an increasing need to remove cadmium from wastewater from an industrial process. Cadmium has been ranked as one of the top 10 priority lists from the top 
275 hazardous materials that have been identified by The Comprehensive Environmental Response, Compensation, and Liability Act in the USA [165], therefore, detection and remediation of $\mathrm{Cd}^{2+}$ ions in the environment are imperative. A review by El-Safty outlined the importance of cadmium in the environment, discussed common techniques to remediate $\mathrm{Cd}^{2+}$ ions, and highlighted the chemosensors used for cadmium monitoring [166]. The chemistry and structural similarities of cadmium is similar to zinc. Both the tetrahedral and octahedral forms are known. The type of Lewis basic atom plays a role in the geometry. For example, Parkin et al. showed that $\mathrm{Zn}^{2+}$ ions preferred a tetrahedral environment when the donor atom was sulfur, whereas the $\mathrm{Cd}^{2+}$ complex showed a six-coordinate environment [167]. Selenolato complexes are known to coordinate to $\mathrm{Zn}^{2+}$ and $\mathrm{Cd}^{2+}$ in a distorted tetrahedral environment [168]. A review published by Sigel and Martin state that the $\mathrm{Cd}^{2+}$ ion could be found in 4,5 , and 6 coordination environments, $20 \%, 8 \%$, and $56 \%$ of the time, respectively [169].

Therefore, it is not surprising that the LMFP reported for the detection of $\mathrm{Cd}^{2+}$ ions is similar to the probes for zinc ions. Additionally, the fluorescence mechanism is alike. For example, Pu et al. synthesized a closely related molecule to probes $\mathbf{1 0}$ and $\mathbf{1 1}$ and subtly changed their binding motif to prepare a sensor for $\mathrm{Cd}^{2+}$ ions [170].

A rhodamine-based conjugated dyad probe (19) has been synthesized by Stalin and coworkers (Scheme 6) [171]. The authors claimed that the FRET mechanism between the rhodamine and pyridine conjugated dyad is responsible for the emission observed upon the coordination of $\mathrm{Cd}^{2+}$ ions in the organic-aqueous system $\left(\mathrm{CH}_{3} \mathrm{CN}\right.$ :HEPES buffer 2:8, v/v, pH 7.2, $\left.10 \mathrm{mM}\right)$. However, upon inspection of their molecular probe, it is difficult to justify the authors claim. For FRET to occur, several criteria must be met: (i) the fluorescence emission spectrum of the donor molecule must overlap the absorption or excitation spectrum of the acceptor chromophore, (ii) the two fluorophores (donor and acceptor) must be in close proximity to one another (typically 1 to $10 \mathrm{~nm}$ ), (iii) the transition dipole orientations of the donor and acceptor must be approximately parallel to each other, and (iv) the fluorescence lifetime of the donor molecule must be of sufficient duration to allow the FRET to occur. The pyridine unit alone is not usually considered a fluorophore. It is more reasonable to assume that the mechanism is an off-on fluorescence mechanism, based on the spirolactam ring opening. However, the authors did show high selectivity and sensitivity towards $\mathrm{Cd}^{2+}$ ions in the presence of other competing metal ions, which was indicated by the appearance of a new fluorescence band at $590 \mathrm{~nm}$, due to $\mathrm{Cd}^{2+}$ coordination. Spectroscopic studies were used to determine a LoD of $1 \times 10^{-8} \mathrm{M}$, which is well below the WHO acceptable limit of $1.85 \mathrm{mM}$ for $\mathrm{Cd}^{2+}$ ions in drinking water. Both the association constant and binding ratio were determined from the absorption spectra. The absorption titration was used to calculate an association constant of $4 \times 10^{4} \mathrm{M}^{-1}$ and, from the Job's plot data, the binding ratio was found to be 1:1. In the presence of sulfide ions CdS was formed, which resulted in decomplexation and the disappearance of the emission band observed at $590 \mathrm{~nm}$. The results described above suggest that the sensor was recycled during the detection of $\mathrm{S}^{2-}$ ions.

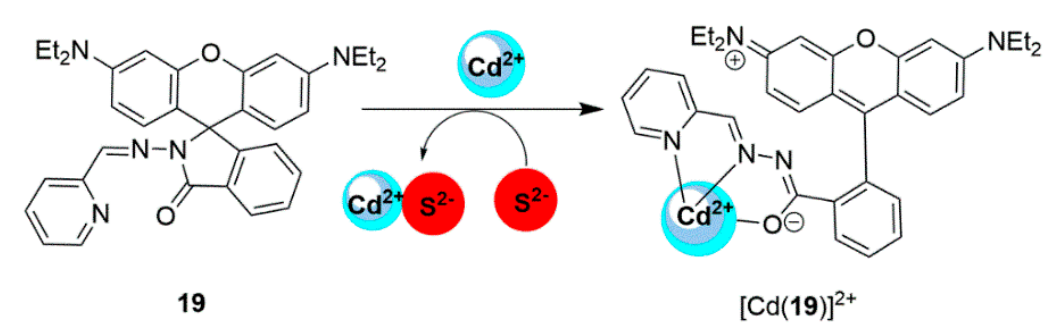

Scheme 6. The proposed binding of $\mathrm{Cd}^{2+}$ ions and chemosensor 19.

A FRET molecular probe incorporating rhodamine was synthesized by Goswami et al. Chemosensor 20 was shown to be selective for $\mathrm{Cd}^{2+}$ ions, with the sensor acting as an 'off-on' FRET sensor capable of detecting $\mathrm{Cd}^{2+}$ ions in a mixed organic-aqueous solvent system. Additionally, a distinctive color change was seen, typical of rhodamine dyes. A quinoline-benzothiazole functional group (FRET donor) was tethered to the rhodamine molecule (FRET acceptor), via a nonconjugated 
spacer, Scheme 7 [172]. As the emission spectra of the quinoline benzothiazole group overlapped significantly with the absorption spectra of the ring-opened rhodamine B dye, it was possible to observe the transfer of energy from donor to acceptor, once the sensor interacted with the $\mathrm{Cd}^{2+}$ ions. Both the quantum yield and FRET efficiency of the sensor were calculated from fluorescence studies carried out in $\mathrm{MeOH} / \mathrm{H}_{2} \mathrm{O}(1: 4, v / v, \mathrm{pH} 7.2,10 \mathrm{mM}$ HEPES buffer solution) and were found to be $\phi=0.37$ and $48 \%$, respectively. These experimental conditions were optimized for the water content. They reported that when the percentage of water was increased above $80 \%$, the intensity ratio $\left(\mathrm{I}_{585} / \mathrm{I}_{470}\right)$ of the emission band decreased significantly, whereas less water content showed modest changes in the emission intensity. From the fluorescence titration, Aich and coworkers found that the lowest concentration of $\mathrm{Cd}^{2+}$ ions detectable by the sensor was $3 \times 10^{-7} \mathrm{M}$ and the association constant (determined using a nonlinear least-squares fit) was found to be $1 \times 10^{5} \mathrm{M}^{-1}$. The other metal ions studied $\left(\mathrm{K}^{+}, \mathrm{Ca}^{2+}\right.$, $\mathrm{Ni}^{2+}, \mathrm{Mn}^{2+}, \mathrm{Zn}^{2+}, \mathrm{Cu}^{2+}, \mathrm{Fe}^{3+}, \mathrm{Cr}^{3+}, \mathrm{Hg}^{2+}$, and $\mathrm{Pb}^{2+}$ ) did not show the same optical response. The 1:1 binding mode was confirmed both in solution and in the solid state. The X-ray crystal structure confirmed that the $\mathrm{Cd}^{2+}$ binds in an octahedral environment with five of the donor groups from compound 20 and a chloride ion in the remaining coordination site.

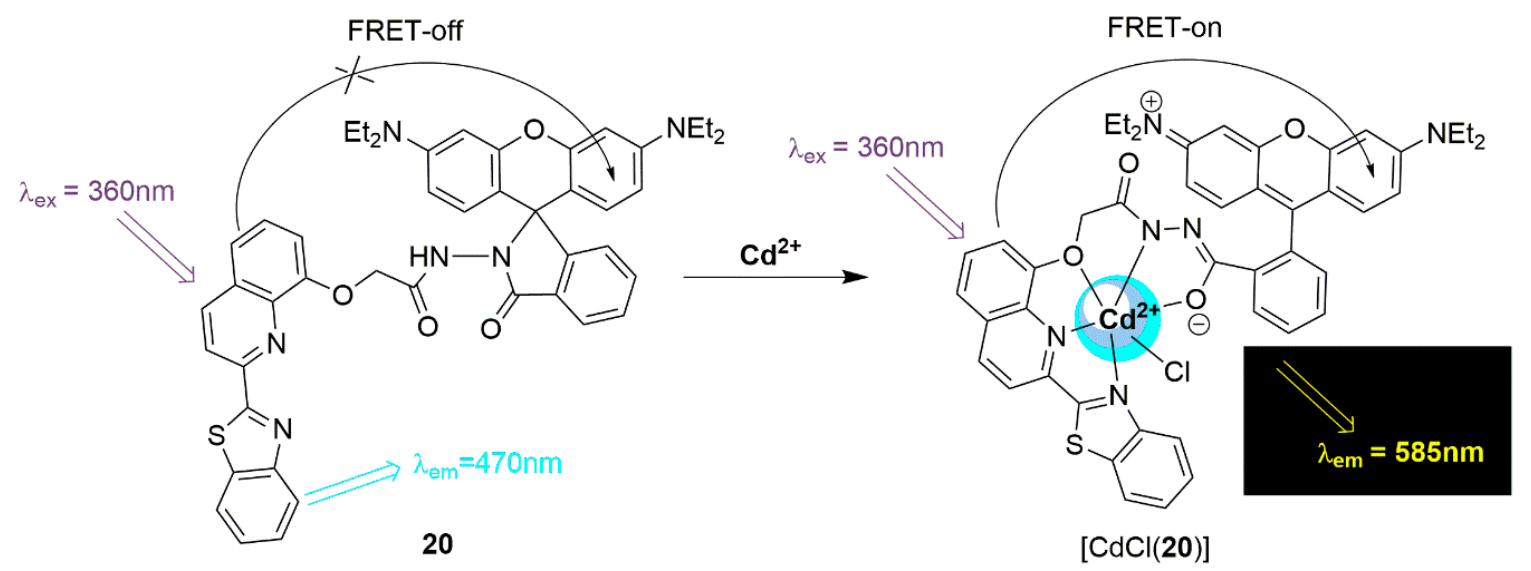

Scheme 7. The binding mode of $\mathrm{Cd}^{2+}$ ions to chemosensor $20 \mathrm{MeOH} / \mathrm{H}_{2} \mathrm{O}(1: 4, v / v, \mathrm{pH} 7.2,10 \mathrm{mM}$ HEPES buffer solution).

As $\mathrm{Cd}^{2+}$ ions are hazardous to the environment the preparation of portable sensing kits is attractive. Goswami immersed thin layer chromatography (TLC) plates soaked with 20 in $\mathrm{MeOH}$ solution $\left(2 \times 10^{-4} \mathrm{M}\right)$, removed excess $\mathrm{MeOH}$ and placed the probe coated plates into a MeOH solution of cadmium ions $\left(2 \times 10^{-3} \mathrm{M}\right)$, which showed distinctive color changes (Figure 7 ).

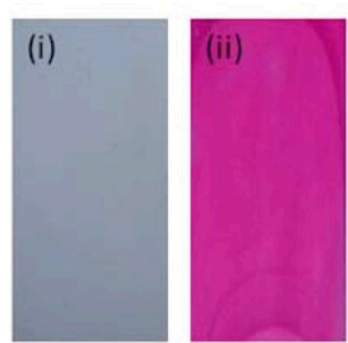

(A)

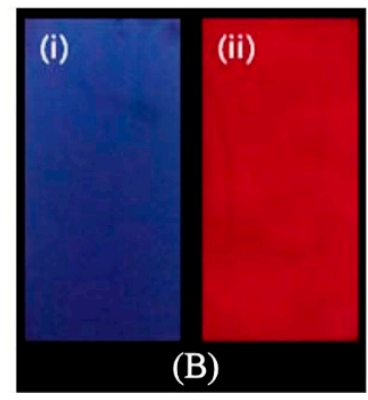

Figure 7. (A) Photographs of TLC plates after the immersion of molecular probe 20 into a $\mathrm{MeOH}$ solution (i) after the addition of $\mathrm{Cd}^{2+}$ ions (ii) under ambient light; and (B) under hand-held UV-light at $365 \mathrm{~nm}$, (i) after the addition of $\mathrm{Cd}^{2+}$ ions, (ii) under hand-held UV-light at $365 \mathrm{~nm}$, Adapted from [172], with permission from American Chemical Society. 
Another popular fluorescent mechanism that is being used in molecular probe design is aggregation induced emission (AIE), a similar mechanism to excimer formation. Wang et al. employed this by tethering a hydrophobic tetraphenylethene (TPE) moiety (hydrophobic part) onto a $\beta$-cyclodextrin (hydrophilic part), via a click reaction to give compound 21. Therefore, by varying the ratios of water and organic solvent the mechanism could be turned on and off. The triazole moiety was used as the Lewis basic site to coordinate the $\mathrm{Cd}^{2+}$ ions [171]. In solutions containing $\leq 50 \%$ water, the sensor gave no significant emission when the probe was excited at $330 \mathrm{~nm}$. However, upon the addition of $\mathrm{Cd}^{2+}$ ions, a noticeable emission band emerged around $476 \mathrm{~nm}$. This could be attributed to the overlap of the tetraphenylethene groups as a result of the 2:1 coordination between the sensor and $\mathrm{Cd}^{2+}$ ions. This same behavior was observed as the water content of the solvent system was increased up to $98 \%$. In higher concentrations of water, the solution of the sensor becomes strongly emissive at $476 \mathrm{~nm}$, and this emission was visible with the naked eye, Figure 8 . This strong emission was due to the formation of aggregates in solution, owing to the decreased solubility of the sensor. Zhang et al. observed that in a solution of $\mathrm{DMSO} / \mathrm{H}_{2} \mathrm{O}(1: 1, v / v)$ the sensor only responded to $\mathrm{Cd}^{2+}$ ions and no other metal ions and they were able to detect $\mathrm{Cd}^{2+}$ ions at concentrations as low as $1 \times 10^{-8} \mathrm{M}$.
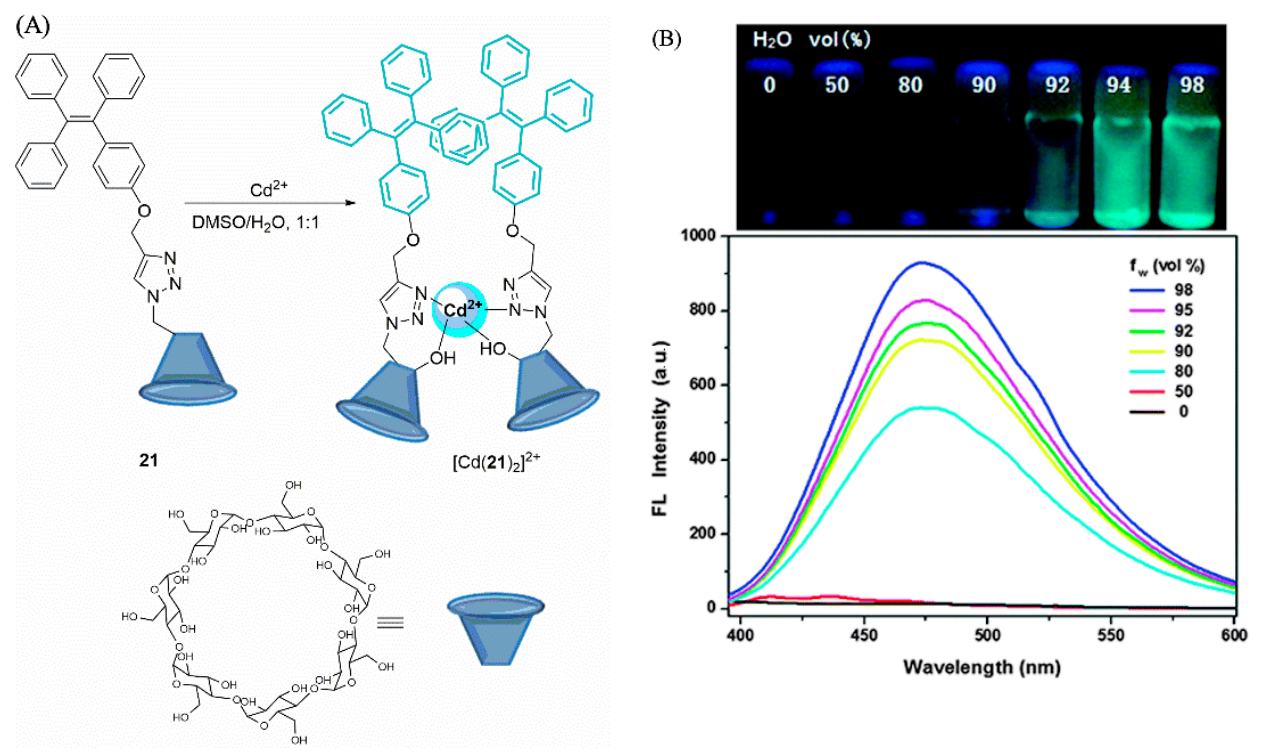

Figure 8. (A) The proposed binding mode of chemosensor 21 and $\mathrm{Cd}^{2+}$ ions and (B) the emission turn-on in $50 \mu \mathrm{M}$ solution of 21 with a different ratio of DMSO- $\mathrm{H}_{2} \mathrm{O}\left(\lambda_{\mathrm{ex}}=330 \mathrm{~nm}\right)$. Aggregation could be seen by the naked-eye once the water content was greater than $90 \%$. Adapted from [173] with permission from The Royal Society of Chemistry.

Many LMFPs have been adsorbed (physisorption or chemisorption) onto surfaces to improve sensitivity. This is done to increase the number of binding sites, by incorporating a number of the desired molecular probes onto a single platform. Commonly used scaffolds are mesoporous silica materials. These materials are rigid and porous and have been used to support a number of molecular sensors. An advantage of these materials is that they are optically transparent in the visiable range, therefore, the signal generated is genuinely from the receptor and the analyte. These types of materials have been used in sensor applications and for remediation purposes [119,129,174,175]. A reusable fluorescent sensor capable of detecting $\mathrm{Cd}^{2+}, \mathrm{Hg}^{2+}$, and $\mathrm{Pb}^{2+}$ ions in aqueous solutions was synthesized by Zhu et al. by physidorption, of a 2,2-dipicoylamine modified naphthalimide fluorophore, 22, onto the surface of a silica microsphere [176]. It is inherently hydrophilic and capable of metal detection and adsorption (Scheme 8), as indicated by increases in its fluorescence intensity. Control studies indicated that, in the absence of the silylpropylamine linkers on the microspheres, no adsorption of metal ions had occurred. Under optimal conditions (low concentration of metal ions and 22 at $\mathrm{pH} 4.5-10)$, compound 22 had an adsorptivity greater than 95\%. In acidic media $(\mathrm{pH}<4.5)$, the 
adsorption capability of the sensor was greatly diminished, which allowed the desorption of metal ions from the sensor. Presumably, the nitrogen atoms become protonated, removing the ability of the molecular probe to form a Lewis acid-base adduct, before the acidic medium removes the metal ions. This allows microspheres coated with 22 to be recycled multiple times, by washing them with an acidic solution, then readjusting the $\mathrm{pH}$ by adding base. Fluorescence studies determined that the LoD of $\mathbf{2 2}$ was in the $\mathrm{nM}$ concentration range with an association constant of $2.3 \times 10^{7} \mathrm{M}^{-1}$ for $\mathrm{Cd}^{2+}$ ions.

Interestingly, this molecular probe was able to remove $\mathrm{Cd}^{2+}$ (and $\mathrm{Hg}^{2+}$ and $\mathrm{Pb}^{2+}$ ) from tap water, lab wastewater, and simulated biological fluid. Samples were spiked with $2.0 \mathrm{mg} \cdot \mathrm{L}^{-1} \mathrm{Cd}^{2+}$ salts and $99 \%, 98 \%$, and $96 \%$ of the metal was recovered from tap water, wastewater, and biological fluid, respectively, indicating that the molecular probe is a good candidate for cadmium remediation, but it remains to be seen if the probe can selectively remove metals from a mixture of metal ions in the samples.

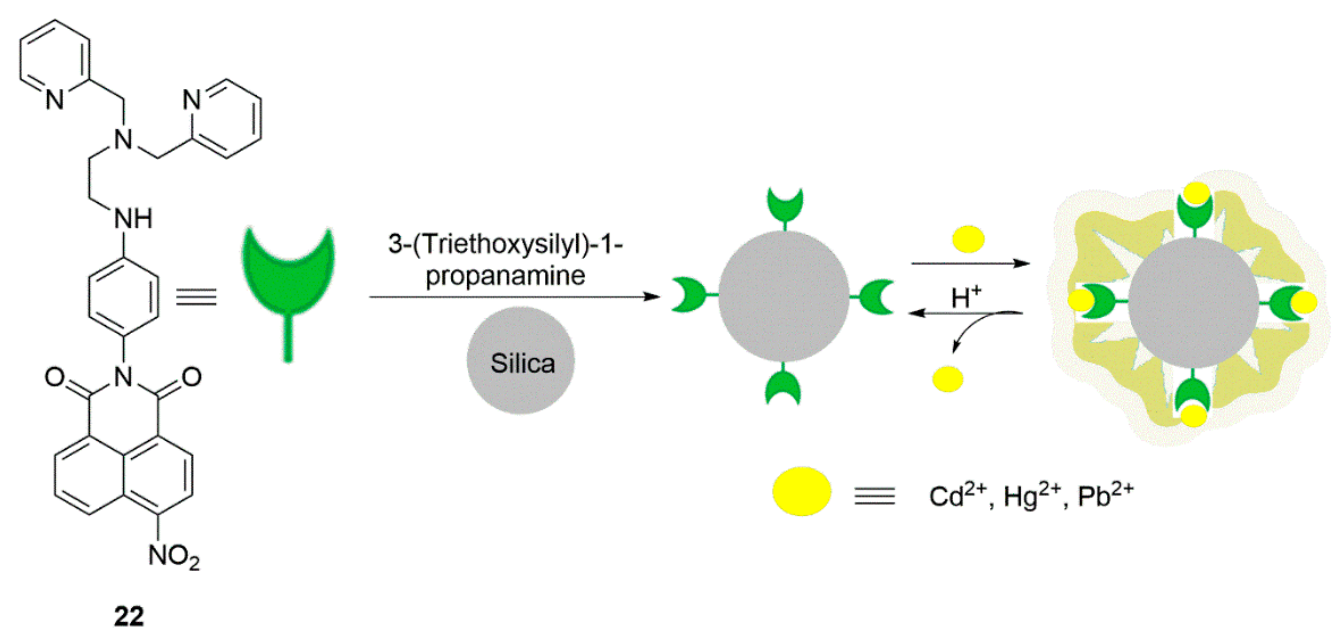

Scheme 8. Chemosensor 22, attached to silica, is able to undergo a fluorescence turn on, upon the addition of $\mathrm{Cd}^{2+}, \mathrm{Hg}^{2+}$, and $\mathrm{Pb}^{2+}$. The removal of the metal was achieved by the addition of acid.

$\mathrm{Lv}$ and Shen synthesized a ratiometric porphyrin-based fluorescent probe (23) for detecting $\mathrm{Cd}^{2+}$ ions in aqueous systems from $\mathrm{pH} 6.5$ to 10 [177]. The incorporation of sulfonic groups enhances the probe's water solubility of the porphyrin ring system. The $2,2^{\prime}$-dipyridylamine (DPA) possesses remarkable binding ability towards $\mathrm{Cd}^{2+}$ ions; therefore two DPA groups were attached to coordinate the $\mathrm{Cd}^{2+}$ ions. The porphyrin fluorophore serves as an ideal signaling unit owing to its large conjugated $\pi$ plane. Upon the coordination of DPA to $\mathrm{Cd}^{2+}$ ions, a ratiometric fluorescent change to the emission spectra of the probe was observed. The fluorescence mechanism is based on an intramolecular charge transfer (ICT). Compound 23 shows a good solubility in aqueous solutions without the addition of an organic solvent. Spectroscopic studies were carried out in HEPES buffer solution (pH 7.4). Upon the addition of $\mathrm{Cd}^{2+}$ ions to a solution of the probe, the emission wavelength shifted from 653 to $611 \mathrm{~nm}(\phi=0.15)$. The noticeable hypsochromic shift of $42 \mathrm{~nm}$ was indicative of a reduction in the electron donating ability of the DPA moieties, upon $\mathrm{Cd}^{2+}$ ions coordination, as the $\mathrm{Cd}^{2+}$ ion is electron-withdrawing. Moreover, as the $\mathrm{Cd}^{2+}$ ions are coordinated to the DPA molecule through the nitrogen atom, the porphyrin ring system is perturbed subtly, therefore, decreasing the conjugation, and shifting the wavelength in the blue direction. Direct fluorimetric titration as a function of $\mathrm{Cd}^{2+}$ ion concentration was used to calculate a dissociation constant $\left(K_{d}\right)$ value of $31 \mu \mathrm{M}$, and a Job's plot showed a 1:2 binding ratio between the sensor and $\mathrm{Cd}^{2+}$ ions. Often signaling systems that depend on fluorescence changes (increases or decreases) at a fixed wavelength, suffer from uncertainty in absolute fluorescence measurements; however, a ratiometric fluorescence response enhances the reliability of the signaling from a quantitative viewpoint. Through linear regression of the calibration plot $\left(\left[\mathrm{F}_{611} / \mathrm{F}_{653}\right]\right.$ vs $\left.\left[\mathrm{Cd}^{2+}\right]\right)$, the detection limit was calculated to be $0.032 \mu \mathrm{M}$. Furthermore, the $\mathrm{Cd}^{2+}$ ions could be 
removed from the DPA groups by the addition of EDTA. As compound 23 showed good aqueous solubility studies in Hela cells and A549 (adenocarcinomic human alveolar basal epithelial) cells, the two cancer lines remained $87 \%$ viable, implying that the sensor exhibited minimal cytotoxicity and is likely safe for use in bioimaging.

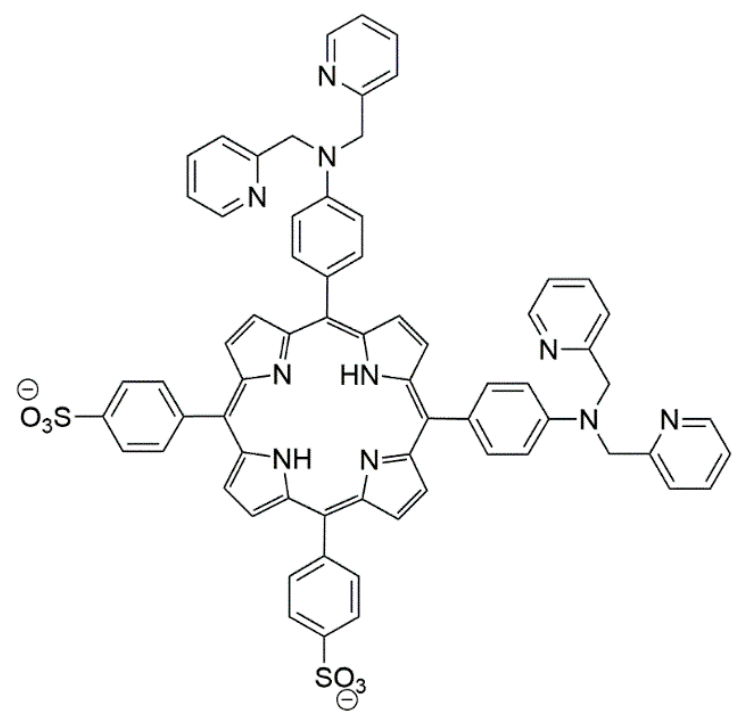

23

Siva and Chellapa synthesized a ratiometric benzimidazole tagged coumarin probe 24 . Compound 24 could selectively detect $\mathrm{Cd}^{2+}$ and $\mathrm{F}^{-}$ions in a $\mathrm{CH}_{3} \mathrm{CN} / \mathrm{H}_{2} \mathrm{O}(1: 9, v / v)$ HEPES-buffered solutions at $\mathrm{pH}$ 7.52, Scheme 9 [178]. The UV-Vis absorption spectrum showed three distinct bands at 292, 342, and $401 \mathrm{~nm}$. The addition of $\mathrm{Cd}^{2+}$ ions led to a hyperchromic shift at 292 and $343 \mathrm{~nm}$, and a hypochromic shift at $401 \mathrm{~nm}$, through an isosbestic point at $367 \mathrm{~nm}$, indicative of metal complexes in solution. Upon exciting probe 24 at $340 \mathrm{~nm}$, two distinct emission bands at 410 and $530 \mathrm{~nm}$ were observed. The addition of $\mathrm{Cd}^{2+}$ ions led to a blue emission band at $410 \mathrm{~nm}$ and an increase in emission intensity, at $530 \mathrm{~nm}$, through an isoemissive point $518 \mathrm{~nm}$. From these spectral changes the association constant was calculated to be $3.5 \times 10^{3} \mathrm{M}^{-1}$, using a modified Benesi-Hildebrand method and the LoD was determined to be $1.5 \times 10^{-10} \mathrm{M}$. The addition of the $\mathrm{Cd}^{2+}$ ions inhibited the intermolecular charge transfer (ICT) between the lone pair on the secondary amine in the imidazole ring system and the carbonyl group on the coumarin unit. It is reasonable that the molecular probe would chelate the metal ions in a tridentate fashion, via the three Lewis basic sites (Scheme 9, red bonds). Additionally, the authors carried out an extensive anion study which showed very little spectral changes for a number of tetrabutylammonium salts (TBAX, where $\mathrm{X}=\mathrm{F}^{-}, \mathrm{Cl}^{-}, \mathrm{Br}^{-}, \mathrm{I}^{-}, \mathrm{OAc}^{-}, \mathrm{NO}_{3}^{-}, \mathrm{H}_{3} \mathrm{PO}_{4}^{-}, \mathrm{CN}^{-}$). Fluoride was the only anion to produce a small changes in the fluorescence spectrum, which was also shown to inhibit the ICT mechanism, by forming a hydrogen bonding interaction with the NH group in the benzimidazole group.<smiles>Cc1ccc2oc(=O)c(/C=N/c3ccccc3-c3nc4ccccc4[nH]3)c(C)c2c1Cl</smiles>

Scheme 9. Proposed binding of molecular probe 24 and $\mathrm{Cd}^{2+}$ ions. 
Another LMFP coumarin dyad, 25, was prepared by Kumar and Ahmed [179]. The molecular probe served as, both, a colorimetric sensor and a fluorescent sensor, through chelation-enhanced fluorescence (CHEF), Figure 9. Upon the addition of $\mathrm{Cd}^{2+}$ ions in a HEPES-buffered solution $(20 \mathrm{mM}$, $\mathrm{CH}_{3} \mathrm{CN}: \mathrm{H}_{2} \mathrm{O}, 3: 7, v / v, \mathrm{pH}$ 7.0) of probe 25 , the solution changed from yellow to colorless, whereas there were no color changes observed upon the addition of the other metal ions studied $\left(\mathrm{Na}^{+}, \mathrm{K}^{+}\right.$, $\mathrm{Ba}^{2+}, \mathrm{Ca}^{2+}, \mathrm{Mg}^{2+}, \mathrm{Cr}^{3+}, \mathrm{Mn}^{2+}, \mathrm{Fe}^{3+}, \mathrm{Co}^{2+}, \mathrm{Ni}^{2+}, \mathrm{Cu}^{2+}, \mathrm{Zn}^{2+}, \mathrm{Pb}^{2+}, \mathrm{Ag}^{+}, \mathrm{Al}^{3+}, \mathrm{Hg}^{2+}, \mathrm{Hg}^{+}$, and $\left.\mathrm{Sn}^{2+}\right)$. On the addition of $\mathrm{Cd}^{2+}$ ions to a solution of 25 , there was a blue shift in the absorbance band from $387 \mathrm{~nm}$ to $370 \mathrm{~nm}$, whereas the addition of other metal ions resulted in no notable changes to the absorbance spectra. Titration studies were carried out to further study the interactions between 25 and $\mathrm{Cd}^{2+}$ ions. The gradual changes in the absorbance bands suggests that a new species was produced during the titration. A Job's plot was used to verify the formation of a 1:1 complex between the sensor and cadmium ions and a Benesi-Hilderbrand plot was used to calculate an association constant of $1.8 \times 10^{6} \mathrm{M}^{-1}$. Furthermore, the LoD was calculated to be $6.3 \times 10^{-8} \mathrm{M}$. The fluorescence data of the sensor with different metal ions was analogous to the absorbance data, as there were only notable spectroscopic changes in the presence of $\mathrm{Cd}^{2+}$ ions. Under the same solution conditions as the absorbance experiments, 25 was non-fluorescent. However, in the presence of $\mathrm{Cd}^{2+}$ ions, a gradual increase in the emission band at $495 \mathrm{~nm}$ was observed and the absolute fluorescence quantum yield $(\phi)$ increased by a factor of nine, upon coordination with the $\mathrm{Cd}^{2+}$ ions. A fluorescence lifetime decay was observed from 0.217 to $1.97 \mathrm{~ns}$, after the addition of $\mathrm{Cd}^{2+}$ ions, indicative of the strong coordination between the sensor and $\mathrm{Cd}^{2+}$ ions. In an attempt to prepare a workable probe, test strips were prepared, which changed color upon the immersion into a $\mathrm{Cd}^{2+}$ solution $\left(5 \times 10^{-4} \mathrm{M}\right)$, Figure 9 .

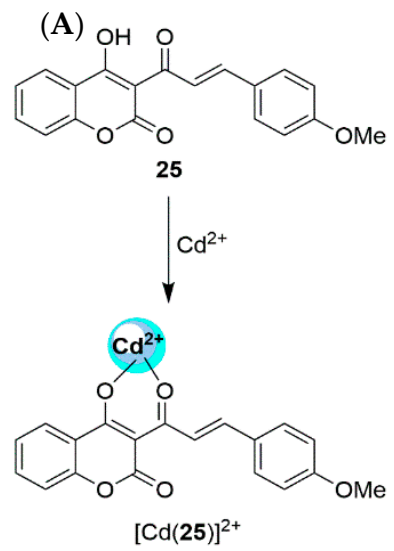

(B)

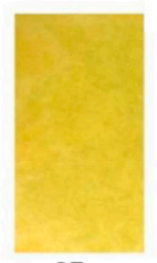

25

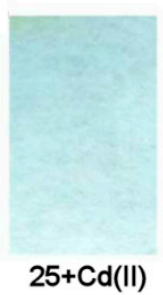

$25+C d(I I)$

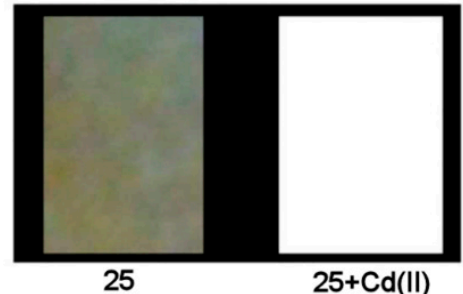

$25+C d(I I)$

Figure 9. (A) Proposed binding between compound 25 and $\mathrm{Cd}^{2+}$ ions and (B) photographs of colorimetric (left) and fluorometric (right) test kits. The filter papers were coated with $25(0.1 \mathrm{mM})$ and then immersed into a HEPES-buffered solution $\left(20 \mathrm{mM}, \mathrm{CH}_{3} \mathrm{CH}-\mathrm{H}_{2} \mathrm{O} 3: 7, v / v, \mathrm{pH}\right.$ 7). Adapted from [179] with permission from the Centre National de la Recherche Scientifique (CNRS) and the Royal Society of Chemistry.

Interestingly, the authors used their probe to monitor the amount of $\mathrm{Cd}^{2+}$ in lipstick, hair dye, and makeup cream as $\mathrm{Cd}^{2+}$ is a common ion found in the preparation of these cosmetics. Spectrofluorometry and AAS analysis showed the amount of $\mathrm{Cd}^{2+}$ ions in the samples to be very similar (Table 2). 
Table 2. The calculated concentration of $\mathrm{Cd}^{2+}$ ions in cosmetics and personal care samples by fluorometric and atomic absorption spectroscopy (AAS) [179].

\begin{tabular}{|c|c|c|}
\hline \multirow{2}{*}{ Sample } & \multicolumn{2}{|c|}{ Amount of $\mathrm{Cd}^{2+}$ in $\left.\mathrm{mol} \cdot \mathrm{L}^{-1}\right)$} \\
\hline & Fluorometric with Probe 25 & AAS \\
\hline Lipstick & $2.07 \times 10^{-6}$ & $1.96 \times 10^{-6}$ \\
\hline Hair color & $1.12 \times 10^{-6}$ & $1.06 \times 10^{-6}$ \\
\hline Makeup cream & $7.92 \times 10^{-6}$ & $7.20 \times 10^{-6}$ \\
\hline
\end{tabular}

Many molecular probes designed to bind cadmium can also bind zinc ions and it is often difficult to distinguish between the two. The binding ratio between the metal and the probe can be enough to discriminate between two metal ions. For example, LMWP 26 was synthesized by Rajak et al. Scheme 10 [180]. Fluorene-pyridine were coupled together via an imine bond. Compound 26 served as both a colorimetric sensor, producing noticeable color changes in the presence of both zinc and cadmium, and a turn-on fluorescence sensor. As $\mathrm{Cd}^{2+}$ ions were added to a $\mathrm{CH}_{3} \mathrm{CN}: \mathrm{H}_{2} \mathrm{O}$ solution $(8: 2, v / v, 10 \mathrm{mM}$ HEPES, $\mathrm{pH} 7.4)$ of $\mathbf{2 6}$, the solution changed from pale yellow to deep orange, whereas a deep pink color was observed in the presence of $\mathrm{Zn}^{2+}$ ions. The UV-Vis titration data showed the emergence of several new bands, upon the addition of $\mathrm{Cd}^{2+}$ ions to a solution of the sensor, with a noticeable difference to that of the $\mathrm{Zn}^{2+}$ ion titration. Fluorescence titrations further highlighted the probe's selectivity for $\mathrm{Cd}^{2+}$ and $\mathrm{Zn}^{2+}$ ions.

Decomplexation of the $[\mathrm{CdCl}(26)]$ complex and subsequent emission turn off could be accomplished with the addition of $\mathrm{S}^{2-}$ ions to a solution of the complex. The fluorescence turn-off also served as a means of distinguishing between $\mathrm{Zn}^{2+}$ and $\mathrm{Cd}^{2+}$ ions, as decomplexation of the $\mathrm{Zn}^{2+}$ ion's complex did not occur in the presence of $\mathrm{S}^{2-}$ ions. A Job's plot verified the binding stoichiometry of the sensor for $\mathrm{Cd}^{2+}$ ions as 1:1 with an association constant of $6.4 \times 10^{4} \mathrm{M}^{-1}$, calculated from a Benesi-Hildebrand plot using the data from UV-Vis titrations. The weak fluorescence band seen around $430 \mathrm{~nm}$ is due to the lone pair on the nitrogen atom on the imine group quenching the intensity. However, on chelation of $\mathrm{Cd}^{2+}$ ions with the sensor, the PET process is prevented and the molecule becomes less flexible, as the free rotation of the azomethine carbon is also restricted. The coordination environment was further validated by studying the ${ }^{1} \mathrm{H}$ NMR titration of $\mathrm{Cd}^{2+}$ ions into a solution of the sensor which showed a clear disappearance of the phenolic proton and a downfield shift of the azomethine proton. From the fluorescence titration, an $\mathrm{LoD}$ of $0.53 \mu \mathrm{M}$ for $\mathrm{Cd}^{2+}$ ions was calculated and a fluorescence quantum yield of 0.996 was observed, whereas the fluorescence quantum yield of 26 was calculated to be 0.042 . As $\mathrm{Zn}^{2+}$ and $\mathrm{Cd}^{2+}$ produced different optical inputs with one output, a binary logic gate function could be produced Table 3). This selective behavior mimics an OR binary logic gate (Figure 10).

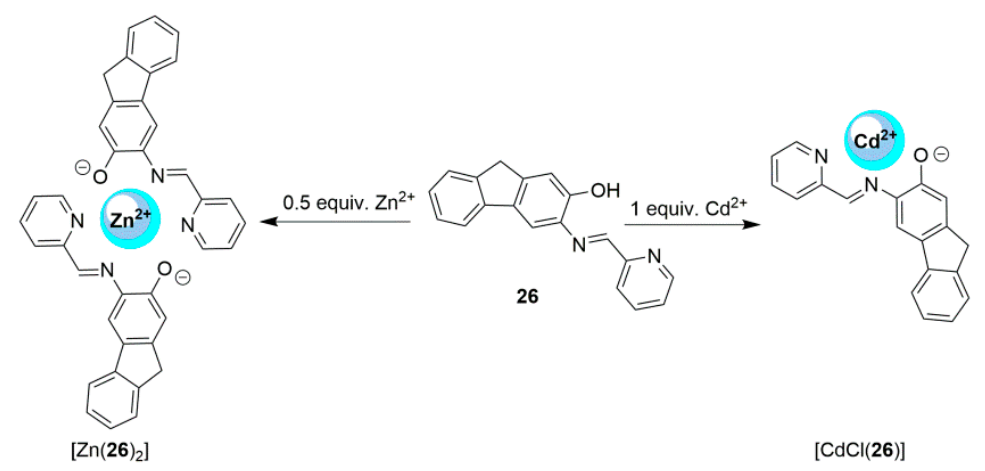

Scheme 10. Schematic representation the binding behavior of probe 26 and $\mathrm{Cd}^{2+}$ and $\mathrm{Zn}^{2+}$ ions. 


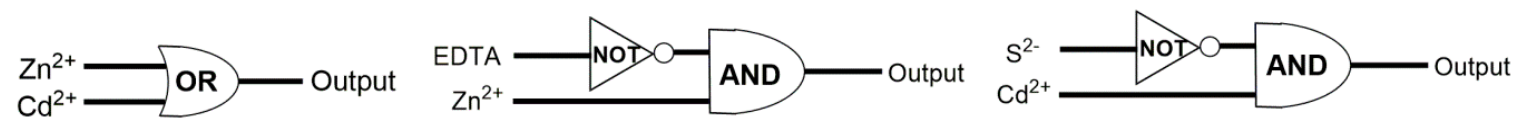

Figure 10. Logic schemes prepared from the binary inputs/outputs in the Truth tables [180].

Table 3. Truth table highlighting the binary inputs and the corresponding digital output [180].

\begin{tabular}{|c|c|c|c|c|c|c|c|c|}
\hline \multicolumn{3}{|c|}{ (A) } & \multicolumn{3}{|c|}{ (B) } & \multicolumn{3}{|c|}{ (C) } \\
\hline $\mathrm{Zn}^{2+}$ & $\mathrm{Cd}^{2+}$ & $\begin{array}{c}\text { Output }^{*} \\
\lambda_{\mathrm{em}} 485 \text { or } 495 \mathrm{~nm}\end{array}$ & $\mathrm{Zn}^{2+}$ & EDTA & $\begin{array}{c}\text { Output * } \\
\lambda_{\text {em }} 485 \mathrm{~nm}\end{array}$ & $\mathrm{Cd}^{2+}$ & $\mathrm{S}^{2-}$ & $\frac{\text { Output }^{*}}{\lambda_{\text {em }} 495 \mathrm{~nm}}$ \\
\hline 0 & 0 & 0 & 0 & 0 & 0 & 0 & 0 & 0 \\
\hline 1 & 0 & 1 & 1 & 0 & 1 & 1 & 0 & 1 \\
\hline 0 & 1 & 1 & 0 & 1 & 0 & 0 & 1 & 0 \\
\hline
\end{tabular}

* (A) OR logic gate, the output " 1 " is assigned to $\mathrm{Zn}^{2+}$ and $\mathrm{Cd}^{2+}$ when the emission bands appears at 485 and $495 \mathrm{~nm}$, respectively and " 0 " in the absence of metal i.e., no emission. (B) and (C) logic gates operate as an INHIBIT function (a combination of an AND function plus an additional event, in this xample NOT). Addition of the metal produces the output " 1 " and the inverter (EDTA for $\mathrm{Zn}^{2+}$ or $\mathrm{S}^{2-}$ for $\mathrm{Cd}^{2+}$ ) switches off the emission, output " 0 ".

A simple cleft-shaped fluorescent chemosensor, 27, was prepared by Qian and Yang, Scheme 11 [181]. Originally prepared to bind group 1 and group 2 metal ions, $\mathrm{NH}_{4}{ }^{+}$ions and heavy metal salts in methanol and at high concentrations $\left(1.9 \times 10^{-2} \mathrm{M}\right)$ by Maass and Vögtle [182-184], the molecular cleft did not discriminate between different metal ions. The fluorescence spectra for $10 \mu \mathrm{M}$ of compound $27\left(20 \mathrm{mM}\right.$ Tris- $\mathrm{HCl}, \mathrm{pH}$ 7.4) with $\mathrm{Cd}^{2+}$ ions showed a significant fluorescence band at $417 \mathrm{~nm}$. The other metals studied did not show any response $\left(\mathrm{Ba}^{2+}, \mathrm{Mn}^{2+}, \mathrm{Hg}^{2+}, \mathrm{Ni}^{2+}, \mathrm{Ca}^{2+}\right.$, $\mathrm{Cu}^{2+}, \mathrm{Co}^{2+}, \mathrm{Pb}^{2+}, \mathrm{Mg}^{2+}, \mathrm{Zn}^{2+}, \mathrm{Cd}^{2+}, \mathrm{Fe}^{2+}, \mathrm{Fe}^{3+}, \mathrm{Cr}^{3+}, \mathrm{Ag}^{+}, \mathrm{Li}^{+}, \mathrm{Na}^{+}$, and $\left.\mathrm{K}^{+}\right)$. The PET mechanism quenched the initial fluorescence intensity, via the lone pairs on the nitrogen atom. On the addition of $\mathrm{Cd}^{2+}$ ions, the flexible molecular cleft became rigid and the fluorescence increased, due to CHEF, and the $\pi-\pi^{*}$ transitions gave rise to the emission band observed. The association constant calculated by the nonlinear least square analysis was found to be $5.3 \times 10^{7} \mathrm{M}^{-1}$.

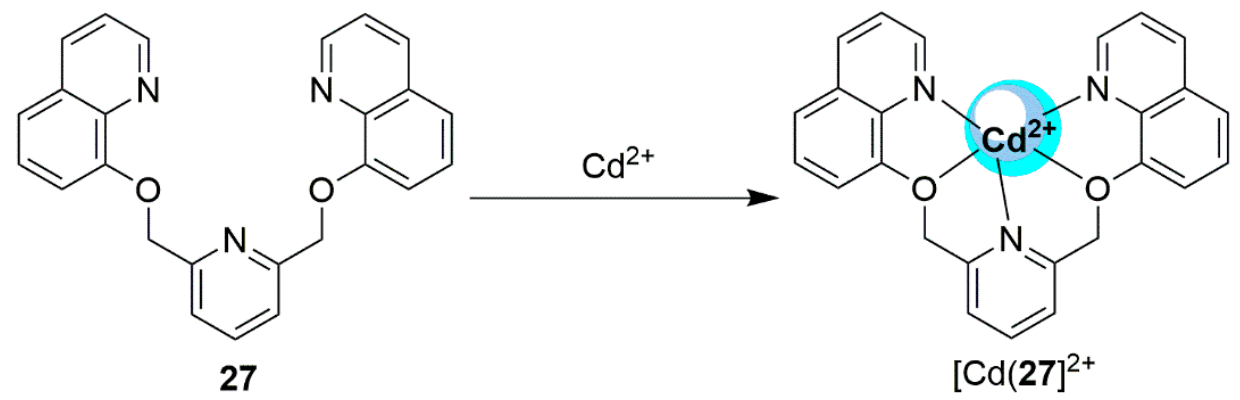

Scheme 11. Proposed binding mode of 27 and $\mathrm{Cd}^{2+}$ ions.

Liu and Wang took advantage of the encapsulating and adsorbing capabilities of cationic surfactant hexadecyl trimethyl ammonium bromide (CTAB) and the selectivity of thymine-squaraine based fluorescent chemosensor $\mathbf{2 8}$, to develop a system capable of sensing and capturing $\mathrm{Cd}^{2+}$ ions, Figure 11 [185]. The thymine moiety of 28 efficiently bound to $\mathrm{Cd}^{2+}$ ions, while the squaraine moiety served as a signaling unit whose spectroscopic performances could be tuned by changing its solution environments. The CTAB micelles could induce aggregation of the squaraine dyes, reducing the likelihood of any intermolecular electron transfer. On the addition of $\mathrm{Cd}^{2+}$ ions, the fluorescence intensity of compound 28 increased. Optimal conditions for the system were observed when the concentration of CTAB was less than $1 \mathrm{mM}$. At higher concentrations, the CTAB micelles made it difficult for the $\mathrm{Cd}^{2+}$ ions to access the thymine moiety via an adsorption process into the cell. Under these conditions, a 5-fold increase in the emission band at $660 \mathrm{~nm}$ was observed for compound 28 
in the presence of $\mathrm{Cd}^{2+}$ ions. There was no notable emission change observed for any other metal ions that were studied $\left(\mathrm{K}^{+}, \mathrm{Zn}^{2+}, \mathrm{Li}^{+}, \mathrm{Fe}^{3+}, \mathrm{Hg}^{2+}, \mathrm{Fe}^{2+}, \mathrm{Ag}^{+} \mathrm{Co}^{2+} \mathrm{Na}^{+} \mathrm{Ca}^{2+}\right.$, and $\left.\mathrm{Cu}^{2+}\right)$. The sensor was also found to be very sensitive, demonstrating an $\mathrm{LoD}$ in the $\mathrm{nM}$ range. The binding constant was determined using a Benesi-Hildebrand plot and found to be $2 \times 10^{3} \mathrm{M}^{-1}$. Additionally, a Job's plot revealed that the binding stoichiometry between the squaraine moiety and $\mathrm{Cd}^{2+}$ ions was $1: 1$. Competition studies did not highlight any notable inhibition, due to the presence of other metal ions. However, the presence of some anionic and non-ionic surfactants (sodium dodecyl sulfate (SDS), Dodecylbenzene sulfonic acid sodiym salt (SDBS), and Triton X-100) did diminish the probe's ability to detect $\mathrm{Cd}^{2+}$ ions. The micelle was found to be stable to photobleaching, as decomplexation did not occur when the soft material was exposed to constant irradiation for $6 \mathrm{~h}$.
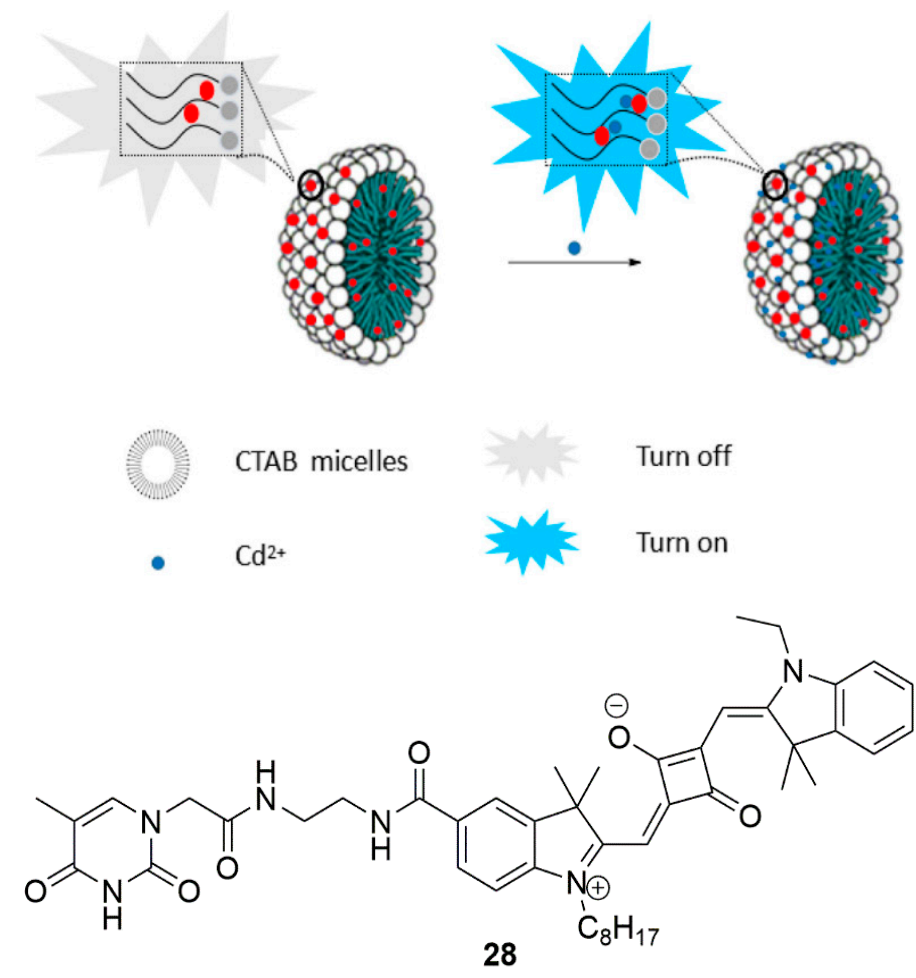

Figure 11. The proposed intermolecular interaction between compound 28 and the $\mathrm{Cd}^{2+}$ ions encapsulated in the micelle. Adapted and reprinted from [183], with permission from Elsevier.

Two turn-"on" fluorescent sensors compounds 29a and $29 \mathbf{b}$ were synthesized by Xu and coworkers, Scheme 12 [186]. Both compounds could bind both $\mathrm{Zn}^{2+}$ and $\mathrm{Cd}^{2+}$ ions in a $\mathrm{CH}_{3} \mathrm{OH} / \mathrm{H}_{2} \mathrm{O}$ solution $\left(1: 1, v / v\right.$, Tris, $10 \mathrm{mmol} \cdot \mathrm{L}^{-1}, \mathrm{pH}$ 7.4). These molecular probes displayed a weak fluorescence emission band, however, in the presence of $\mathrm{Zn}^{2+}$ and $\mathrm{Cd}^{2+}$ ions, an eight-fold increase in the emission intensity, due to CHEF mechanism, was observed at $430 \mathrm{~nm}$. Data obtained from the fluorescence titrations and Job's plots, suggested a 1:1 complex formation. This was supported by NMR studies. The calculated association constants of compounds $29 \mathrm{a}$ and $29 \mathrm{~b}$ to $\mathrm{Cd}^{2+}$ ions were $1.5 \times 10^{7} \mathrm{M}^{-1}$ and $1.0 \times 10^{6} \mathrm{M}^{-1}$, respectively. Competition studies were carried out using other metal ions but there were no notable interferences observed in the fluorescence spectra. There were however interferences from biologically relevant anions, namely adenosine triphosphate (ATP), adenosine diphosphate (ADP), and other phosphate ions. Complete quenching was observed when phosphate ions were introduced to a solution of the complex demonstrating the complex's ability to serve as an on-off sensor for phosphate ions. 


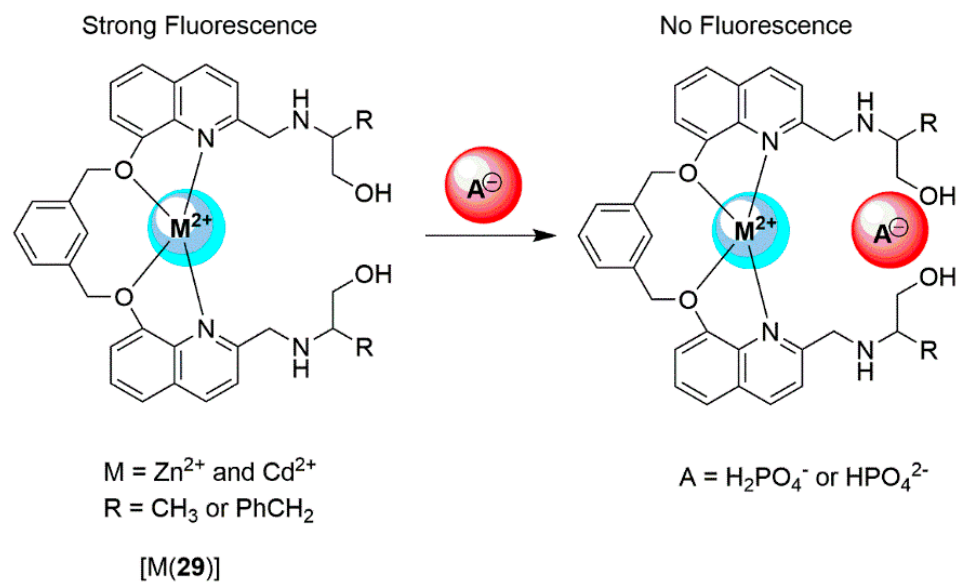

Scheme 12. The proposed interaction between the molecular sensors and the metal ions. The binding cavity size was ideal to chelate $\mathrm{Cd}^{2+}$ or $\mathrm{Zn}^{2+}$ ions. When the phosphate anion was added, the fluorescence intensity was switched off.

Kim and Harrison synthesized a tripodal receptor containing quinoline and pyridyl aminophenol moieties (compound 30) [187]. It was shown to prefer to coordinate with $\mathrm{Zn}^{2+}$ ions in $\mathrm{CH}_{3} \mathrm{CN}$ solution but had a preference for $\mathrm{Cd}^{2+}$ ions in aqueous solutions. Optical investigations were carried out in the presence of 19 different nitrate metal salts $\left(\mathrm{Na}^{+}, \mathrm{K}^{+}, \mathrm{Zn}^{2+}, \mathrm{Cd}^{2+}, \mathrm{Mg}^{2+}, \mathrm{Ca}^{2+}, \mathrm{Al}^{3+}, \mathrm{Ga}^{3+}, \mathrm{In}^{3+}, \mathrm{Pb}^{+}\right.$, $\left.\mathrm{Hg}^{2+}, \mathrm{Cr}^{3+}, \mathrm{Mn}^{2+}, \mathrm{Fe}^{2+}, \mathrm{Fe}^{3+}, \mathrm{Co}^{2+}, \mathrm{Ni}^{2+}, \mathrm{Cu}^{2+}, \mathrm{Ag}^{+}\right)$at $10 \mu \mathrm{M}$ in $\mathrm{CH}_{3} \mathrm{CN}$ solution. The addition of $\mathrm{Zn}^{2+}$ ions lead to a large fluorescence enhancement $(\phi=0.001$ to $\phi=0.24)$ at $510 \mathrm{~nm}$. The only other metal ion that produced an emission intensity increase was $\mathrm{Cd}^{2+}$ but to a lesser extent, approximately one third of the magnitude seen for $\mathrm{Zn}^{2+}(\phi=0.039)$. The other metals did not lead to an increase in fluorescent intensity, but several did interfere with the probe's ability to bind to $\mathrm{Zn}^{2+}$. Similar optical investigations were undertaken in a $\mathrm{CH}_{3} \mathrm{CN}: \mathrm{H}_{2} \mathrm{O}(1: 1, v / v)$ HEPES-buffered solution (10 mM, pH 7.4). The fluorescence enhancement seen in the presence of $\mathrm{Cd}^{2+}$ remained the same, but the fluorescence enhancement seen in the presence of $\mathrm{Zn}^{2+}$ was only $10 \%$ of that seen in $\mathrm{CH}_{3} \mathrm{CN}$. Other metal ions did not lead to an increase in intensity, but $\mathrm{Zn}^{2+}, \mathrm{Cr}^{3+}, \mathrm{Cu}^{2+}, \mathrm{Co}^{2+}, \mathrm{Ni}^{2+}, \mathrm{Hg}^{2+}$ interfered with $\mathrm{Cd}^{2+}$ binding. The differences in fluorescence intensities between the two solvent systems suggested that the coordination environments for $\mathrm{Cd}^{2+}$ ions were similar in both. The $\mathrm{Zn}^{2+}$ ion could adopt an equilibrium between tetrahedral and octahedral geometries. The binding environment for $\left[\mathrm{Cd}\left(\mathrm{NO}_{3}\right)_{2}(30)\right]$ was confirmed by solid-state studies (Figure 12) and supported by NMR studies. The weak fluorescence seen for $\mathbf{3 0}$ was a consequence of PET quenching, which was inhibited upon the coordination of $\mathrm{Zn}^{2+}$ ions. The binding constants, in $\mathrm{CH}_{3} \mathrm{CN}$ were calculated to be $1.4 \times 10^{6} \mathrm{M}^{-1}$ and $5.6 \times 10^{5} \mathrm{M}^{-1}$, for $\mathrm{Zn}^{2+}$, and $\mathrm{Cd}^{2+}$ respectively, but it is unclear how these binding constants were obtained, as no binding isotherms were reported. It was also claimed that 30 bound $\mathrm{Cd}^{2+}$ ions more favorably than $\mathrm{Zn}^{2+}$ ions in an organic-aqueous system. No binding constants were reported to back up this claim, only a single fluorescence spectrum showed that the intensity was greater for $\mathrm{Cd}^{2+}$ ions.
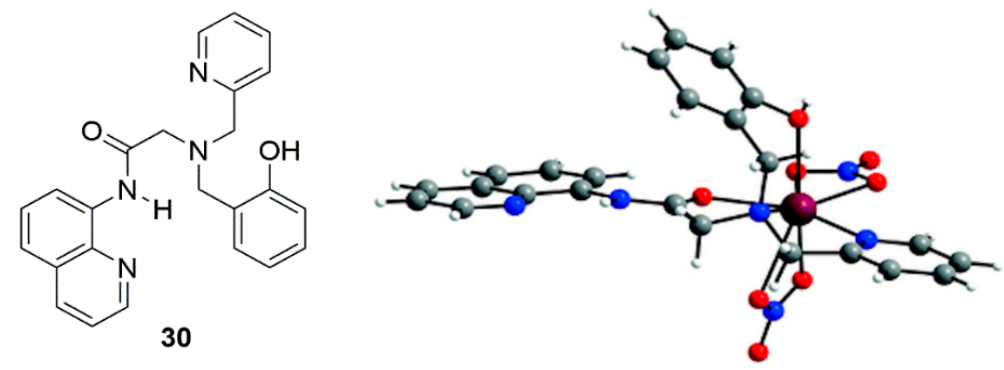

Figure 12. X-Ray crystal structure of $\left[\mathrm{Cd}\left(\mathrm{NO}_{3}\right)_{2}(30)\right]$. Adapted from [187] with permission from The Royal Society of Chemistry. 
Hou and Wang developed a phenylene-acetylene based compound 31 that was capable of selectively detecting $\mathrm{Fe}^{2+}$ by colorimetric methods and $\mathrm{Cd}^{2+}$ and $\mathrm{Zn}^{2+}$ via ratiometric fluorescent detection [188]. Optical studies were carried out in the presence of 23 different chloride or perchlorate metal salts $\mathrm{CLi}^{+}, \mathrm{Ba}^{2+}, \mathrm{Ca}^{2+}, \mathrm{K}^{+}, \mathrm{Li}+, \mathrm{Mg}^{2+}, \mathrm{Mn}^{2+}, \mathrm{Na}^{+}, \mathrm{Cr}^{3+}, \mathrm{Au}^{3+}, \mathrm{Zr}^{4+}, \mathrm{Rh}^{3+}, \mathrm{Pb}^{2+}, \mathrm{Ag}^{+}, \mathrm{Co}^{2+}, \mathrm{Cu}^{2+}$, $\left.\mathrm{Ni}^{2+}, \mathrm{Hg}^{2+}, \mathrm{Cd}^{2+}, \mathrm{Zn}^{2+}, \mathrm{Fe}^{2+}, \mathrm{Fe}^{3+}, \mathrm{Pt}^{2+}\right)$. In an $\mathrm{EtOH}: \mathrm{H}_{2} \mathrm{O}(10 \mu \mathrm{M}, 1: 1, v / v)$ solution, 31 showed two $\pi-\pi^{*}$ absorption bands at $286 \mathrm{~nm}$ and $327 \mathrm{~nm}$, and the addition of $\mathrm{Fe}^{2+}$ ion led to the appearance of a new peak at $573 \mathrm{~nm}$, with a corresponding color change from colorless to purple-red. The other metals did not produce any significant changes in the absorption spectra, and their presence did not interfere with the probe's response to $\mathrm{Fe}^{2+}$. Job's plot and ESI-MS data indicated that the $31: \mathrm{Fe}^{2+}$ complex had a 2:1 binding stoichiometry and the association constant was calculated to be $3.4 \times 10^{7} \mathrm{M}^{-1}$. The limit of detection for the method was found to be $2.0 \times 10^{-8} \mathrm{M}$. When excited at $340 \mathrm{~nm}, 31$ showed an emission at $408 \mathrm{~nm}$ and the addition of $\mathrm{Cd}^{2+}$ ions led to a decrease in the intensity of the emission at $408 \mathrm{~nm}$, the appearance of a new emission at $475 \mathrm{~nm}$, and a change in fluorescent color from blue to cyan. The addition of $\mathrm{Zn}^{2+}$ ions led to a decrease in the intensity of the emission at $408 \mathrm{~nm}$, the appearance of a new emission at $498 \mathrm{~nm}$, and a change in fluorescent color from blue to yellow-green. No other metals showed a significant response, and only $\mathrm{Fe}^{2+}$ interfered with the probe's response to $\mathrm{Cd}^{2+}$ and $\mathrm{Zn}^{2+}$. The ratios of the two emissions $\left(\mathrm{I}_{475} / \mathrm{I}_{408}\right.$ and $\left.\mathrm{I}_{498} / \mathrm{I}_{408}\right)$ could be used to calculate the LoD for $\mathrm{Cd}^{2+}$ and $\mathrm{Zn}^{2+}$ of $2.6 \times 10^{-8} \mathrm{M}$ and $2.0 \times 10^{-9} \mathrm{M}$, respectively. Job's plot and ESI-MS data indicated that the 31: $\mathrm{Cd}^{2+}$ complex had a 1:1 binding stoichiometry and the association constant was calculated to be $0.2 \times 10^{6} \mathrm{M}^{-1}$. The 31: $\mathrm{Zn}^{2+}$ complex had a 2:1 binding stoichiometry, and an association constant of $0.9 \times 10^{6} \mathrm{M}^{-1} .{ }^{1} \mathrm{H}$ NMR data indicated that the metals bound to the nitrogen atoms; the proposed sensing mechanism for the probe toward $\mathrm{Fe}^{2+}, \mathrm{Cd}^{2+}$, and $\mathrm{Zn}^{2+}$ is presented in Scheme 13.

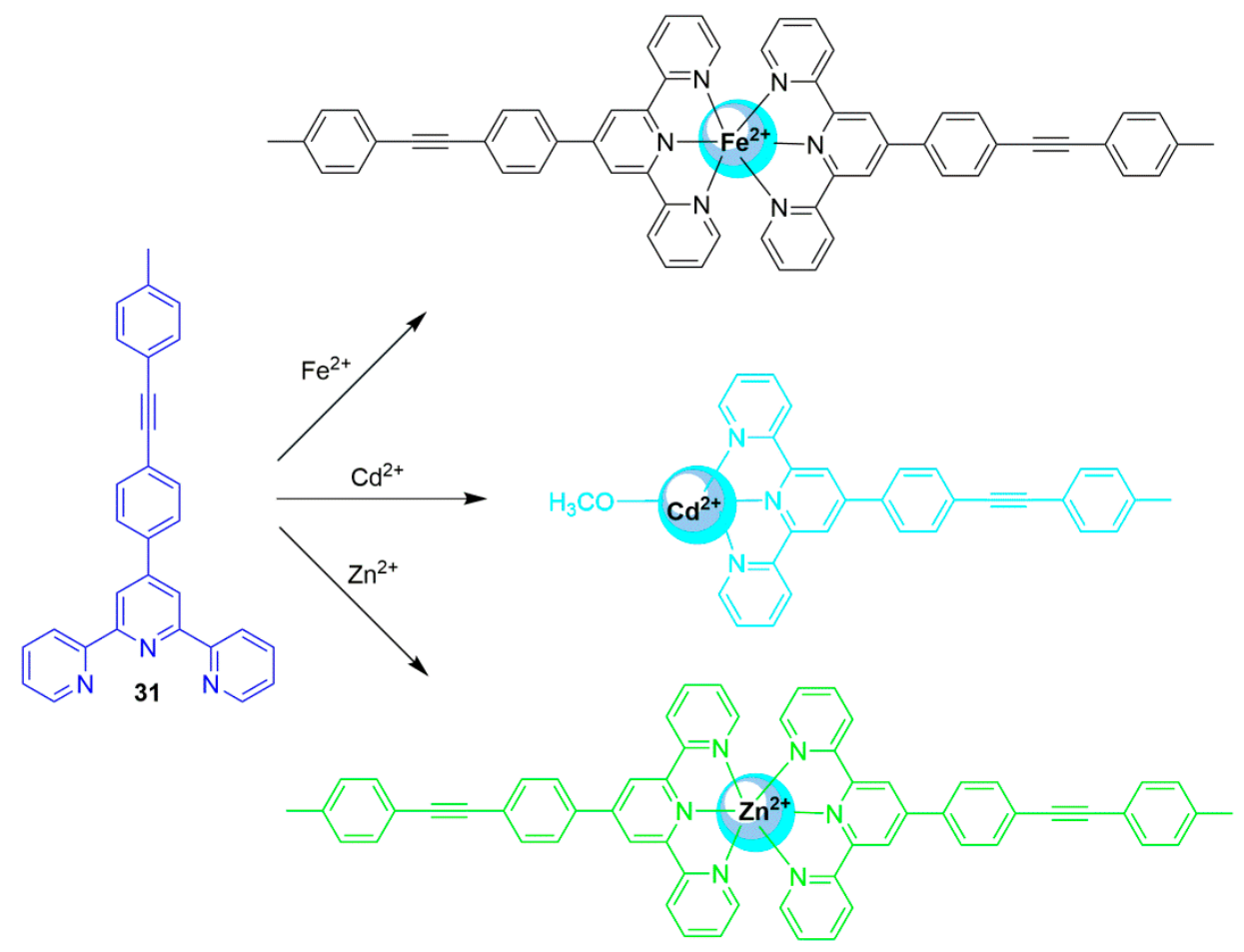

Scheme 13. The binding modes of probe 31 and the different metal ions.

\subsection{Mercury Probes}

Out of the three metal ions in group 12, mercury in the form of organic mercury is the most toxic. Therefore, designing molecular chemosensors for mercury ions is a very important endeavor, especially in aqueous systems, as certain biological species readily convert metallic mercury into organic mercury. There have been many different types of fluorescent sensors for mercury, recent examples include 
quantum dots [189], biosensors [8], carbon dots [190], carbon nanoparticles [191], gold and silver nanoparticles [192,193], but the focus in this final section is on LMFP sensors.

Highly selective off-on optical sensor 32 was synthesized by Ahmed et al. for the detection of mercuric ions in an organic-aqueous, HEPES-buffered $\left(\mathrm{CH}_{3} \mathrm{CN}: \mathrm{H}_{2} \mathrm{O}, 1: 2, v / v, \mathrm{pH} 7.2\right)$ system [194], Compound 32 drastically changed color from yellow $(340 \mathrm{~nm})$ to purple $(550 \mathrm{~nm})$, upon the addition of $\mathrm{Hg}^{2+}$ ions and was also found to be highly fluorescent, with an emission band at $430 \mathrm{~nm}$, when the coordination complex was formed in situ. The weak fluorescence emission of $\mathbf{3 2}$ was a consequence of PET quenching which was inhibited upon by the coordination of the $\mathrm{Hg}^{2+}$ ions. The binding constant was calculated to be $1.9 \times 10^{3} \mathrm{M}^{-1}$ using the Benesi-Hildebrand linear regression analysis, which showed a straight line. However on closer inspection of the regression line, the data presented was not a Benesi-Hildebrand plot. The authors plotted an intensity ratio versus concentration of $\mathrm{Hg}^{2+}$ ions, therefore, the binding constant reported should be viewed with a little skepticism. The coordination environment was confirmed by IR and NMR studies, as compound $\mathbf{3 2}$ had distinct functional groups (carbonyl and hydrazide) that could act as IR labels, the stretching frequencies shifted when coordinated to $\mathrm{Hg}^{2+}$ ion, the tridentate binding motif was further supported by DFT calculations. The $\mathrm{Hg}^{2+}$ ion was removed from the binding site by the addition of $\mathrm{KI}$ ions to precipitate $\mathrm{HgI}_{2}$, which turned off the emission signal. Therefore, this "off-on-off" approach could be translated into binary code to build an INHIBIT logic gate (a combination function consisting of and AND gate plus one other event, in this example a NOT event), Figure 13.

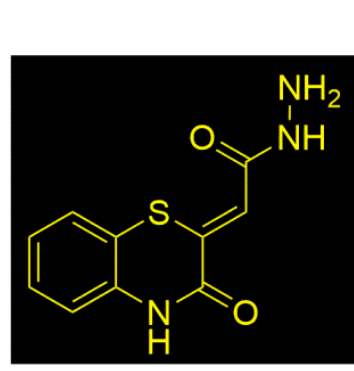

32

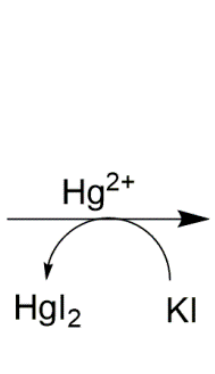

(A)

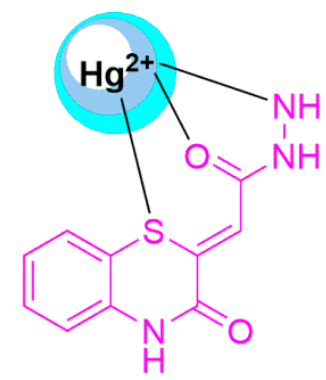

$[\mathrm{Hg}(32)]^{2+}$

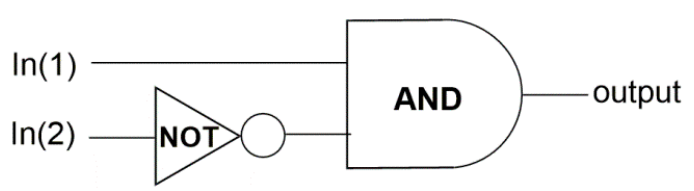

(B)

\begin{tabular}{ccc}
\hline \multicolumn{2}{c}{ Input } & Output \\
\hline In $1\left(\mathrm{Hg}^{2+}\right)$ & In $2(\mathrm{KI})$ & Fluorescence enhancement at $429 \mathrm{~nm}$ \\
\hline 0 & 0 & 0 \\
0 & 1 & 0 \\
1 & 0 & 1 \\
1 & 1 & 0 \\
\hline
\end{tabular}

(C)

Figure 13. Molecular probe 32, highlights the proposed binding environment and color and fluorescence changes (A) chemical scheme, (B) circuit diagram corresponding to the $\mathrm{Hg}^{2+}$ and $\mathrm{KI}$ inputs and (C) truth tabled [194]. 
Aggregation-induced emission (AIE) has become a popular mechanism exploited for sensors often used in chemodosimeter and chemoreactand type molecular probes. A recent review covers the use of chemodosimeters (non-reversible covalent bonds and chemoreactands with reversible covalent bonds), whereby, the optical properties were different from the bound and unbound chemical adducts [53]. Chatterjee and coworkers have prepared chemodosimeter 33 to detect organic and inorganic $\mathrm{Hg}^{2+}$ species, Figure 14 [193]. The probe functions based on a mercury ion-promoted transmetalation reaction between tetraphenylethylene mono-boronic acid 33 and $\mathrm{Hg}^{2+}$ ions. For aggregation to occur, the correct working concentration needed to be established, which was found to be $30 \mu \mathrm{M}\left(\mathrm{H}_{2} \mathrm{O}-\mathrm{THF}\right.$ (90:10)). On the addition of $\mathrm{HgCl}_{2}$ to probe 33, transmetalation occurred to form compound 33a. As a consequence of the chemical transformation, the planarity of $33 \mathrm{a}-\mathrm{HgCl}$ was restored and the onset of AIE occurred. The AIE aggregation was supported by transmission electron microscopy (TEM) and dynamic light scattering (DLS) experiments, which showed average nanoaggregates of $36 \mathrm{~nm}$ but, after the addition of $\mathrm{HgCl}_{2}$ to the $30 \mu \mathrm{M}$ solution of 33, these grew to $690 \mathrm{~nm}$. No other metal was shown to transmetalate compound 33, therefore, the molecular chemodosimeter was very specific for $\mathrm{Hg}^{2+}$ ions. Interestingly, methylmercury ion was also shown to undergo transmetalation, forming $33 \mathbf{b}$, which also aggregated and turned on emission. As methylmercury ion readily bioaccumulates in fish, the chemodosimeter was tested using zebrafish embryos. In the presence of methylmercury ion, fluorescence microscopic images showed that a distinctive blue glow occurred. This elegant experiment showed that transmetallation of the C-B bond to $\mathrm{C}-\mathrm{Hg}$ bond, and aggregation can occur in vivo, making this a highly attractive approach to monitor organomercury species, in higher order fish species.

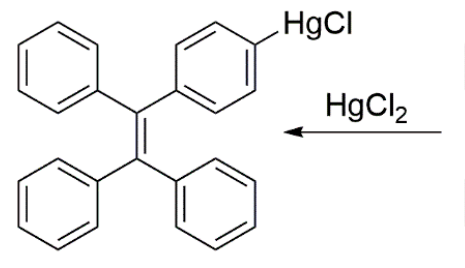

$33 a$

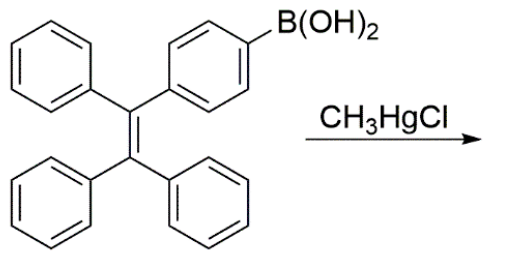

33

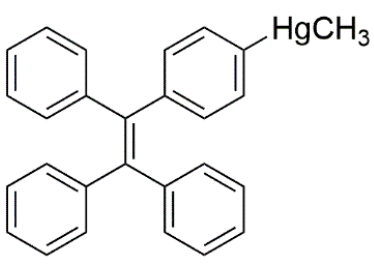

33b

(A)

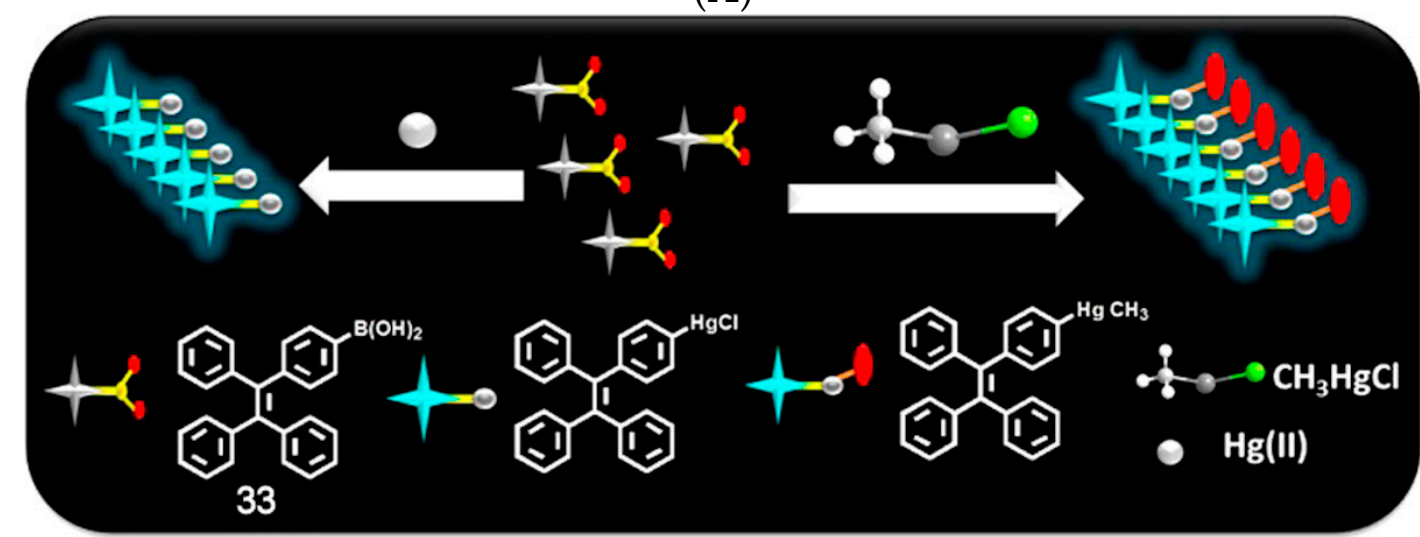

(B)

Figure 14. Schematic representation of the sensing process of chemodosimeter 32 on the addition of $\mathrm{Hg}^{2+}$ ion and $\mathrm{CH}_{3} \mathrm{Hg}^{+}$. Reprinted (adapted) with permission from [195]. (A) Chemical Scheme, (B) proposed fluorescence aggregation

Another chemodosimeter, has been developed by Ou et al. [196] who employed a protection-deprotection strategy to monitor mercury. This approach takes advantage of the distinctly different electronic properties of two different molecules. For example, protected aldehydes and ketones can be deprotected with $\mathrm{Hg}^{2+}$ salts. As no other metal ion causes a selective cleavage under 
these conditions, the molecular probes are highly selective for $\mathrm{Hg}^{2+}$ ions. Thioacetal-modified pyrene sensor 34 was prepared and was shown to be cleaved by $\mathrm{Hg}^{2+}$ ions, to form pyrenecarboxaldehyde 34a, Scheme 14. Compound 34 undergoes an off-on fluorescence response when $\mathrm{Hg}^{2+}$ ions are added. The $\mathrm{Hg}^{2+}$ ions deprotect the thioacetals to form the aldehyde functional group, confirmed by ${ }^{1} \mathrm{H} \mathrm{NMR}$ as the aldehyde proton appeared at $10.82 \mathrm{ppm}$. The UV-Vis and fluorescence experiments were used to verify that one equivalent of $\mathrm{Hg}^{2+}$ ions were needed to fully convert 34 to $34 \mathrm{a}$.

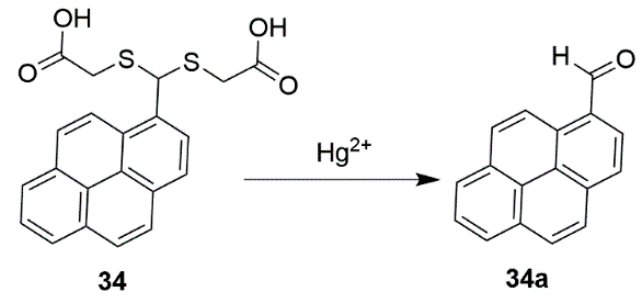

Scheme 14. Chemodosimeter 34.

The pyridine ring is a versatile moiety and is often found in molecular receptors. Tetrahydrodibenzo phenanthridines, contain a pyridine functional group with five fused six-membered ring systems with connectivity, shown in Figure 15. This arrangement of ring systems are found in natural products and biologically active compounds [197,198]. Two bis(dithioester) substituted phenanthridines, compound 35 and compound 36, were synthesized by Sundaramurthy et al., who showed that they could coordinate with $\mathrm{Hg}^{2+}$ ions [199]. Mono-sulfur derivative 35 demonstrated a strong fluorescence turn on signal in an aqueous solution, in the presence of $\mathrm{Hg}^{2+}$ ions, whereas tetra-sulfur derivative 36 showed a strong fluorescence quenching towards $\mathrm{Hg}^{2+}$ ions. The binding stoichiometry of both sensors toward $\mathrm{Hg}^{2+}$ ions was $1: 1$, according to the UV-Vis absorption spectra, fluorescence measurements, and computation (DFT) studies. The LoD for the mono-sulfur derivative was found to be as low as $0.91 \mathrm{nM}$ for $\mathrm{Hg}^{2+}$ ions, while the bis(dithioester) derivative demonstrated an LoD of $0.04 \mathrm{nM}$. The spectroscopic changes were also seen in paper-based test strips as seen in Figure 15.

(A)

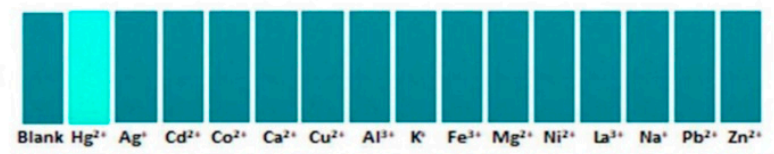

(B)

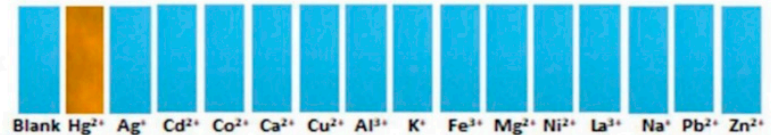

(C)

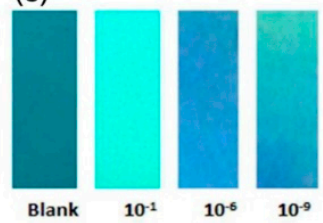

(D)

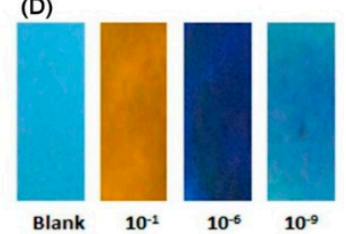

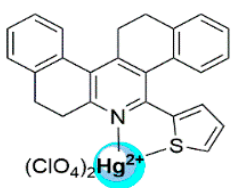

$\left[\mathrm{Hg}\left(\mathrm{ClO}_{4}\right)_{2} 35\right]$

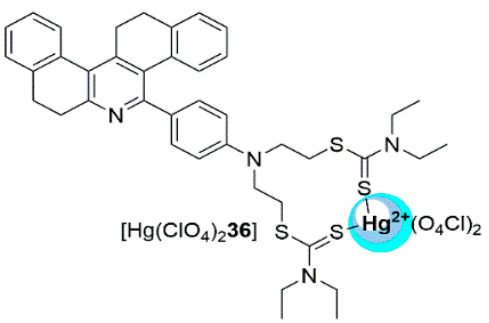

Figure 15. Changes in the fluorescence of probes 35 and 36 in paper strips with different metal ions (A) probe 35 (B) probe 36, and at different concentration (nM) of $\mathrm{Hg}^{2+}$ ions (C) probe 35 and (D) probe 36. Adapted from [199] with permission from the Centre National de la Recherche Scientifique (CNRS) and the Royal Society of Chemistry.

Anthracene-based, reusable fluorescent sensor 37 was synthesized via a one-pot reaction imine condensation by Misra et al. [200]. As anthracene is hydrophobic, it was expected that compound 37 would aggregate when the solvent mixture had a high content of water. By changing the THF: $\mathrm{H}_{2} \mathrm{O}$ ratio, it was found that the optimal working condition required $70 \%$ water. A strong emission band 
around $518 \mathrm{~nm}$ was observed $(20 \mu \mathrm{M})$ with a calculated $\phi$ of 0.614 . As the water content was increased, the molecules came closer together to restrict intramolecular rotation around the imine bond and, therefore, increased the fluorescence emissions, Scheme 15. In solutions where the water content was low, very weak emission bands were observed in the fluorescence spectra $(\phi=0.002)$. When $\mathrm{Hg}\left(\mathrm{NO}_{3}\right)_{2}$ was added to the aggregates, significant optical quenching was seen in the fluorescence emission, due to the heavy atom effect. This was a consequence of perturbating the intersystem crossing from the first singlet state $\left(S_{1}\right)$ to the lowest triplet state $\left(T_{1}\right)$, thereby, increasing the spin-orbit coupling from the aromatic scaffold of the molecular probe to the external heavy atom [201,202], upon the coordination of the $\mathrm{Hg}^{2+}$ ions to 37, through chelation. Therefore, the Stern-Volmer analysis showed the quenching constant $\left(K_{\mathrm{sv}}\right)$ to be $2.5 \times 10^{5} \mathrm{M}^{-1}$ and the LoD was found to be in the ppb concentration range ( $\left.3 \mathrm{ppb}\right)$. Moreover, analysis of municipal water and river water from the local area, using probe 37 detected $\mathrm{Hg}^{2+}$ ions.

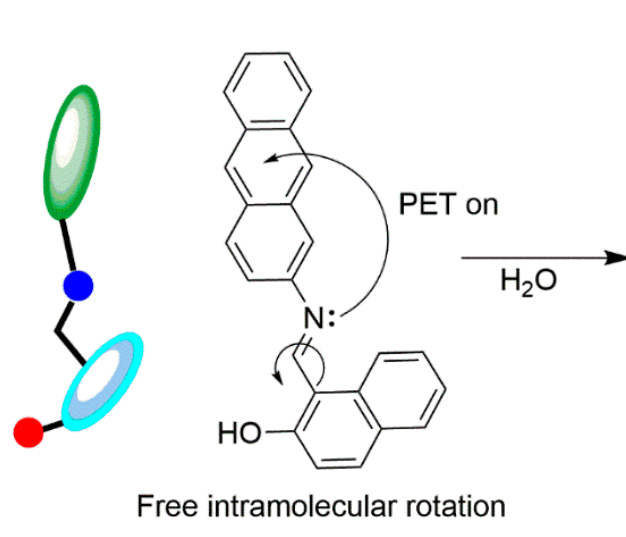

37

Weakly Fluorescent

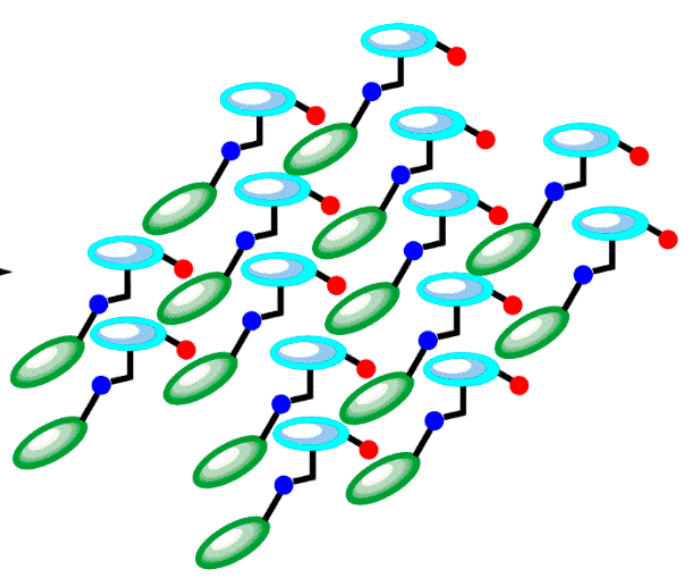

Strongly Fluorescent

Scheme 15. Proposed aggregation behavior of 37 in water.

The rhodamine fluorophore has been used as a molecular probe for a variety of metal ions over the years and xanthene derivatives have previously been highlighted in this review. Compound 38 was shown to distinguish between $\mathrm{Hg}^{2+}$ and $\mathrm{Cu}^{2+}$ ions. It was prepared by Gao and Zheng who showed that either in the absence or presence of UV light, a distinction could be made between $\mathrm{Hg}^{2+}$ and $\mathrm{Cu}^{2+}$ ions, Scheme 16 [203]. Optical studies were carried out in the presence of 16 different metal nitrate salts $\mathrm{Hg}^{2+}, \mathrm{Cu}^{2+}, \mathrm{Ag}^{+}, \mathrm{K}^{+}, \mathrm{Al}^{3+}, \mathrm{Ca}^{2+}, \mathrm{Na}^{+}, \mathrm{Ba}^{2+}, \mathrm{Co}^{2+}, \mathrm{Cd}^{2+}, \mathrm{Fe}^{3+}, \mathrm{Mg}^{2+}, \mathrm{Mn}^{2+}, \mathrm{Zn}^{2+}, \mathrm{Ni}^{2+}$, $\left.\mathrm{Pb}^{2+}\right)$ in a IPA: $\mathrm{H}_{2} \mathrm{O}$ solvent $(25 \mu \mathrm{M}, 8: 1, v / v)$. Probe 38 was initially colorless, indicative of the closed lactam moiety. However, on the addition of one equivalent of $\mathrm{Hg}^{2+}$ ions, a new band at $557 \mathrm{~nm}$ was observed (colorless to pink), indicating that the spirolactam ring was in the open form, which is very common for these molecular probes. Compound 38 shows a very weak emission intensity, but an emission band was seen at $578 \mathrm{~nm}$, when $\mathrm{Hg}^{2+}$ ions were added to the solution $\left(\lambda_{\mathrm{ex}}=550 \mathrm{~nm}\right)$. This phenomenon was not seen in the presence of the other metal cations. Copper(II) is well-known to quench the fluorescence emission, therefore, it was not surprising that an emission signal was not seen on the addition of $\mathrm{Cu}^{2+}$ ions, but on the addition of $\mathrm{Hg}^{2+}$ ions, a new absorption band was seen at $559 \mathrm{~nm}$ and a visible color change from colorless to purple was observed. The coexistence of $\mathrm{Hg}^{2+}$ and $\mathrm{Cu}^{2+}$ in the solution showed a decrease in the emission intensity of the band at $559 \mathrm{~nm}$, indicating that the presence of $\mathrm{Hg}^{2+}$ interfered with $\mathrm{Cu}^{2+}$ detection. One way to deliberately make their mixed system monitor one of the ions over the other, is to take advantage of solubility products. Bromide ions were used to precipitate $\mathrm{HgBr}_{2}\left(K_{\mathrm{sp}}=3 \times 10^{-7}\right)$, enabling the detection of $\mathrm{Cu}^{2+}$ ions. 


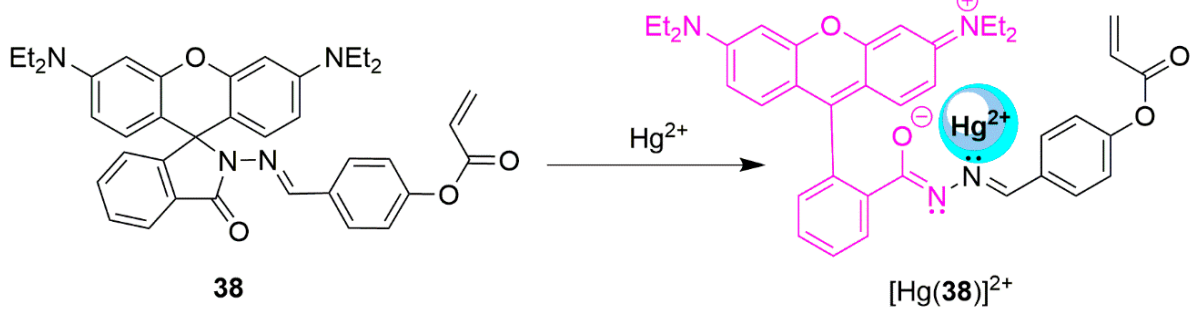

Scheme 16. The coordination of 38 to $\mathrm{Hg}^{2+}$ ions.

As mercury is classified as a "soft" metal, mercury ions forms many stable ionic compounds that are insoluble [204,205]. Thermodynamic stability is further enhanced when "soft" Lewis bases are present in the receptor, for example sulfur atoms [206]. The carbonyl group $(C=O)$ in the lactam ring in rhodamine probes could be readily converted to the analogous thio $(C=S)$ group, by using Lawesson's reagent. Zhou, $\mathrm{Hu}$ and Yao synthesized thiooxo-rhodamine B hydrazine compounds 39 and 40, which contain a number of sulfur atoms to help the molecular probe to selectively coordinate to $\mathrm{Hg}^{2+}$ over other metal ions [203]. Both molecular probes are colorless but addition of $\mathrm{Hg}^{2+}$ ions leads to a significant increase in absorption at $560 \mathrm{~nm}$, due to the spirolactam ring-opening. No optical changes were seen in the presence of the other metals $\left(\mathrm{Na}^{+}, \mathrm{K}^{+}, \mathrm{Mg}^{2+}, \mathrm{Ca}^{2+}, \mathrm{Al}^{3+}, \mathrm{Cr}^{3+}, \mathrm{Ba}^{2+}, \mathrm{Hg}^{2+}, \mathrm{Mn}^{2+}\right.$, $\left.\mathrm{Pb}^{2+}, \mathrm{Cd}^{2+}, \mathrm{Ni}^{2+}, \mathrm{Zn}^{2+}, \mathrm{Co}^{2+}, \mathrm{Fe}^{3+}\right)$ in a EtOH/HEPES solution (5 $\mathrm{MM} \mathrm{1:1,v/v} \mathrm{pH} \mathrm{7.4)} \mathrm{but} \mathrm{Ag}^{+}$and $\mathrm{Cu}^{2+}$ ions increased in intensity at $560 \mathrm{~nm}$. Probe 40 selectively detected $\mathrm{Hg}^{2+}$ ions via an "off-on" response in solution. The Job's plot and UV-Vis titration data indicated that the stoichiometry between 40 and $\mathrm{Hg}^{2+}$ ions was 1:2. This is unsurprising as there is free rotation around the bisthiophene bond, so the two rhodamine units could adapt an anti-conformation with the $\mathrm{Hg}^{2+}$ ions bound in each coordination environment. By comparison, compound 39 bound the $\mathrm{Hg}^{2+}$ ions in a 1:1 ratio. The association constants for $\mathbf{3 9}$ and $\mathbf{4 0}$ with mercury were calculated using the Benesi-Hildebrand method and was found to be $4 \times 10^{5} \mathrm{M}^{-1}$ and $1.3 \times 10^{11} \mathrm{M}^{-2}$, respectively. Interestingly, the fluorescence mechanism for the two molecular probes was very different. Molecular probe 39 was shown to exhibit a FRET mechanism, due to overlap between the emission spectra of the bisthiophene donor and the absorption spectra of the rhodamine B acceptor. Compound $\mathbf{4 0}$ did not show FRET and the fluorescence emission was due to the ring-opening of the spriolactam. The authors also demonstrated that compounds 39 and 40 could monitor the levels of $\mathrm{Hg}^{2+}$ ions in municipal water.
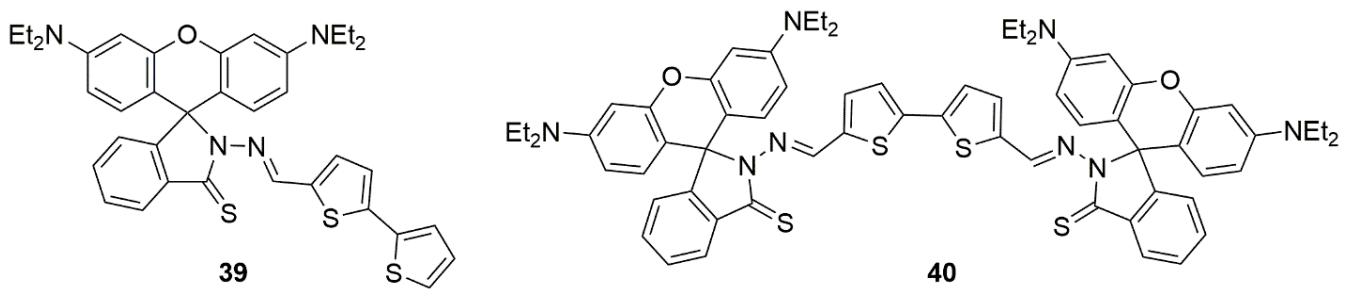

4,4-Difluoro-4-bora-3a,4a-diaza-s-indacene (BODIPY) possesses unique spectroscopic signatures and the BODIPY moiety has been used extensively in molecular probe design [207-209]. Qiu, Zhang, and Yin synthesized a BODIPY-based probe with a dipyridylamino (DPA) receptor (compound 41), for which the optical response was different for $\mathrm{Cu}^{2+}, \mathrm{Hg}^{2+}$, and $\mathrm{Pb}^{2+}$ ions [210]. On the addition of the $\mathrm{Cu}^{2+}, \mathrm{Hg}^{2+}$, and $\mathrm{Pb}^{2+}$ ions, the optical response was different for each metal ion. Optical studies were carried out in the presence of a number of different perchlorate metal salts $\left(\mathrm{Ag}^{+}, \mathrm{Ba}^{2+}, \mathrm{Ca}^{2+}, \mathrm{Cd}^{2+}\right.$, $\left.\mathrm{Co}^{2+}, \mathrm{Cu}^{2+}, \mathrm{Fe}^{2+}, \mathrm{Hg}^{2+}, \mathrm{K}^{+}, \mathrm{Mg}^{2+}, \mathrm{Na}^{+}, \mathrm{Ni}^{2+}, \mathrm{Pb}^{2+}, \mathrm{Zn}^{2+}\right)$ in a $2.0 \mu \mathrm{MCH}_{3} \mathrm{CN}$ solution. The presence of $\mathrm{Hg}^{2+}$ and $\mathrm{Pb}^{2+}$ in the solution, lead to a blue shift in the maximum absorbance peak from $595 \mathrm{~nm}$ to $572 \mathrm{~nm}$ and a visible color change from blue to purple. The presence of $\mathrm{Cu}^{2+}$ ions in the solution led to a blue shift in the maximum absorbance from $595 \mathrm{~nm}$ to $512 \mathrm{~nm}$, and a visible color change from blue to fuchsia. Compound 41 showed a single weak emission, when it was excited at $365 \mathrm{~nm}$. The presence of $\mathrm{Hg}^{2+}$ and $\mathrm{Pb}^{2+}$ ions led to a new emission band at $587 \mathrm{~nm}$ and a change from dark red 
fluorescence to orange fluorescence. The presence of $\mathrm{Cu}^{2+}$ ions led to an emission band at $545 \mathrm{~nm}$ and a change from dark red fluorescence to green fluorescence. Competition studies have showed that the presence of $\mathrm{Cu}^{2+}$ ions in the solution quenched the $\mathrm{Hg}^{2+}$ and $\mathrm{Pb}^{2+}$ ions fluorescent responses. The presence of other metal ions did not influence the $\mathrm{Cu}^{2+}$ response. Both $\mathrm{Hg}^{2+}$ and $\mathrm{Pb}^{2+}$ ions could be removed from the binding site of 41, when EDTA was added to the solution. A Job's plot and ESI-MS data indicated a 1:1 binding stoichiometry, and ${ }^{1} \mathrm{H}$ NMR data indicated that the probe's fluorescent and colorimetric responses were due to $\pi$ delocalization between the N-pyridyl and BODIPY groups, caused by the coordination of the metal ions to the BODIPY and DPA groups. $\mathrm{As}^{\mathrm{Hg}^{2+}}, \mathrm{Pb}^{2+}$ and $\mathrm{Cu}^{2+}$ produced different emission intensities it was possible to construct OR, NOT, and AND logic circuits, where the inputs were the metal ions and the output was the emission intensity at $587 \mathrm{~nm}$. If the emission intensity was greater than a chosen arbitrary unit (150 au), then " 1 " was assigned for (i) both $\mathrm{Hg}^{2+}$ and $\mathrm{Pb}^{2+}$, (ii) $\mathrm{Hg}^{2+}$, or (iii) $\mathrm{Pb}^{2+}$ on their own were present, meaning that the gate was opened. If, $\mathrm{Cu}^{2+}$ was present alone, with $\mathrm{Hg}^{2+}$ or $\mathrm{Pb}^{2+}$ or both $\mathrm{Hg}^{2+}$ and $\mathrm{Pb}^{2+}$, it led to a situation whereby the intensity was lower than $150 \mathrm{au}$, therefore a " 0 " was assigned, meaning the gate was closed. Therefore, the combinations of the three different metal ions gave rise to different logic gates (OR, NOT, and AND), Figure 16.

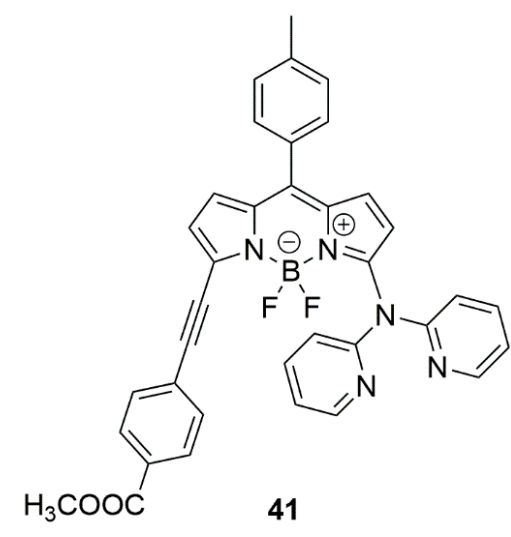

(A)

\begin{tabular}{cccc}
\hline Input (1) & Input (2) & Input (3) & Output \\
\hline 0 & 0 & 0 & 0 \\
1 & 0 & 0 & 1 \\
0 & 1 & 0 & 1 \\
0 & 0 & 1 & 0 \\
1 & 1 & 0 & 1 \\
1 & 0 & 1 & 0 \\
0 & 1 & 1 & 0 \\
1 & 1 & 1 & 0 \\
\hline
\end{tabular}

(B)

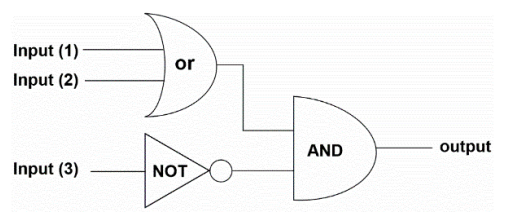

(C)

Figure 16. Truth table and logic circuit input (1), (2), and (3) $\mathrm{Pb}^{2+}, \mathrm{Hg}^{2+}$, and $\mathrm{Cu}^{2+}$ ions $(20 \mu \mathrm{M}$, $\mathrm{CH}_{3} \mathrm{CN}$ ), respectively, and output is the fluorescence intensity at $587 \mathrm{~nm}$ [210]. (A) molecular probe, (B) truth table and (C) circuit. 
Gao and Chen synthesized a Schiff-base probe with coumarin and benzimidazole fluorophores (42), which was capable of simultaneously detecting $\mathrm{Hg}^{2+}$ and $\mathrm{Cu}^{2+}$ ions, by two different mechanisms [211]. Compound 42 produced a fluorescence emission enhancement, when bound to $\mathrm{Hg}^{2+}$ ions, whereas, the $\mathrm{Cu}^{2+}$ ions quenched the emission band. A weak fluorescence intensity at $426 \mathrm{~nm}(\phi=0.009)$ was seen for 42 in a $10 \mu \mathrm{M}$ HEPES:DMSO $(20 \mathrm{mM}, 9: 1, v / v)$ solution. A significant enhancement was seen in the presence of $\mathrm{Hg}^{2+}$ ions $(\phi=0.152)$, whereas in the presence of $\mathrm{Cu}^{2+}$ ions, a red shift to $448 \mathrm{~nm}$ was seen, but the emission band was reduced in intensity $(\phi=0.005)$. Job's plot analysis and fluorescence titration data both indicated a 1:1 binding ratio for both the $\mathrm{Cu}^{2+}$ and $\mathrm{Hg}^{2+}$ complexes. The structure of the complexes was supported by HRMS, IR, and NMR studies. The $\mathrm{Hg}^{2+}$ ion bound in a tridentate fashion, but the molecular probes underwent hydrolysis via a mercury-promoted hydrolysis (Scheme 17), so the fluorescence emission was due to the coumarin-carboxaldehyde being formed. Fluorescence titration data were used to determine the probe's sensitivity to $\mathrm{Hg}^{2+}$ and $\mathrm{Cu}^{2+}$ ions, and the Benesi-Hildebrand equation used to calculate the association constants for the probe towards $\mathrm{Cu}^{2+}$ ions and $\mathrm{Hg}^{2+}$ ions, gave $7 \times 10^{4} \mathrm{M}^{-1}$ and $9 \times 10^{4} \mathrm{M}^{-1}$, respectively.

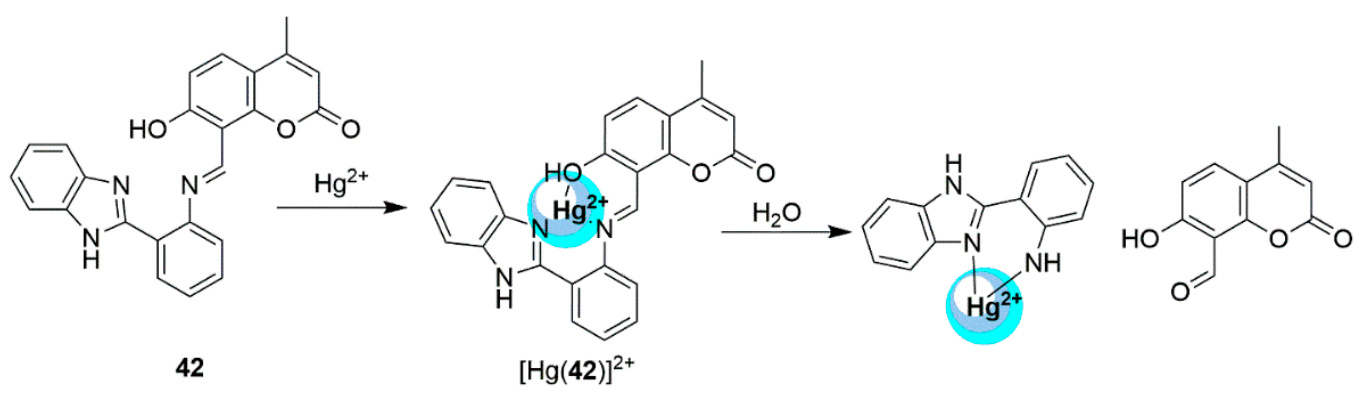

Scheme 17. The coordination and subsequent hydrolysis of molecular probe $\mathbf{4 2}$.

Another example of molecular chemodosimeter that can selectively monitor $\mathrm{Hg}^{2+}$ ions is compound 43 [212]. A solution of compound 43 in $10 \mu \mathrm{M}$ HEPES $(10 \mathrm{mM}, \mathrm{pH} 7)$ had a maximum absorption band at $315 \mathrm{~nm}$, and when excited at $371 \mathrm{~nm}$, a weak emission band was observed at $450 \mathrm{~nm}$. Interestingly, the authors failed to mention why the excitation wavelength used in their studies was so far removed from the maximum absorption band. An increase in absorption and emission intensity was seen when $\mathrm{Hg}^{2+}$ ions were added to 43 . The fluorescence quantum yield of $\mathbf{4 3}$ was calculated with respect to rhodamine $\mathrm{B}$ and found to be $\phi=0.027$. The addition of one equivalence of $\mathrm{Hg}^{2+}$ led to a ten-fold increase in fluorescent intensity $(\phi=0.22)$, which was accompanied by a change in fluorescence from colorless to blue. No other metal cation showed the same response $\left(\mathrm{Zn}^{2+}, \mathrm{Hg}^{2+}, \mathrm{Na}^{+}\right.$, $\left.\mathrm{Pb}^{2+}, \mathrm{Co}^{2+}, \mathrm{K}^{+}, \mathrm{Ni}^{2+}, \mathrm{Cu}^{2+}, \mathrm{Al}^{3+}, \mathrm{Mn}^{2+}, \mathrm{Cr}^{3+}, \mathrm{Mg}^{2+}, \mathrm{Fe}^{3+}, \mathrm{Cd}^{2+}\right)$. ESI-MS and NMR studies showed that the fluorescence emission was due to the cleavage of the carbonothioate, via a $\mathrm{Hg}^{2+}$-promoted hydrolysis, thereby, forming 7-hydroxy-4-methylcoumarin dye, which was highly fluorescent. This "simple" molecule was used to monitor deliberately spiked tap water with $\mathrm{Hg}^{2+}$, to show that it could be used in a real-world application.<smiles>Cc1cc(=O)oc2cc(OC(=S)Oc3ccccc3)ccc12</smiles>

43

The imine functional group can undergo hydrolysis under acidic conditions [213]. This is a well-known and thoroughly investigated mechanism, whereby the rate determine step is the initial nucleophilic addition to the carbon-nitrogen double bond. It has also been shown that metal ions can accelerate the hydrolysis mechanism via a substrate-metal association, whereby the metal ion is 
coordinated to the nitrogen atom, enhancing the substrate for nucleophilic attack [214]. Compound 44 was prepared by Duan et al. [215]. It was shown that compound 44 works as a turn-on sensor through $\mathrm{Hg}^{2+}$ promoted hydrolysis, in which the imine is cleaved to form the coumarin aldehyde fluorophore and a 5-aminoisophthalic acid methyl ester. The cleavage did not occur in the presence of other metal ions $\left(\mathrm{Na}^{+}, \mathrm{K}^{+}, \mathrm{Mg}^{2+}, \mathrm{Ca}^{2+}, \mathrm{Cd}^{2+}, \mathrm{Mn}^{2+}, \mathrm{Fe}^{2+}, \mathrm{Co}^{2+}, \mathrm{Ni}^{2+}, \mathrm{Cu}^{2+}, \mathrm{Zn}^{2+}, \mathrm{Ag}^{+}, \mathrm{Pb}^{2+}, \mathrm{Hg}^{2+}\right)$ in a $2 \times 10^{-6} \mathrm{M}$ $\mathrm{CH}_{3} \mathrm{CN}: \mathrm{H}_{2} \mathrm{O}$ 8:2 (v/v) solution at physiological $\mathrm{pH}\left(0.1 \mathrm{M} \mathrm{KClO}_{4}\right.$ buffer, $\mathrm{pH}$ 7.3). Compound 44 displayed a weak fluorescence signal at $530 \mathrm{~nm}$. The lone pair on the nitrogen atom PET, quenched the emission intensity. On the addition of $\mathrm{Hg}^{2+}$ ions, a 20-fold increase in emission was seen at $490 \mathrm{~nm}$. The emission at $490 \mathrm{~nm}$ was assigned to the coumarin aldehyde fluorophore, and the ratio between the intensity at $490 \mathrm{~nm}$ and $530 \mathrm{~nm}\left(\mathrm{I}_{490} / \mathrm{I}_{530}\right)$ was used to detect $\mathrm{Hg}^{2+}$ ions, via a ratiometric approach. The $\mathrm{LoD}$ of $\mathrm{Hg}^{2+}$ was calculated to be in the nanomolar concentration range. Fluorescence was significantly turned on as $\mathbf{4 4}$ broke down into two separate molecules, one of which, the coumarin aldehyde is highly fluorescent. It was reasoned that 44 could be used to monitor $\mathrm{Hg}^{2+}$ ions in the human breast adenocarcinoma cell (MCF-7) line, which was observed when the cells were incubated with $\mathrm{Hg}^{2+}$ ions.<smiles>CCNc1ccc2cc(/C=N/c3cc(C(=O)OC)cc(C(=O)OC)c3)c(=O)oc2c1</smiles>

\section{Multivariate Analysis}

Molecular recognition between low molecular weight fluorescent probes (LMFPs) and metal cations has dominated the field for many years. Sensor arrays, using statistical analysis and pattern-recognition algorithms are now becoming the main approach to measure and monitor a number of analytes in a single experiment, and a recent review written by Jolliffe, highlights some recent examples in fluorescent sensing arrays [216]. Here, we give a couple of recent examples on this new sensing approach, to highlight the direction of research in the field.

Minami et al. used commercially available dyes (alizarin red, bromopyrogallol red, and pyrogallol red) that contained the catechol moiety [217]. The catechol functional groups reacted with 3-nitrophenylbornoic acid (3-NPBA) to form a dynamic covalent bond. The metal ion competed with the boronic acid for the catechol moiety; thus, upon coordination of the metal ion, 3-NPBA was displaced. The metal-dye complex generated different colors, depending on the dye and the metal, Scheme 18.

The coordination of the catechol dyes and 3-NPBA resulted in blue shifts in the absorption spectra, and the addition of metal ions led to a red shift, due to the displacement of 3-NPBA and the formation of a dye-metal complex. FAB-MS and titration isotherms indicated that both the dye:3-NPBA and dye:metal complexes had a 1:1 stoichiometry. Extensive univariant work gave an understanding of the interaction and the $K_{\text {assoc }}$ for selected metal ions $\left(\mathrm{Cu}^{2+}, \mathrm{Ni}^{2+}\right.$ and $\left.\mathrm{Zn}^{2+}\right)$, which were in the range of $5 \times 10^{2} \mathrm{M}^{-1}$ to $>10^{6} \mathrm{M}^{-1}$. The array utilized a 384 well microplate for high throughput screening. The response of the sensor array in the presence of 11 metals was investigated (50 mM HEPES buffer solution containing $10 \mathrm{mM} \mathrm{NaCl}$ interferant, $40 \mu \mathrm{M}$ catechol dye, $4 \mathrm{mM}$ 3-NPBA, and $10 \mu \mathrm{M}$ metals) and was capable of discriminating between $\mathrm{Ni}^{2+}, \mathrm{Cu}^{2+}, \mathrm{Zn}^{2+}, \mathrm{Cd}^{2+}, \mathrm{Co}^{2+}, \mathrm{Fe}^{2+}, \mathrm{Hg}^{2+}, \mathrm{Al}^{3+}, \mathrm{Pb}^{2+}$, $\mathrm{Ga}^{3+}$, and $\mathrm{Ca}^{2+}$. LDA analysis indicated that $95.2 \%$ of variance was sufficient to discriminate between the different metals, and the cross-validation method indicated a $100 \%$ correct classification within each cluster, Figure 17A. A potential semi-quantitative analysis to determine the concentration of the 
metals was demonstrated using a mixture of $\mathrm{Cu}^{2+}, \mathrm{Zn}^{2+}$, and $\mathrm{Ni}^{2+}$, and a regression analysis using a support vector machine (SVM) algorithm (Figure 17B). The results of the semi-quantitative assay, where the three different metals were tested at a concentration range of 0-3.7 ppm with 20 repetitions at each concentration, showed that a plot of the actual vs. predicted concentrations was highly accurate. The concentration range over which the results were obtained $\left(\mathrm{Ni}^{2+}<30 \mathrm{ppm}, \mathrm{Cu}^{2+}<2.5 \mathrm{ppm}\right.$, $\mathrm{Zn}^{2+}<6 \mathrm{ppm}$ ), the method's potential for high-throughput screening, and the fact that the assay gave no response in the presence of other metals common in environmental water sources, such as $\mathrm{K}^{+}, \mathrm{Na}^{+}$, $\mathrm{Mg}^{2+}$, indicated that the assay developed by Sasaki and coworkers could be a useful tool for real time testing, in environmental water sources.

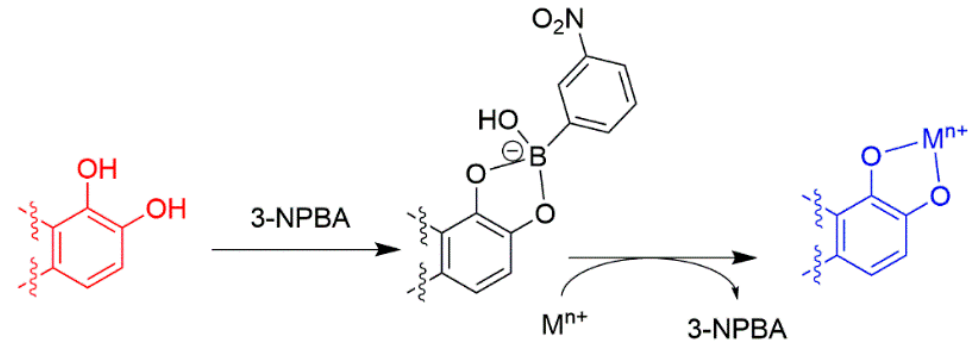<smiles>O=C1c2ccccc2C(=O)c2c1cc(S(=O)(=O)[O-])c(O)c2O</smiles>

Alizarin red S<smiles>O=c1c(Br)cc2c(-c3ccccc3[S+](=O)[O-])c3cc(Br)c(O)c(O)c3oc-2c1O</smiles>

Bromopyrogallol red<smiles>O=c1ccc2c(-c3ccccc3[S+](=O)[O-])c3ccc(O)c(O)c3oc-2c1O</smiles><smiles>O=[N+]([O-])c1cccc(B(O)O)c1</smiles>

Pyrogallol red 3-nitrophenyboronic acid

Scheme 18. The displacement approach by which the dyes formed a dynamic bond with the boronic acid derivative which was then displaced upon the coordination of the metal ion.

(A)

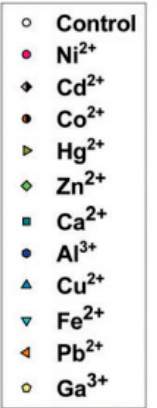

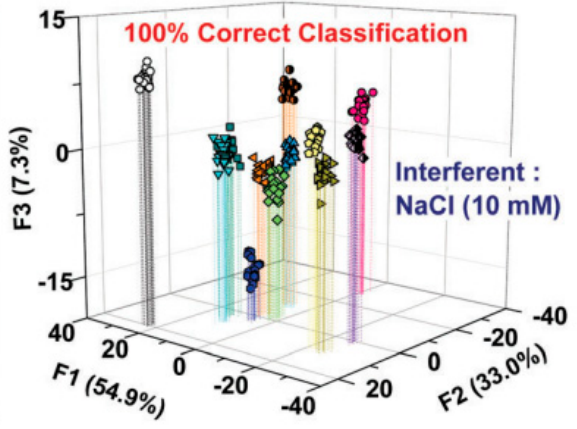

(B)

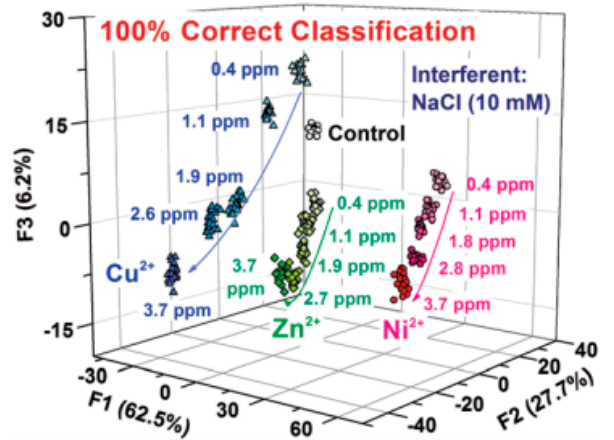

Figure 17. (A) Linear discriminant analysis (LDA) score plots for the response of the sensor array to 11 analytes (and control) in a HEPES buffer $(50 \mathrm{mM})$ solution, with sodium chloride $(10 \mathrm{mM})$. The [metal ion] $=10 \mathrm{mM}$. 20 repetitions were measured for each analyte. (B) The cross-validation routine shows $100 \%$ correct classification LDA results of the semi-quantitative assay, toward three different metal ions $\left(\mathrm{Cu}^{2+}, \mathrm{Zn}^{2+}\right.$ and $\left.\mathrm{Ni}^{2+}\right)$; concentration range of 0-3.7 ppm.\%. Adapted from [218] with permission from The Royal Society of Chemistry. 
Our group has carried out multivariate pattern recognition approaches to the binding between coumarin-enamine probes (compounds 45a-e) and ten divalent metal ions [219]. The coordination of the metal ions with compounds $45 \mathbf{b}-\mathbf{e}$, through the nitrogen atom, showed optical responses in a univariant approach, but the data were limited in terms of discrimination. To capture this wealth of information and to be able to carry out the discrimination of metal cations as proposed, a multivariate approach was adopted. A multimode microwell plate reader was utilized, allowing for rapid and automated acquisition of multivariate data. The sensor array comprised compounds $\mathbf{4 5 b}$ to $\mathbf{4 5 f}$. Compound 45a did not possess a binding site on the aromatic ring system, so it was used as a reference.<smiles>CCNc1ccc2c(c1)OC(=O)C(=CNC(=O)[AlH2])C2=O</smiles>

45a-e<smiles>Cc1ccccc1</smiles><smiles>Cc1ccccn1</smiles>

b<smiles>Cc1ccncc1</smiles>

d<smiles>Cc1cccnc1</smiles>

C<smiles>Cc1ncccn1</smiles>

e

The absorbance response of this array of four sensors at 330, 380, 400, and $430 \mathrm{~nm}$, and fluorescence intensity at $330 / 450 \mathrm{~nm}, 330 / 528 \mathrm{~nm}, 330 / 580 \mathrm{~nm}, 380 / 450 \mathrm{~nm}, 380 / 528 \mathrm{~nm}$, and $380 / 450 \mathrm{~nm}\left(\lambda_{\text {ex }} / \lambda_{\text {em }}\right)$ were determined concurrently. The sensing array was exposed to a panel of analytes comprising the chloride salts of- $\mathrm{Ca}^{2+}, \mathrm{Cd}^{2+}, \mathrm{Co}^{2+}, \mathrm{Cu}^{2+}, \mathrm{Fe}^{2+}, \mathrm{Hg}^{2+}, \mathrm{Mg}^{2+}, \mathrm{Ni}^{2+}, \mathrm{Pb}^{2+}$, and $\mathrm{Zn}^{2+}$, and all measurements were conducted in the same solvent (DMSO) as the univariate analysis for consistency. The sensor array was exposed to each metal multiple times, generating a cluster of 18 replicates for each analyte. This approach generated a very large multivariate data set $(4 \times$ sensors by $10 \times$ analytes by $18 \times$ replicates $=720$ data points, each described by nine instrumental variables). Linear discriminant analysis (LDA) was used to organize the high-dimensionality data and to extract the most relevant information, ultimately providing the information necessary to classify the ten analytes considered.

The well-established LDA algorithm computed a linear combination of the original variables that maximized the separation between multiple analytes, while minimizing the separation between replicate measurements of the same analyte [218]. In doing so, the algorithm generated a new set of variables, called factors, which were returned in order of decreasing relative information content. Data reduction was then accomplished by retaining only the first two or three LDA factors and dropping the higher-order ones. This produced a transformed dataset, in which each point was associated with a pair or a triplet of numbers, respectively, typically referred to as the factor scores of those points. These factor scores could be used as coordinates in plotting the transformed points in either a two- or three-dimensional plot.

It was shown that, the first two factors obtained from the LDA analysis, out of the ten present in the system, accounted for $80.7 \%$ of the total information content of the original system. A two-dimensional score plot (Figure 18) was obtained that showed clear clustering of the data-replicate measurements of samples of each divalent metal ion were classified as similar and grouped together by the LDA analysis. In short, the pattern-based approach was capable of differentiating almost all ten divalent metal cations, using the additional information collected through patterning and multivariate analysis. However, this analysis failed to definitively separate the ten metal ions, this was due to similarities in geometry that was adopted upon the binding of the molecular probe. 


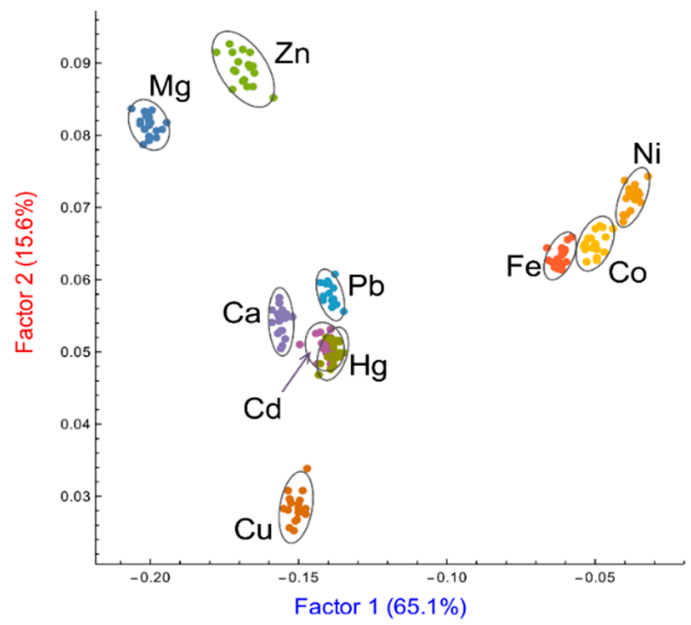

(A)

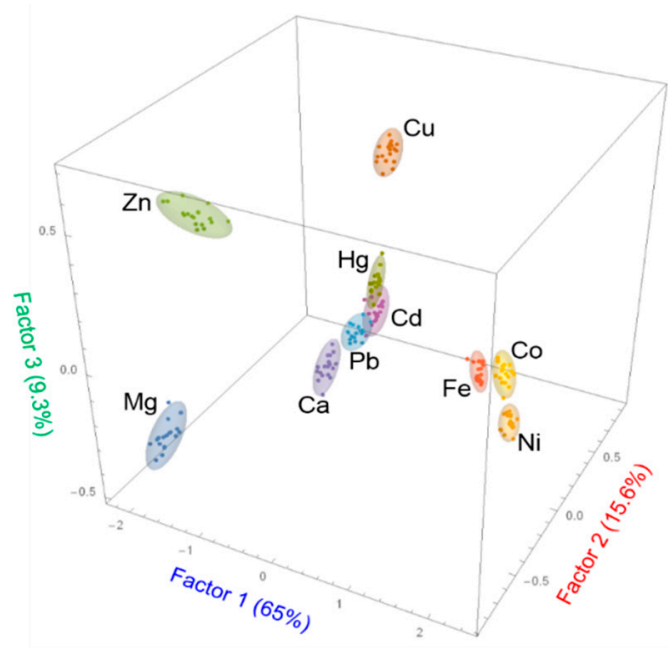

(B)

Figure 18. (A) Two-dimensional LDA score plot for the analysis of probes 45a-e binding 10 divalent metal chlorides. (B) A three-dimensional LDA score plot captured $90 \%$ of all information available from the pattern recognition system, significantly improving on the separation of difficult cases that were imperfectly discriminated, using the two-dimensional results. Confidence ellipsoids were drawn at 95\% confidence. Adapted from [218] with permission from The Royal Society of Chemistry.

\section{Conclusions and Future Prospects}

The chemical sensors that have been highlighted throughout this review showcase recent low molecular weight fluorescent probes designed to target the group 12 triad $\left(\mathrm{Zn}^{2+}, \mathrm{Cd}^{2+}\right.$, and $\left.\mathrm{Hg}^{2+}\right)$. During the last few years there has been a great deal of work on the design, synthesis, and detection of these metal ions. Much of the work presented here is focused on the traditional approach of sensor design, where the spectroscopic response is univariant in nature i.e., one LMFP targets one metal. As small molecule recognition becomes more popular, it is becoming more challenging to prepare novel compounds, but as computer power improves significantly, monitoring and discriminating metal ions in a complex environment seems to be the direction in which the sensor community is moving. Groups still publish their findings on LMFP and, whilst writing this review and taking a closer look at the data, it is clear that there are some general omissions or misleading statements. One of the biggest challenges is to work in $100 \%$ aqueous system, however, the systems are often in a mixture of organic-aqueous systems, and more often than not, only a fraction is water. Nevertheless, it has been claimed that a particular probe works in water. Additionally, there is often little or no discussion on the aqueous chemistry of the metal ion which influences the coordination. Moreover, many reports often omit a serious discussion on speciation, in their particular system, claiming that only a 1:1 probe-metal exists, when the data often suggest that other species might exist. More often than not, the counter-anion is omitted and authors make the assumption that it plays no role in binding, but only exists to balance the charge, when many counter ions can form bridging species. This is particularly important if a system is to work in an aqueous system, as anions might not exist in their conjugate base form, depending on the $\mathrm{pH}$, which might influence the speciation. Additionally, care must be taken in reporting equilibrium constants using old linear regression methods, for example, the Benesi-Hilderbrand double reciprocal plot and Job's plot analysis. Even though they are easy to use they are significantly over used and misinterpreted. For example, subtle curvature in the Benesi-Hilderbrand plot is often mistaken as indicative of a 1:1 binding, but in fact it more often than not implies a more complicated equilibria occurring in the system. There are many problems associated with these regression calculations. Computer power has significantly improved over the years and software now exists for non-linear regression analysis to calculate more precise binding constants, including those involving complex equilibria. 
Author Contributions: The authors comprise a graduate student (A.D.J.), an undergraduate student (R.M.C.) and the principle investigator (K.J.W.). Each student contributed significantly to the review. All three authors extensively carried out the literature search and wrote specific sections. A.D.J. wrote the section pertaining to the cadmium section, R.M.C. wrote the section on mercury, and K.J.W. put together the remaining sections and looked after the overall management of the manuscript.

Funding: This research received no external funding.

Acknowledgments: The financial support for this work was provided, in part, by the NSF grant OCE-0963064 and the Eagle Scholars Program for Undergraduate Research (Eagle SPUR) at the University of Southern Mississippi. The authors would also like to thank the department of chemistry and biochemistry and the honors college for their continued support and Peter Cragg at University of Brighton, School of Pharmacy and Biomolecular Sciences for constructive criticism

Conflicts of Interest: The authors declare no conflict of interest.

\section{References}

1. Eggins, B.R. Chemical Sensors and Biosensors; John Wiley \& Sons: Chichester, UK, 2007.

2. Girigoswami, K.; Akhtar, N. Nanobiosensors and fluorescence based biosensors: An overview. Int. J. Nano Dimens. 2019, 10, 1-17.

3. Xiong, S.; Deng, Y.; Zhou, Y.; Gong, D.; Xu, Y.; Yang, L.; Chen, H.; Chen, L.; Song, T.; Luo, A. Current progress in biosensors for organophosphorus pesticides based on enzyme functionalized nanostructures: A review. Anal. Methods 2018, 10, 5468-5479. [CrossRef]

4. Liao, Z.; Wang, J.; Zhang, P.; Zhang, Y.; Miao, Y.; Gao, S.; Deng, Y.; Geng, L. Recent advances in microfluidic chip integrated electronic biosensors for multiplexed detection. Biosens. Bioelectron. 2018, 121, 272-280. [CrossRef]

5. Kumar, S.; Tripathy, S.; Jyoti, A.; Singh, S.G. Recent advances in biosensors for diagnosis and detection of sepsis: A comprehensive review. Biosens. Bioelectron. 2019, 124-125, 205-215. [CrossRef]

6. Fothergill, S.M.; Joyce, C.; Xie, F. Metal enhanced fluorescence biosensing: From ultra-violet towards second near-infrared window. Nanoscale 2018, 10, 20914-20929. [CrossRef]

7. Cheng, F.; Tang, X.L.; Kardashliev, T. Transcription factor-based biosensors in high-throughput screening: Advances and applications. Biotechnol. J. 2018, 13, e1700648. [CrossRef] [PubMed]

8. Ashrafi, A.M.; Koudelkova, Z.; Sedlackova, E.; Richtera, L.; Adam, V. Electrochemical sensors and biosensors for determination of mercury ions. J. Electrochem. Soc. 2018, 165, B824-B834. [CrossRef]

9. Aldewachi, H.; Chalati, T.; Woodroofe, M.N.; Bricklebank, N.; Sharrack, B.; Gardiner, P. Gold nanoparticle-based colorimetric biosensors. Nanoscale 2018, 10, 18-33. [CrossRef] [PubMed]

10. Sher, M.; Zhuang, R.; Demirci, U.; Asghar, W. Paper-based analytical devices for clinical diagnosis: Recent advances in the fabrication techniques and sensing mechanisms. Expert Rev. Mol. Diagn. 2017, 17, 351-366. [CrossRef]

11. Saidur, M.; Aziz, A.A.; Basirun, W. Recent advances in DNA-based electrochemical biosensors for heavy metal ion detection: A review. Biosens. Bioelectron. 2017, 90, 125-139. [CrossRef] [PubMed]

12. Liu, Y.; Deng, Y.; Dong, H.; Liu, K.; He, N. Progress on sensors based on nanomaterials for rapid detection of heavy metal ions. Sci. China Chem. 2017, 60, 329-337. [CrossRef]

13. Lan, L.; Yao, Y.; Ping, J.; Ying, Y. Recent advances in nanomaterial-based biosensors for antibiotics detection. Biosens. Bioelectron. 2017, 91, 504-514. [CrossRef] [PubMed]

14. Jayanthi, V.S.A.; Das, A.B.; Saxena, U. Recent advances in biosensor development for the detection of cancer biomarkers. Biosens. Bioelectron. 2017, 91, 15-23. [CrossRef]

15. National Research Council. Expanding the Vision of Sensor Materials; National Academemis Press: Washington, DC, USA, 1995; Chapter 6; pp. 73-88. [CrossRef]

16. McNaught, A.D.; Wilkinson, A. IUPAC Compendium of Chemical Terminology, 2nd ed.; Blackwell Scientific Publications: Oxford, UK, 2014.

17. Macielag, M.J. Antibiotic Discovery and Development; Springer: Berlin/Heidelberg, Germany, 2012; pp. 793-820.

18. Hulanicki, A.; Glab, S.; Ingman, F. Chemical sensors: Definitions and classification. Pure Appl. Chem. 1991, 63, 1247-1250. [CrossRef]

19. Phan, M.-H.; Peng, H.-X. Giant magnetoimpedance materials: Fundamentals and applications. Prog. Mater. Sci. 2008, 53, 323-420. [CrossRef] 
20. Xu, H.; Li, Y.; Huang, N.-J.; Yu, Z.-R.; Wang, P.-H.; Zhang, Z.-H.; Xia, Q.-Q.; Gong, L.-X.; Li, S.-N.; Zhao, L. Temperature-triggered sensitive resistance transition of graphene oxide wide-ribbons wrapped sponge for fire ultrafast detecting and early warning. J. Hazard. Mater. 2019, 363, 286-294. [CrossRef]

21. Kobayashi, M. A perspective on steep-subthreshold-slope negative-capacitance field-effect transistor. Appl. Phys. Express 2018, 11, 110101. [CrossRef]

22. Li, C.; Tan, Q.; Jia, P.; Zhang, W.; Liu, J.; Xue, C.; Xiong, J. Review of research status and development trends of wireless passive LC resonant sensors for harsh environments. Sensors 2015, 15, 13097-13109. [CrossRef]

23. Balandin, A.A. Low-frequency $1 / \mathrm{f}$ noise in graphene devices. Nat. Nanotechnol. 2013, 8, 549-555. [CrossRef]

24. Suárez, P.L.; García-Cortés, M.; Fernández-Argüelles, M.T.; Encinar, J.R.; Valledor, M.; Ferrero, F.J.; Campo, J.C.; Costa-Fernández, J.M. Functionalized phosphorescent nanoparticles in (bio)chemical sensing and imaging-A review. Anal. Chim. Acta 2019, 1046, 16-31. [CrossRef]

25. Darr, J.A.; Poliakoff, M. New directions in inorganic and metal-organic coordination chemistry in supercritical fluids. Chem. Rev. 1999, 99, 495-542. [CrossRef] [PubMed]

26. Carter, S.; Fisher, A.S.; Hinds, M.W.; Lancaster, S.; Marshall, J. Atomic spectrometry update. Review of advances in the analysis of metals, chemicals and materials. J. Anal. Atom. Spectrom. 2013, 28, 1814-1869. [CrossRef]

27. Shazzo, Y.K.; Karpov, Y.A. Laser sampling in inductively coupled plasma mass spectrometry in the inorganic analysis of solid samples: Elemental fractionation as the main source of errors. J. Anal. Chem. 2016, 71, 1069-1080. [CrossRef]

28. Chen, S.-H.; Li, Y.-X.; Li, P.-H.; Xiao, X.-Y.; Jiang, M.; Li, S.-S.; Zhou, W.-Y.; Yang, M.; Huang, X.-J.; Liu, W.-Q. Electrochemical spectral methods for trace detection of heavy metals: A review. TrAC Trends Anal. Chem. 2018, 106, 139-150. [CrossRef]

29. Fen, Y.W.; Yunus, W.M.M. Surface plasmon resonance spectroscopy as an alternative for sensing heavy metal ions: A review. Sens. Rev. 2013, 33, 305-314.

30. West, M.; Ellis, A.T.; Potts, P.J.; Streli, C.; Vanhoof, C.; Wobrauschek, P. 2016 Atomic Spectrometry update-A review of advances in X-ray fluorescence spectrometry and its applications. J. Anal. Atom. Spectrom. 2016, 31, 1706-1755. [CrossRef]

31. De Silva, A.P.; Gunaratne, H.N.; Gunnlaugsson, T.; Huxley, A.J.; McCoy, C.P.; Rademacher, J.T.; Rice, T.E. Signaling recognition events with fluorescent sensors and switches. Chem. Rev. 1997, 97, 1515-1566. [CrossRef]

32. Wu, J.; Liu, W.; Ge, J.; Zhang, H.; Wang, P. New sensing mechanisms for design of fluorescent chemosensors emerging in recent years. Chem. Soc. Rev. 2011, 40, 3483-3495. [CrossRef] [PubMed]

33. Valeur, B.; Leray, I. Design principles of fluorescent molecular sensors for cation recognition. Coord. Chem. Rev. 2000, 205, 3-40. [CrossRef]

34. Kang, J.; Huo, F.; Zhang, Y.; Chao, J.; Glass, T.E.; Yin, C. A novel near-infrared ratiometric fluorescent probe for cyanide and its bioimaging applications. Spectrochim. Acta Part A 2019, 209, 95-99. [CrossRef]

35. Masteri-Farahani, M.; Khademabbasi, K. Heavy atom quenching of CdS quantum dots photoluminescence: Evidences for electron transfer mechanism. J. Lumin. 2018, 204, 130-134. [CrossRef]

36. Czerwieniec, R.; Yu, J.; Yersin, H. Blue-light emission of $\mathrm{Cu}(\mathrm{I})$ complexes and singlet harvesting. Inorg. Chem. 2011, 50, 8293-8301. [CrossRef] [PubMed]

37. Zu, F.; Yan, F.; Bai, Z.; Xu, J.; Wang, Y.; Huang, Y.; Zhou, X. The quenching of the fluorescence of carbon dots: A review on mechanisms and applications. Microchim. Acta 2017, 184, 1899-1914. [CrossRef]

38. Birks, J. Excimers. Rep. Prog. Phys. 1975, 38, 903-974. [CrossRef]

39. Lu, H.; Zheng, Y.; Zhao, X.; Wang, L.; Ma, S.; Han, X.; Xu, B.; Tian, W.; Gao, H. Highly efficient far red/near-infrared solid fluorophores: Aggregation-induced emission, intramolecular charge transfer, twisted molecular conformation, and bioimaging applications. Angew. Chem. Int. Ed. 2016, 55, 155-159. [CrossRef] [PubMed]

40. Padalkar, V.S.; Seki, S. Excited-state intramolecular proton-transfer (ESIPT)-inspired solid state emitters. Chem. Soc. Rev. 2016, 45, 169-202. [CrossRef] [PubMed]

41. Rasheed, T.; Bilal, M.; Nabeel, F.; Iqbal, H.M.; Li, C.; Zhou, Y. Fluorescent sensor based models for the detection of environmentally-related toxic heavy metals. Sci. Total Environ. 2018, 615, 476-485. [CrossRef] [PubMed] 
42. Steed, J.W. Coordination and organometallic compounds as anion receptors and sensors. Chem. Soc. Rev. 2009, 38, 506-519. [CrossRef] [PubMed]

43. Amendola, V.; Fabbrizzi, L.; Mosca, L. Anion recognition by hydrogen bonding: Urea-based receptors. Chem. Soc. Rev. 2010, 39, 3889-3915. [CrossRef]

44. Hua, Y.; Flood, A.H. Click chemistry generates privileged $\mathrm{CH}$ hydrogen-bonding triazoles: The latest addition to anion supramolecular chemistry. Chen. Soc. Rev. 2010, 39, 1262-1271. [CrossRef]

45. Dougherty, D.A. The cation- $\pi$ interaction. Acc. Chem. Res. 2012, 46, 885-893. [CrossRef] [PubMed]

46. Zheng, B.; Wang, F.; Dong, S.; Huang, F. Supramolecular polymers constructed by crown ether-based molecular recognition. Chem. Soc. Rev. 2012, 41, 1621-1636. [CrossRef]

47. Harada, A.; Takashima, Y.; Nakahata, M. Supramolecular polymeric materials via cyclodextrin-guest interactions. Acc. Chem. Res. 2014, 47, 2128-2140. [CrossRef] [PubMed]

48. Gale, P.A.; Howe, E.N.; Wu, X. Anion receptor chemistry. Chem 2016, 1, 351-422. [CrossRef]

49. Schmidt, B.V.; Barner-Kowollik, C. Dynamic macromolecular material design-The versatility of cyclodextrin-based host-guest chemistry. Angew. Chem. Int. Ed. 2017, 56, 8350-8369. [CrossRef] [PubMed]

50. Zhou, J.; Yu, G.; Huang, F. Supramolecular chemotherapy based on host-guest molecular recognition: A novel strategy in the battle against cancer with a bright future. Chem. Soc. Rev. 2017, 46, 7021-7053. [CrossRef] [PubMed]

51. Wu, X.; Howe, E.N.; Gale, P.A. Supramolecular transmembrane anion transport: New assays and insights. Acc. Chem. Res. 2018, 51, 1870-1879. [CrossRef] [PubMed]

52. Zhao, J.; Yang, D.; Yang, X.-J.; Wu, B. Anion coordination chemistry: From recognition to supramolecular assembly. Coord. Chem. Rev. 2019, 378, 415-444. [CrossRef]

53. Wallace, K.J.; Johnson, A.D.; Jones, W.S.; Manandhar, E. Chemodosimeters and chemoreactands for sensing ferric ions. Supramol. Chem. 2018, 30, 353-383. [CrossRef]

54. Manandhar, E.; Wallace, K.J. Host-guest chemistry of pyrene-based molecular receptors. Inorg. Chim. Acta 2012, 381, 15-43. [CrossRef]

55. McEwen, J.J.; Wallace, K.J. Squaraine dyes in molecular recognition and self-assembly. Chem. Commun. 2009, 42, 6339-6351. [CrossRef] [PubMed]

56. Wallace, K.J. Molecular dyes used for the detection of biological and environmental heavy metals: Highlights from 2004 to 2008. Supramol. Chem. 2009, 21, 89-102. [CrossRef]

57. Michalke, B.; Willkommen, D.; Drobyshev, E.; Solovyev, N. The importance of speciation analysis in neurodegeneration research. TrAC Trends Anal. Chem. 2018, 104, 160-170. [CrossRef]

58. Kozlowski, H.; Luczkowski, M.; Remelli, M.; Valensin, D. Copper, zinc and iron in neurodegenerative diseases (Alzheimer's, Parkinson's and prion diseases). Coord. Chem. Rev. 2012, 256, 2129-2141. [CrossRef]

59. Chasapis, C.T.; Loutsidou, A.C.; Spiliopoulou, C.A.; Stefanidou, M.E. Zinc and human health: An update. Arch. Toxicol. 2012, 86, 521-534. [CrossRef] [PubMed]

60. Que, E.L.; Domaille, D.W.; Chang, C.J. Metals in neurobiology: Probing their chemistry and biology with molecular imaging. Chem. Rev. 2008, 108, 1517-1549. [CrossRef] [PubMed]

61. Zeng, X.; Xu, X.; Boezen, H.M.; Huo, X. Children with health impairments by heavy metals in an e-waste recycling area. Chemosphere 2016, 148, 408-415. [CrossRef] [PubMed]

62. Clemens, S.; Ma, J.F. Toxic heavy metal and metalloid accumulation in crop plants and foods. Annu. Rev. Plant Biol. 2016, 67, 489-512. [CrossRef] [PubMed]

63. Parrotta, L.; Guerriero, G.; Sergeant, K.; Cai, G.; Hausman, J.-F. Target or barrier? The cell wall of early-and later-diverging plants vs cadmium toxicity: Differences in the response mechanisms. Front. Plant Sci. 2015, 6, 133. [CrossRef]

64. Nagajyoti, P.C.; Lee, K.D.; Sreekanth, T. Heavy metals, occurrence and toxicity for plants: A review. Environ. Chem. Lett. 2010, 8, 199-216. [CrossRef]

65. Obrist, D.; Kirk, J.L.; Zhang, L.; Sunderland, E.M.; Jiskra, M.; Selin, N.E. A review of global environmental mercury processes in response to human and natural perturbations: Changes of emissions, climate, and land use. Ambio 2018, 47, 116-140. [CrossRef] [PubMed]

66. Sundseth, K.; Pacyna, J.; Pacyna, E.; Pirrone, N.; Thorne, R. Global sources and pathways of mercury in the context of human health. Int. J. Environ. Res. Public Health 2017, 14, 105. [CrossRef] [PubMed] 
67. Chen, S.; Pei, R.; Zhao, T.; Dyer, D.J. Gold Nanoparticle Assemblies by Metal Ion-Pyridine Complexation and Their Rectified Quantized Charging in Aqueous Solutions. J. Chem. Phys. B 2002, 106, 1903-1908. [CrossRef]

68. McCarroll, M.E.; Shi, Y.; Harris, S.; Puli, S.; Kimaru, I.; Xu, R.; Wang, L.; Dyer, D.J. Computational prediction and experimental evaluation of a photoinduced electron-transfer sensor. J. Chem. Phys. B 2006, 110, 22991-22994. [CrossRef] [PubMed]

69. Hudson, G.A.; Cheng, L.; Yu, J.; Yan, Y.; Dyer, D.J.; McCarroll, M.E.; Wang, L. Computational studies on response and binding selectivity of fluorescence sensors. J. Phys. Chem. B 2009, 114, 870-876. [CrossRef] [PubMed]

70. Kowalczyk, T.; Lin, Z.; Voorhis, T.V. Fluorescence quenching by photoinduced electron transfer in the $\mathrm{Zn}^{2+}$ sensor Zinpyr-1: A computational investigation. J. Chem. Phys. B 2010, 114, 10427-10434. [CrossRef]

71. Venkataraman, D.; Du, Y.; Wilson, S.R.; Hirsch, K.A.; Zhang, P.; Moore, J.S. A coordination geometry table of the $d$-block elements and their ions. J. Chem. Educ. 1997, 74, 915-918. [CrossRef]

72. Ebnou, F.; M'Haiham, M.; Ebeid, K.; Carpenter-Warren, C.L.; Slawin, A.M.; Woollins, J.D.; Dhia, M.T.B.; Sanhoury, M.A. Synthesis, characterization, and structural properties of mercury (II), cadmium (II) and zinc (II) tripiperidinophosphine chalcogenide complexes. Polyhedron 2019, 159, 206-211. [CrossRef]

73. Rajput, G.; Yadav, M.K.; Drew, M.G.; Singh, N. Influence of the ligand frameworks on the coordination environment and properties of new phenylmercury (ii) $\beta$-oxodithioester complexes. Dalton Trans. 2015, 44, 5909-5916. [CrossRef]

74. Ghosh, D.C.; Gupta, K. A new scale of electronegativity of 54 elements of periodic table based on polarizability of atoms. J. Theor. Comput. Chem. 2006, 5, 895-911. [CrossRef]

75. Crichton, R. Biological Inorganic Chemistry: A New Introduction to Molecular Structure and Function; Academic Press: Cambridge, MA, USA, 2019; Chapter 12; pp. 339-362. [CrossRef]

76. Tang, L.; Qiu, R.; Tang, Y.; Wang, S. Cadmium-zinc exchange and their binary relationship in the structure of Zn-related proteins: A mini review. Metallomics 2014, 6, 1313-1323. [CrossRef] [PubMed]

77. Lane, T.W.; Saito, M.A.; George, G.N.; Pickering, I.J.; Prince, R.C.; Morel, F.M. Biochemistry: A cadmium enzyme from a marine diatom. Nature 2005, 435, 42. [CrossRef] [PubMed]

78. Lane, T.W.; Morel, F.M. A biological function for cadmium in marine diatoms. Proc. Natl. Acad. Sci. USA 2000, 97, 4627-4631. [CrossRef] [PubMed]

79. Daeneke, T.; Khoshmanesh, K.; Mahmood, N.; de Castro, I.; Esrafilzadeh, D.; Barrow, S.; Dickey, M.; Kalantar-Zadeh, K. Liquid metals: Fundamentals and applications in chemistry. Chem. Soc. Rev. 2018, 47, 4073-4111. [CrossRef] [PubMed]

80. McDermott, B.; Koch, C. Preparation of beta brass by mechanical alloying of elemental copper and zinc. Scr. Metall. 1986, 20, 669-672. [CrossRef]

81. Marshall, S.; Marshall, G. Dental amalgam: The materials. Adv. Dent. Res. 1992, 6, 94-99. [CrossRef]

82. Shi, G.L.; Li, D.J.; Wang, Y.F.; Liu, C.H.; Hu, Z.B.; Lou, L.Q.; Rengel, Z.; Cai, Q.S. Accumulation and distribution of arsenic and cadmium in winter wheat (Triticum aestivum L.) at different developmental stages. Sci. Total Environ. 2019, 667, 532-539. [CrossRef] [PubMed]

83. Zhao, F.-J.; Ma, Y.; Zhu, Y.-G.; Tang, Z.; McGrath, S.P. Soil contamination in China: Current status and mitigation strategies. Environ. Sci. Technol. 2014, 49, 750-759. [CrossRef]

84. Kim, K.-H.; Kabir, E.; Jahan, S.A. A review on the distribution of $\mathrm{Hg}$ in the environment and its human health impacts. J. Hazard. Mater. 2016, 306, 376-385. [CrossRef]

85. Tsakiris, K.A. Saint Ioannis Lampadistis, the first possible case of blindness due to organic mercury poisoning in history. J. Med. Biogr. 2018, 26, 207-210. [CrossRef]

86. Langford, N.; Ferner, R. Toxicity of mercury. J. Hum. Hypertens. 1999, 13, 651-656. [CrossRef]

87. Budnik, L.T.; Casteleyn, L. Mercury pollution in modern times and its socio-medical consequences. Sci. Total Environ. 2019, 654, 720-734. [CrossRef] [PubMed]

88. Kainz, M.; Telmer, K.; Mazumder, A. Bioaccumulation patterns of methyl mercury and essential fatty acids in lacustrine planktonic food webs and fish. Sci. Total Environ. 2006, 368, 271-282. [CrossRef] [PubMed]

89. EPA United States Environmental Protection Agencey. National Primary Drinking Water Regulations. Available online: https://www.epa.gov/ground-water-and-drinking-water/national-primary-drinkingwater-regulations\#Inorganic (accessed on 24 April 2019).

90. Guidelines for Drinking-Water Quality. Available online: https://www.who.int/water_sanitation_health/ dwq/gdwq0506.pdf (accessed on 24 April 2019). 
91. Levaot, N.; Hershfinkel, M. How cellular $\mathrm{Zn}^{2+}$ signaling drives physiological functions. Cell Calcium 2018, 75, 53-63. [CrossRef] [PubMed]

92. Huang, L.; Tepaamorndech, S. The SLC30 family of zinc transporters-A review of current understanding of their biological and pathophysiological roles. Mol. Asp. Med. 2013, 34, 548-560. [CrossRef] [PubMed]

93. Matsui, C.; Takatani-Nakase, T.; Hatano, Y.; Kawahara, S.; Nakase, I.; Takahashi, K. Zinc and its transporter ZIP6 are key mediators of breast cancer cell survival under high glucose conditions. FEBS Lett. 2017, 591, 3348-3359. [CrossRef]

94. Malm, J.; Hellman, J.; Hogg, P.; Lilja, H. Enzymatic action of prostate-specific antigen (PSA or hK3): Substrate specificity and regulation by $\mathrm{Zn}^{2+}$, a tight-binding inhibitor. Prostate 2000, 45, 132-139.

95. Weiss, J.H.; Sensi, S.L.; Koh, J.Y. $\mathrm{Zn}^{2+}$ : A novel ionic mediator of neural injury in brain disease. Trends Pharmacol. Sci. 2000, 21, 395-401. [CrossRef]

96. Tomat, E.; Lippard, S.J. Imaging mobile zinc in biology. Curr. Opin. Chem. Biol. 2010, 14, 225-230. [CrossRef]

97. Mocchegiani, E.; Bertoni-Freddari, C.; Marcellini, F.; Malavolta, M. Brain, aging and neurodegeneration: Role of zinc ion availability. Prog. Neurobiol. 2005, 75, 367-390. [CrossRef]

98. Leinweber, B.; Barofsky, E.; Barofsky, D.F.; Ermilov, V.; Nylin, K.; Beckman, J.S. Aggregation of ALS mutant superoxide dismutase expressed in Escherichia coli. Free Radic. Biol. Med. 2004, 36, 911-918. [CrossRef]

99. Woo, H.; You, Y.; Kim, T.; Jhon, G.-J.; Nam, W. Fluorescence ratiometric zinc sensors based on controlled energy transfer. J. Mater. Chem. 2012, 22, 17100-17112. [CrossRef]

100. Kwon, J.E.; Lee, S.; You, Y.; Baek, K.-H.; Ohkubo, K.; Cho, J.; Fukuzumi, S.; Shin, I.; Park, S.Y.; Nam, W. Fluorescent zinc sensor with minimized proton-induced interferences: Photophysical mechanism for fluorescence turn-on response and detection of endogenous free zinc ions. Inorg. Chem. 2012, 51, 8760-8774. [CrossRef] [PubMed]

101. Comby, S.; Tuck, S.A.; Truman, L.K.; Kotova, O.; Gunnlaugsson, T. New trick for an old ligand! The sensing of $\mathrm{Zn}(\mathrm{II})$ using a lanthanide based ternary $\mathrm{Yb}(\mathrm{III})$-cyclen-8 hydroxyquinoline system as a dual emissive probe for displacement assay. Inorg. Chem. 2012, 51, 10158-10168. [CrossRef] [PubMed]

102. Tsikalas, G.K.; Lazarou, P.; Klontzas, E.; Pergantis, S.A.; Spanopoulos, I.; Trikalitis, P.N.; Froudakis, G.E.; Katerinopoulos, H.E. A “turn-on"-turning-to-ratiometric sensor for zinc(II) ions in aqueous media. RSC Adv. 2014, 4, 693-696. [CrossRef]

103. Badetti, E.; Wurst, K.; Licini, G.; Zonta, C. Multimetallic architectures from the self-assembly of amino acids and tris (2-pyridylmethyl) amine zinc(II) complexes: Circular dichroism enhancement by chromophores organization. Chem.-Eur. J. 2016, 22, 6515-6518. [CrossRef] [PubMed]

104. Wang, D.; Ren, A.-M.; Zou, L.-Y.; Guo, J.-F.; Huang, S. A theoretical investigation of a series of novel two-photon zinc ion fluorescent probes based on bipyridine. J. Photochem. Photobiol. A 2017, 341, 20-30. [CrossRef]

105. Panunzi, B.; Borbone, F.; Capobianco, A.; Concilio, S.; Diana, R.; Peluso, A.; Piotto, S.; Tuzi, A.; Velardo, A.; Caruso, U. Synthesis, spectroscopic properties and DFT calculations of a novel multipolar azo dye and its zinc(II) complex. Inorg. Chem. Commun. 2017, 84, 103-108. [CrossRef]

106. Zhu, M.-Y.; Zhao, K.; Song, J.; Wang, C.-K. Responsive mechanism and molecular design of di-2-picolylamine-based two-photon fluorescent probes for zinc ions. Chin. Phys. B 2018, 27, 023302. [CrossRef]

107. Xia, S.; Shen, J.; Wang, J.; Wang, H.; Fang, M.; Zhou, H.; Tanasova, M. Ratiometric fluorescent and colorimetric BODIPY-based sensor for zinc ions in solution and living cells. Sens. Actuators B Chem. 2018, 258, 1279-1286. [CrossRef]

108. Zhao, K.; Song, J.; Zhu, M.-Y.; Zhang, H.; Wang, C.-K. Isomerism and coordination mode effects on two-photon absorption of tris (picolyl) amine-based fluorescent probes for zinc ions. Chin. Phys. B 2018, 27, 103301. [CrossRef]

109. Oehme, I.; Wolfbeis, O.S. Optical sensors for determination of heavy metal ions. Microchim. Acta 1997, 126, 177-192. [CrossRef]

110. Kimura, E.; Aoki, S. Zinc Biochemistry, Physiology, and Homeostasis; Springer: Berlin/Heidelberg, Germany, 2001; pp. 5-18.

111. Jiang, P.; Guo, Z. Fluorescent detection of zinc in biological systems: Recent development on the design of chemosensors and biosensors. Coord. Chem. Rev. 2004, 248, 205-229. [CrossRef] 
112. Lim, N.C.; Schuster, J.V.; Porto, M.C.; Tanudra, M.A.; Yao, L.; Freake, H.C.; Brückner, C. Coumarin-based chemosensors for zinc(II): Toward the determination of the design algorithm for CHEF-type and ratiometric probes. Inorg. Chem. 2005, 44, 2018-2030. [CrossRef] [PubMed]

113. Thompson, R.B. Studying zinc biology with fluorescence: ain't we got fun? Curr. Opin. Chem. Biol. 2005, 9, 526-532. [CrossRef]

114. Maret, W. Zinc coordination environments in proteins as redox sensors and signal transducers. Antioxid. Redox Signal. 2006, 8, 1419-1441. [CrossRef]

115. Carol, P.; Sreejith, S.; Ajayaghosh, A. Ratiometric and near-infrared molecular probes for the detection and imaging of zinc Ions. Chem. Asian J. 2007, 2, 338-348. [CrossRef] [PubMed]

116. Dai, Z.; Canary, J.W. Tailoring tripodal ligands for zinc sensing. New J. Chem. 2007, 31, 1708-1718. [CrossRef]

117. Nolan, E.M.; Lippard, S.J. Small-molecule fluorescent sensors for investigating zinc metalloneurochemistry. Acc. Chem. Res. 2008, 42, 193-203. [CrossRef]

118. Terai, T.; Nagano, T. Fluorescent probes for bioimaging applications. Curr. Opin. Chem. Biol. 2008, 12, 515-521. [CrossRef]

119. Sarkar, K.; Dhara, K.; Nandi, M.; Roy, P.; Bhaumik, A.; Banerjee, P. Selective zinc(II)-ion fluorescence sensing by a functionalized mesoporous material covalently grafted with a fluorescent chromophore and consequent biological applications. Adv. Funct. Mater. 2009, 19, 223-234. [CrossRef]

120. Xu, Z.; Yoon, J.; Spring, D.R. Fluorescent chemosensors for $\mathrm{Zn}^{2+}$. Chem. Soc. Rev. 2010, 39, $1996-2006$. [CrossRef]

121. Pluth, M.D.; Tomat, E.; Lippard, S.J. Biochemistry of mobile zinc and nitric oxide revealed by fluorescent sensors. Annu. Rev. Biochem. 2011, 80, 333-355. [CrossRef]

122. Carter, K.P.; Young, A.M.; Palmer, A.E. Fluorescent sensors for measuring metal ions in living systems. Chem. Rev. 2014, 114, 4564-4601. [CrossRef] [PubMed]

123. Lee, M.H.; Kim, J.S.; Sessler, J.L. Small molecule-based ratiometric fluorescence probes for cations, anions, and biomolecules. Chem. Soc. Rev. 2015, 44, 4185-4191. [CrossRef] [PubMed]

124. Mason, W.T. Fluorescent and Luminescent Probes for Biological Activity: A Practical Guide to Technology for Quantitative Real-Time Analysis; Academic Press: London, UK, 1999.

125. Johnson, I. Fluorescent probes for living cells. Histochem. J. 1998, 30, 123-140. [CrossRef]

126. Krężel, A.; Maret, W. Zinc-buffering capacity of a eukaryotic cell at physiological pZn. J. Biol. Inorg. Chem. 2006, 11, 1049-1062. [CrossRef] [PubMed]

127. Outten, C.E.; O'halloran, T.V. Femtomolar sensitivity of metalloregulatory proteins controlling zinc homeostasis. Science 2001, 292, 2488-2492. [CrossRef]

128. Assaf, S.; Chung, S.-H. Release of endogenous $\mathrm{Zn}^{2+}$ from brain tissue during activity. Nature 1984, 308, 734-736. [CrossRef]

129. Zhang, L.; Clark, R.J.; Zhu, L. A heteroditopic fluoroionophoric platform for constructing fluorescent probes with large dynamic ranges for zinc ions. Chem. Eur. J. 2008, 14, 2894-2903. [CrossRef] [PubMed]

130. Pati, P.B.; Zade, S.S. Selective colorimetric and "turn-on" fluorimetric detection of cyanide using a chemodosimeter comprising salicylaldehyde and triphenylamine groups. Eur. J. Org. Chem. 2012, 6555-6561. [CrossRef]

131. Chakraborty, B.; Halder, P.; Chakraborty, S.; Das, O.; Paria, S. Synthesis, characterization and emission study of zinc(II) and cobalt(II) complexes: Bis(bidentate) iminophenols as zinc(II) selective fluorescence probes. Inorg. Chim. Acta 2012, 387, 332-337. [CrossRef]

132. Zhao, L.Y.; Mi, Q.L.; Wang, G.K.; Chen, J.H.; Zhang, J.F.; Zhao, Q.H.; Zhou, Y. 1,8-Naphthalimide-based 'turn-on' fluorescent sensor for the detection of zinc ion in aqueous media and its applications for bioimaging. Tetrahedron Lett. 2013, 54, 3353-3358. [CrossRef]

133. Dugave, C.; Demange, L. Cis-trans isomerization of organic molecules and biomolecules: Implications and applications. Chem. Rev. 2003, 103, 2475-2532. [CrossRef]

134. Hisamoto, H.; Tohma, H.; Yamada, T.; Yamauchi, K.-I.; Siswanta, D.; Yoshioka, N.; Suzuki, K. Molecular design, characterization, and application of multi-information dyes for multi-dimensional optical chemical sensing. Molecular design concepts of the dyes and their fundamental spectral characteristics. Anal. Chim. Acta 1998, 373, 271-289. [CrossRef]

135. Natali, M.; Soldi, L.; Giordani, S. A photoswitchable Zn(II) selective spiropyran-based sensor. Tetrahedron 2010, 66, 7612-7617. [CrossRef] 
136. Luo, W.; Liu, M.; Yang, T.; Yang, X.; Wang, Y.; Xiang, H. Fluorescent Zn $\mathrm{n}^{\mathrm{II}}$ Chemosensor Mediated by a 1,8-Naphthyridine Derivative and It's Photophysical Properties. ChemistryOpen 2018, 7, 639-644. [CrossRef]

137. Park, G.J.; Lee, M.M.; You, G.R.; Choi, Y.W.; Kim, C. A turn-on and reversible fluorescence sensor with high affinity to $\mathrm{Zn}^{2+}$ in aqueous solution. Tetrahedron Lett. 2014, 55, 2517-2522. [CrossRef]

138. Park, G.J.; Na, Y.J.; Jo, H.Y.; Lee, S.A.; Kim, A.R.; Noh, I.; Kim, C. A single chemosensor for multiple analytes: Fluorogenic detection of $\mathrm{Zn}^{2+}$ and $\mathrm{OAc}^{-}$ions in aqueous solution, and an application to bioimaging. New J. Chem. 2014, 38, 2587-2594. [CrossRef]

139. Erdemir, S.; Malkondu, S. A novel "turn on" fluorescent sensor based on hydroxy-triphenylamine for $\mathrm{Zn}^{2+}$ and $\mathrm{Cd}^{2+}$ ions in MeCN. Sens. Actuators B Chem. 2013, 188, 1225-1229. [CrossRef]

140. Burdette, S.C.; Walkup, G.K.; Spingler, B.; Tsien, R.Y.; Lippard, S.J. Fluorescent sensors for $\mathrm{Zn}^{2+}$ based on a fluorescein platform: Synthesis, properties and intracellular distribution. J. Am. Chem. Soc. 2001, 123, 7831-7841. [CrossRef] [PubMed]

141. Burdette, S.C.; Frederickson, C.J.; Bu, W.; Lippard, S.J. ZP4, an improved neuronal $\mathrm{Zn}^{2+}$ sensor of the Zinpyr family. J. Am. Chem. Soc. 2003, 125, 1778-1787. [CrossRef]

142. Nolan, E.M.; Ryu, J.W.; Jaworski, J.; Feazell, R.P.; Sheng, M.; Lippard, S.J. Zinspy sensors with enhanced dynamic range for imaging neuronal cell zinc uptake and mobilization. J. Am. Chem. Soc. 2006, 128, 15517-15528. [CrossRef] [PubMed]

143. Tomat, E.; Nolan, E.M.; Jaworski, J.; Lippard, S.J. Organelle-specific zinc detection using zinpyr-labeled fusion proteins in live cells. J. Am. Chem. Soc. 2008, 130, 15776-15777. [CrossRef]

144. Wong, B.A.; Friedle, S.; Lippard, S.J. Solution and fluorescence properties of symmetric dipicolylamine-containing dichlorofluorescein-based $\mathrm{Zn}^{2+}$ sensors. J. Am. Chem. Soc. 2009, 131, 7142-7152. [CrossRef]

145. Du, P.; Lippard, S.J. A highly selective turn-on colorimetric, red fluorescent sensor for detecting mobile zinc in living cells. Inorg. Chem. 2010, 49, 10753-10755. [CrossRef]

146. Sivaraman, G.; Anand, T.; Chellappa, D. Turn-on fluorescent chemosensor for Zn(II) via ring opening of rhodamine spirolactam and their live cell imaging. Analyst 2012, 137, 5881-5884. [CrossRef]

147. Wong, B.A.; Friedle, S.; Lippard, S.J. Subtle modification of 2,2-dipicolylamine lowers the affinity and improves the turn-on of $\mathrm{Zn}(\mathrm{II})$-selective fluorescent sensors. Inorg. Chem. 2009, 48, 7009-7011. [CrossRef] [PubMed]

148. Steed, J.W.; Wallace, K.J. Advances in Supramolecular Chemistry; Gokel, G., Ed.; Cerberus: New York, NY, USA, 2003; Volume 9, pp. 221-262.

149. Jung, J.M.; Kang, J.H.; Han, J.; Lee, H.; Lim, M.H.; Kim, K.-T.; Kim, C. A novel “off-on” type fluorescent chemosensor for detection of $\mathrm{Zn}^{2+}$ and its zinc complex for "on-off" fluorescent sensing of sulfide in aqueous solution, in vitro and in vivo. Sens. Actuators B Chem. 2018, 267, 58-69. [CrossRef]

150. Ravitz, S.F. The solubilities and free energies of some metallic sulfides. J. Phys. Chem. 1936, 40, 61-70. [CrossRef]

151. Fu, Y.; Fan, C.; Liu, G.; Cui, S.; Pu, S. A highly selective and sensitive ratiometric fluorescent chemosensor for $\mathrm{Zn}^{2+}$ based on diarylethene with a benzyl-linked 8-aminoquinoline-2-aminomethylpyridine unit. Dyes Pigm. 2016, 126, 121-130. [CrossRef]

152. Wang, Z.; Cui, S.; Qiu, S.; Zhang, Z.; Pu, S. A highly sensitive fluorescent sensor for $\mathrm{Zn}^{2+}$ based on diarylethene with an imidazole unit. Spectrochim. Acta Part A 2018, 205, 21-28. [CrossRef] [PubMed]

153. Macias-Contreras, M.; Daykin, K.L.; Simmons, J.T.; Allen, J.R.; Hooper, Z.S.; Davidson, M.W.; Zhu, L. Progressive structural modification to a zinc-actuated photoinduced electron transfer (PeT) switch in the context of intracellular zinc imaging. Org. Biomol. Chem. 2017, 15, 9139-9148. [CrossRef] [PubMed]

154. Simmons, J.T.; Allen, J.R.; Morris, D.R.; Clark, R.J.; Levenson, C.W.; Davidson, M.W.; Zhu, L. Integrated and passive 1,2,3-triazolyl groups in fluorescent indicators for zinc(II) ions: Thermodynamic and kinetic evaluations. Inorg. Chem. 2013, 52, 5838-5850. [CrossRef]

155. Michaels, H.A.; Murphy, C.S.; Clark, R.J.; Davidson, M.W.; Zhu, L. 2-Anthryltriazolyl-containing multidentate ligands: Zinc-coordination mediated photophysical processes and potential in live-cell imaging applications. Inorg. Chem. 2010, 49, 4278-4287. [CrossRef] [PubMed]

156. Huang, S.; Clark, R.J.; Zhu, L. Highly sensitive fluorescent probes for zinc ion based on triazolyl-containing tetradentate coordination motifs. Org. Lett. 2007, 9, 4999-5002. [CrossRef] [PubMed] 
157. De Silva, S.A.; Zavaleta, A.; Baron, D.E.; Allam, O.; Isidor, E.V.; Kashimura, N.; Percarpio, J.M. A fluorescent photoinduced electron transfer sensor for cations with an off-on-off proton switch. Tetrahedron Lett. 1997, 38, 2237-2240. [CrossRef]

158. Walkup, G.K.; Burdette, S.C.; Lippard, S.J.; Tsien, R.Y. A new cell-permeable fluorescent probe for $\mathrm{Zn}^{2+}$. J. Am. Chem. Soc. 2000, 122, 5644-5645. [CrossRef]

159. Gee, K.R.; Zhou, Z.-L.; Ton-That, D.; Sensi, S.; Weiss, J. Measuring zinc in living cells. A new generation of sensitive and selective fluorescent probes. Cell Calcium 2002, 31, 245-251. [CrossRef]

160. Yan, J.; Fan, L.; Qin, J.-C.; Li, C.-R.; Yang, Z.-Y. A novel and resumable Schiff-base fluorescent chemosensor for Zn(II). Tetrahedron Lett. 2016, 57, 2910-2914. [CrossRef]

161. Zhang, G.; Li, H.; Bi, S.; Song, L.; Lu, Y.; Zhang, L.; Yu, J.; Wang, L. A new turn-on fluorescent chemosensor based on diketopyrrolopyrrole (DPP) for imaging $\mathrm{Zn}^{2+}$ in living cells. Analyst 2013, 138, 6163-6170. [CrossRef] [PubMed]

162. Manandhar, E.; Broome, J.H.; Myrick, J.; Lagrone, W.; Cragg, P.J.; Wallace, K.J. A pyrene-based fluorescent sensor for $\mathrm{Zn}^{2+}$ ions: A molecular 'butterfly'. Chem. Commun. 2011, 47, 8796-8798. [CrossRef] [PubMed]

163. Manandhar, E.; Cragg, P.J.; Wallace, K.J. Detection of Zn(II) ions by fluorescent pyrene-derived molecular probes. Supramol. Chem. 2014, 26, 141-150. [CrossRef]

164. Rosenthal, M.R. The myth of the non-coordinating anion. J. Chem. Educ. 1973, 50, 331-335. [CrossRef]

165. MacAyeal, J.R. The comprehensive environmental response, compensation, and liability act: The correct paradigm of strict liability and the problem of individual causation. J. Environ. Law 1999, 18, 217-334.

166. Khairy, M.; El-Safty, S.A.; Shenashen, M. Environmental remediation and monitoring of cadmium. TrAC Trends Anal. Chem. 2014, 62, 56-68. [CrossRef]

167. Kimblin, C.; Bridgewater, B.M.; Churchill, D.G.; Hascall, T.; Parkin, G. Bis(mercaptoimidazolyl)(pyrazolyl) hydroborato complexes of Zinc, Cadmium, and Cobalt: Structural evidence for the enhanced tendency of Zinc in biological systems to adopt Tetrahedral M[S4] coordination. Inorg. Chem. 2000, 39, 4240-4243. [CrossRef] [PubMed]

168. Mugesh, G.; Singh, H.B.; Patel, R.P.; Butcher, R.J. Synthesis and structural characterization of monomeric selenolato complexes of zinc, cadmium, and mercury. Inorg. Chem. 1998, 37, 2663-2669. [CrossRef]

169. Sigel, H.; Martin, R.B. The colourless 'chameleon'or the peculiar properties of $\mathrm{Zn}^{2+}$ in complexes in solution. Quantification of equilibria involving a change of the coordination number of the metal ion. Chem. Soc. Rev. 1994, 23, 83-91. [CrossRef]

170. Wang, Z.; Cui, S.; Qiu, S.; Pu, S. A new fluorescence probe based on diarylethene with a benzothiazine unit for selective detection of $\mathrm{Cd}^{2+}$. Tetrahedron 2018, 74, 7431-7437. [CrossRef]

171. Maniyazagan, M.; Mariadasse, R.; Jeyakanthan, J.; Lokanath, N.; Naveen, S.; Premkumar, K.; Muthuraja, P.; Manisankar, P.; Stalin, T. Rhodamine based "turn-on" molecular switch FRET-sensor for cadmium and sulfide ions and live cell imaging study. Sens. Actuators B Chem. 2017, 238, 565-577. [CrossRef]

172. Aich, K.; Goswami, S.; Das, S.; Mukhopadhyay, C.D.; Quah, C.K.; Fun, H.-K. Cd ${ }^{2+}$ triggered the FRET "ON": A new molecular switch for the ratiometric detection of $\mathrm{Cd}^{2+}$ with live-cell imaging and bound X-ray structure. Inorg. Chem. 2015, 54, 7309-7315. [CrossRef]

173. Zhang, L.; Hu, W.; Yu, L.; Wang, Y. Click synthesis of a novel triazole bridged AIE active cyclodextrin probe for specific detection of $\mathrm{Cd}^{2+}$. Chem. Commun. 2015, 51, 4298-4301. [CrossRef]

174. Teolato, P.; Rampazzo, E.; Arduini, M.; Mancin, F.; Tecilla, P.; Tonellato, U. Silica nanoparticles for fluorescence sensing of Zn(II): Exploring the covalent strategy. Chemistry 2007, 13, 2238-2245. [CrossRef]

175. Pal, P.; Rastogi, S.K.; Gibson, C.M.; Aston, D.E.; Branen, A.L.; Bitterwolf, T.E. Fluorescence sensing of zinc(II) using ordered mesoporous silica material (MCM-41) functionalized with $N$-(quinolin-8-yl)-2-[3-(triethoxysilyl) propylamino] acetamide. ACS Appl. Mater. Interfaces 2011, 3, 279-286. [CrossRef]

176. Ding, Y.; Zhu, W.; Xu, Y.; Qian, X. A small molecular fluorescent sensor functionalized silica microsphere for detection and removal of mercury, cadmium, and lead ions in aqueous solutions. Sens. Actuators B Chem. 2015, 220, 762-771. [CrossRef]

177. Huang, W.-B.; Gu, W.; Huang, H.-X.; Wang, J.-B.; Shen, W.-X.; Lv, Y.-Y.; Shen, J. A porphyrin-based fluorescent probe for optical detection of toxic $\mathrm{Cd}^{2+}$ ion in aqueous solution and living cells. Dyes Pigments 2017, 143, 427-435. [CrossRef] 
178. Krishnaveni, K.; Iniya, M.; Jeyanthi, D.; Siva, A.; Chellappa, D. A new multifunctional benzimidazole tagged coumarin as ratiometric fluorophore for the detection of $\mathrm{Cd}^{2+} / \mathrm{F}^{-}$ions and imaging in live cells. Spectrochim. Acta Part A 2018, 205, 557-567. [CrossRef] [PubMed]

179. Kumar, A.; Ahmed, N. A coumarin-chalcone hybrid used as a selective and sensitive colorimetric and turn-on fluorometric sensor for $\mathrm{Cd}^{2+}$ detection. New J. Chem. 2017, 41, 14746-14753.

180. Roy, S.B.; Mondal, J.; Khuda-Bukhsh, A.R.; Rajak, K.K. A novel fluorene based "turn on" fluorescent sensor for the determination of zinc and cadmium: Experimental and theoretical studies along with live cell imaging. New J. Chem. 2016, 40, 9593-9608. [CrossRef]

181. Xu, L.; He, M.-L.; Yang, H.-B.; Qian, X. A simple fluorescent probe for $\mathrm{Cd}^{2+}$ in aqueous solution with high selectivity and sensitivity. Dalton Trans. 2013, 42, 8218-8222. [CrossRef] [PubMed]

182. Tuemmler, B.; Maass, G.; Voegtle, F.; Sieger, H.; Heimann, U.; Weber, E. Open-chain polyethers. Influence of aromatic donor end groups on thermodynamics and kinetics of alkali metal ion complex formation. J. Am. Chem. Soc. 1979, 101, 2588-2598. [CrossRef]

183. Tuemmler, B.; Maass, G.; Weber, E.; Wehner, W.; Voegtle, F. Noncyclic crown-type polyethers, pyridinophane cryptands, and their alkali metal ion complexes: Synthesis, complex stability, and kinetics. J. Am. Chem. Soc. 1977, 99, 4683-4690. [CrossRef]

184. Weber, V.E.; Vogtle, F. Kristalline 1:1-alkalimetallkomplexe nichtcyclischer neutralliganden. Tetrahedron Lett. 1975, 16, 2415-2418. [CrossRef]

185. Liu, X.; Li, N.; Xu, M.-M.; Jiang, C.; Wang, J.; Song, G.; Wang, Y. Turn on fluorescent detection for Cd ${ }^{2+}$ based on surfactant controlled squaraine aggregation. Spectrochim. Acta Part A 2019, 208, 236-242. [CrossRef]

186. Liu, X.; Wang, P.; Fu, J.; Yao, K.; Xue, K.; Xu, K. Turn-on fluorescent sensor for zinc and cadmium ions based on quinolone and its sequential response to phosphate. J. Lumin. 2017, 186, 16-22. [CrossRef]

187. Song, E.J.; Kang, J.; You, G.R.; Park, G.J.; Kim, Y.; Kim, S.-J.; Kim, C.; Harrison, R.G. A single molecule that acts as a fluorescence sensor for zinc and cadmium and a colorimetric sensor for cobalt. Dalton Trans. 2013, 42, 15514-15520. [CrossRef]

188. Zhang, Y.-Y.; Chen, X.-Z.; Liu, X.-Y.; Wang, M.; Liu, J.-J.; Gao, G.; Zhang, X.-Y.; Sun, R.-Z.; Hou, S.-C.; Wang, H.-M. A highly sensitive multifunctional sensor based on phenylene-acetylene for colorimetric detection of $\mathrm{Fe}^{2+}$ and ratiometric fluorescent detection of $\mathrm{Cd}^{2+}$ and $\mathrm{Zn}^{2+}$. Sens. Actuators B Chem. 2018, 273, 1077-1084. [CrossRef]

189. Zhang, W.J.; Liu, S.G.; Han, L.; Luo, H.Q.; Li, N.B. A ratiometric fluorescent and colorimetric dual-signal sensing platform based on $\mathrm{N}$-doped carbon dots for selective and sensitive detection of copper(II) and pyrophosphate ion. Sens. Actuators B Chem. 2019, 283, 215-221. [CrossRef]

190. Plácido, J.; Bustamante-López, S.; Meissner, K.; Kelly, D.; Kelly, S. Microalgae biochar-derived carbon dots and their application in heavy metal sensing in aqueous systems. Sci. Total Environ. 2019, 656, 531-539. [CrossRef]

191. Huang, L.; Yang, Z.; Zhou, Z.; Li, Y.; Tang, S.; Xiao, W.; Hu, M.; Peng, C.; Chen, Y.; Gu, B. A dual colorimetric and near-infrared fluorescent turn-on probe for $\mathrm{Hg}^{2+}$ detection and its applications. Dyes Pigments 2019, 163, 118-125. [CrossRef]

192. Amanulla, B.; Perumal, K.N.; Ramaraj, S.K. Chitosan functionalized gold nanoparticles assembled on sulphur doped graphitic carbon nitride as a new platform for colorimetric detection of trace $\mathrm{Hg}^{2+}$. Sens. Actuators $B$ Chem. 2019, 281, 281-287. [CrossRef]

193. Manivannan, S.; Seo, Y.; Kang, D.-K.; Kim, K. Colorimetric and optical Hg(II) ion sensor developed with conjugates of M13-bacteriophage and silver nanoparticles. New J. Chem. 2018, 42, 20007-20014. [CrossRef]

194. Bahta, M.; Ahmed, N. Design and synthesis of 1,4-benzothiazine hydrazide as selective and sensitive colorimetric and turn-on fluorometric sensor for $\mathrm{Hg}^{2+}$ detection in aqueous medium. J. Photochem. Photobiol. A 2018, 357, 41-48. [CrossRef]

195. Chatterjee, A.; Banerjee, M.; Khandare, D.G.; Gawas, R.U.; Mascarenhas, S.C.; Ganguly, A.; Gupta, R.; Joshi, H. Aggregation-induced emission-based chemodosimeter approach for selective sensing and imaging of $\mathrm{Hg}$ (II) and methylmercury species. Anal. Chem. 2017, 89, 12698-12704. [CrossRef] [PubMed]

196. Gao, Y.; Ma, T.; Ou, Z.; Cai, W.; Yang, G.; Li, Y.; Xu, M.; Li, Q. Highly sensitive and selective turn-on fluorescent chemosensors for $\mathrm{Hg}^{2+}$ based on thioacetal modified pyrene. Talanta 2018, 178, 663-669. [CrossRef]

197. Nakanishi, T.; Suzuki, M.; Saimoto, A.; Kabasawa, T. Structural considerations of NK109, an antitumor benzo[c]phenanthridine alkaloid. J. Nat. Prod. 1999, 62, 864-867. [CrossRef] 
198. Takao, N.; Kamigauchi, M.; Okada, M. Biosynthesis of benzo[c]phenanthridine alkaloids sanguinarine, chelirubine and macarpine. Helv. Chim. Acta 1983, 66, 473-484. [CrossRef]

199. Ponram, M.; Balijapalli, U.; Sambath, B.; Iyer, S.K.; Venkatachalapathy, B.; Cingaram, R.; Sundaramurthy, K.N. Development of paper-based chemosensor for the detection of mercury ions using mono-and tetra-sulfur bearing phenanthridines. New J. Chem. 2018, 42, 8530-8536. [CrossRef]

200. Shyamal, M.; Maity, S.; Maity, A.; Maity, R.; Roy, S.; Misra, A. Aggregation induced emission based "turn-off" fluorescent chemosensor for selective and swift sensing of mercury(II) ions in water. Sens. Actuators B Chem. 2018, 263, 347-359. [CrossRef]

201. Rurack, K. Flipping the light switch 'ON'-The design of sensor molecules that show cation-induced fluorescence enhancement with heavy and transition metal ions. Spectrochim. Acta Part A 2001, 57, 2161-2195. [CrossRef]

202. Shimizu, Y.; Azumi, T. Mechanism of external heavy atom effect on intersystem crossing in fluid solutions. Analysis based on fluorescence decay data. J. Phys. Chem. 1982, 86, 22-26. [CrossRef]

203. Fang, Y.; Li, X.; Li, J.-Y.; Wang, G.-Y.; Zhou, Y.; Xu, N.-Z.; Hu, Y.; Yao, C. Thiooxo-Rhodamine B hydrazone derivatives bearing bithiophene group as fluorescent chemosensors for detecting mercury(II) in aqueous media and living HeLa cells. Sens. Actuators B Chem. 2018, 255, 1182-1190. [CrossRef]

204. Jones, M.M.; Vaughn, W.K. HSAB theory and acute metal ion toxicity and detoxification processes. J. Inorg. Nucl. Chem. 1978, 40, 2081-2088. [CrossRef]

205. Pearson, R.G. Hard and soft acids and bases, HSAB, part II: Underlying theories. J. Chem. Educ. 1968, 45, 643-648. [CrossRef]

206. Pearson, R.G. Hard and soft acids and bases, HSAB, part 1: Fundamental principles. J. Chem. Educ. 1968, 45, 581-587. [CrossRef]

207. Shu, T.; Yang, Z.; Cen, Z.; Deng, X.; Deng, Y.; Dong, C.; Yu, Y. A novel ratiometric fluorescent probe based on a BODIPY derivative for $\mathrm{Cu}^{2+}$ detection in aqueous solution. Anal. Methods 2018, 10, 5755-5762. [CrossRef]

208. Sun, W.; Chen, R.; Cheng, X.; Marin, L. Bodipy-based chemosensors for highly sensitive and selective detection of $\mathrm{Hg}^{2+}$ ions. New J. Chem. 2018, 42, 19224-19231. [CrossRef]

209. Zhou, B.; Qin, S.; Chen, B.; Han, Y. A new BODIPY-based fluorescent "turn-on" probe for highly selective and rapid detection of mercury ions. Tetrahedron Lett. 2018, 59, 4359-4363. [CrossRef]

210. Gu, Z.; Cheng, H.; Shen, X.; He, T.; Jiang, K.; Qiu, H.; Zhang, Q.; Yin, S. A BODIPY derivative for colorimetric fluorescence sensing of $\mathrm{Hg}^{2+}, \mathrm{Pb}^{2+}$ and $\mathrm{Cu}^{2+}$ ions and its application in logic gates. Spectrochim. Acta Part A 2018, 203, 315-323. [CrossRef] [PubMed]

211. Gao, Y.; Zhang, C.; Peng, S.; Chen, H. A fluorescent and colorimetric probe enables simultaneous differential detection of $\mathrm{Hg}^{2+}$ and $\mathrm{Cu}^{2+}$ by two different mechanisms. Sens. Actuators B Chem. 2017, 238, 455-461. [CrossRef]

212. Li, Q.; Hu, Y.; Hou, H.-N.; Yang, W.-N.; Hu, S.-L. A new coumarin-carbonothioate-based turn-on fluorescent chemodosimeter for selective detection of $\mathrm{Hg}^{2+}$. Inorg. Chim. Acta 2018, 471, 705-708. [CrossRef]

213. Patai, S. Chemistry of the Carbon-Nitrogen Double Bond; John Wiley and Sons: Chichester, UK, 1970.

214. Machado, V.G.; Nascimento, M.; Rezende, M. Metal ion catalysis in the hydrolysis of imines. J. Braz. Chem. Soc. 1993, 4, 76-79. [CrossRef]

215. Jiao, Y.; Liu, X.; Zhou, L.; He, H.; Zhou, P.; Duan, C. A schiff-base dual emission ratiometric fluorescent chemosensor for $\mathrm{Hg}^{2+}$ ions and its application in cellular imaging. Sens. Actuators B Chem. 2017, 247, 950-956. [CrossRef]

216. Smith, D.G.; Topolnicki, I.L.; Zwicker, V.E.; Jolliffe, K.A.; New, E.J. Fluorescent sensing arrays for cations and anions. Analyst 2017, 142, 3549-3563. [CrossRef]

217. Sasaki, Y.; Minamiki, T.; Tokito, S.; Minami, T. A molecular self-assembled colourimetric chemosensor array for simultaneous detection of metal ions in water. Chem. Commun. 2017, 53, 6561-6564. [CrossRef]

218. Mallet, A.M.; Davis, A.B.; Davis, D.R.; Panella, J.; Wallace, K.J.; Bonizzoni, M. A cross reactive sensor array to probe divalent metal ions. Chem. Commun. 2015, 51, 16948-16951. [CrossRef]

219. Jing, X.-Y.; Tang, Y.-Y.; Zhang, D. A Fourier-LDA approach for image recognition. Pattern Recognit. 2005, 38, 453-457. [CrossRef]

(C) 2019 by the authors. Licensee MDPI, Basel, Switzerland. This article is an open access article distributed under the terms and conditions of the Creative Commons Attribution (CC BY) license (http://creativecommons.org/licenses/by/4.0/). 